\title{
Project Summaries 1997
}
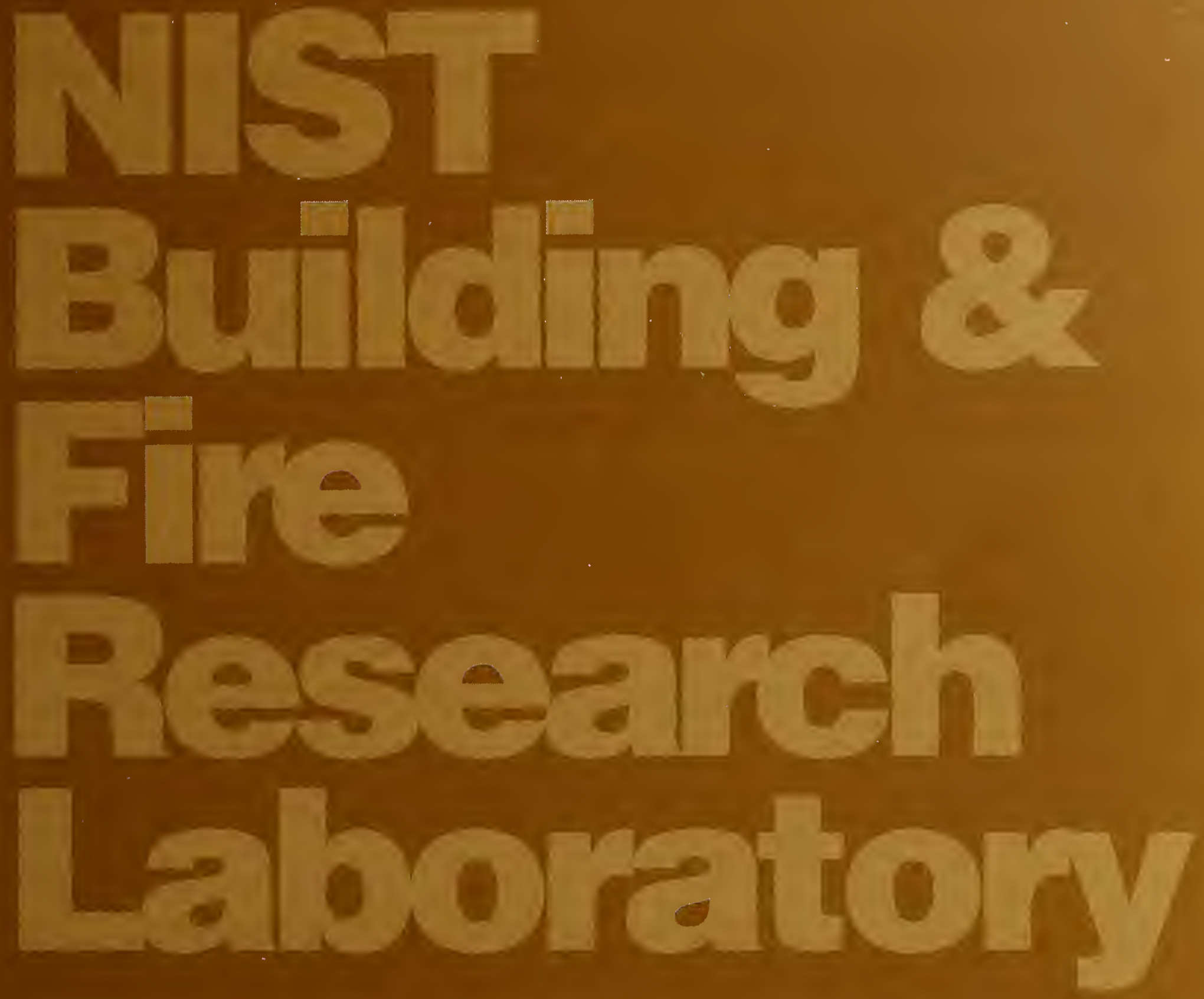

U.S. Department of Commerce

Technology Administration 



\section{Project \\ Summaries 1997}

NIST SP 838-13
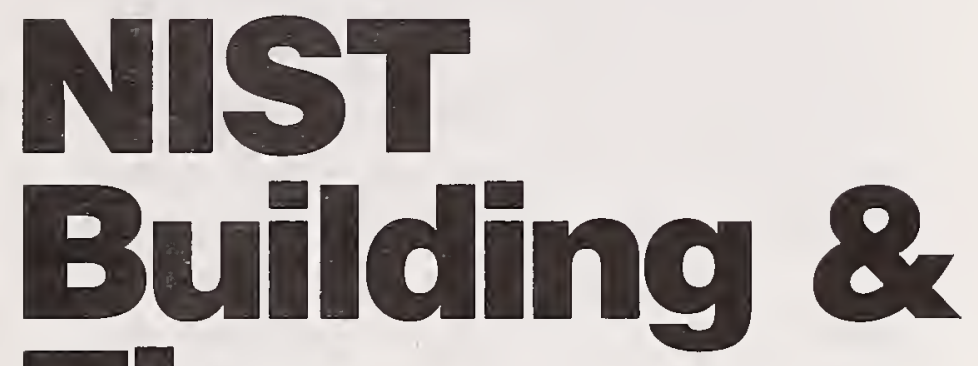

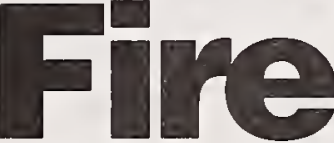

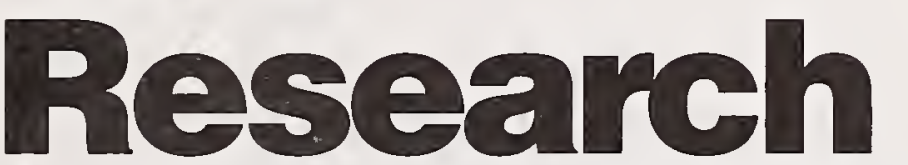

Laboratory

Noel J. Raufaste

November 1997

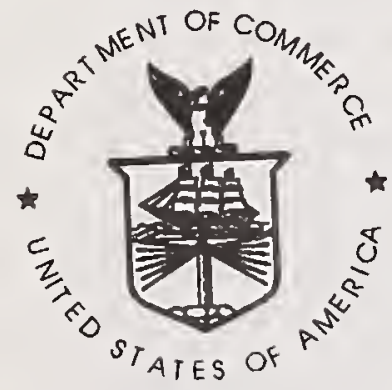

U.S. Department of Commerce

William M. Daley, Secretary

\section{Technology}

Administration

Gary R. Bachula

Under Secretary for Technology

National Institute of Standards and Technology

Raymond G. Kammer, Director 
National Institute of Standards and Technology

Special Publication 838-13

Natl. Inst. Stand. Technol.

Spec. Publ. 838-13

219 pages (Nov. 1997)

CODEN: NSPUE2
U.S. Government Printing Office Washington: 1997
For sale by the Superintendent of Documents U.S. Government Printing Office Washington, DC 20402 


\section{FOREWORD}

The National Institute of Standards and Technology's (NIST), Building and Fire Research Laboratory (BFRL) is one of NIST's seven Laboratories. The mission of BFRL is to enhance the competitiveness of U.S. industry and public safety by developing performance prediction methods, measurement technologies, and technical advances needed to assure improvement of the life cycle quality and economy of constructed facilities. Constructed facilities include all buildings and their furnishings and the public and private utilities and public works that support business, commerce, industry, and homes. BFRL's efforts are closely coordinated with complementary activities of industry, professional and trade organizations, academe, and other agencies of government.

Construction is one of the Nation's largest industries. In 1996, new construction amounted to $\$ 569$ billion; with renovation added, the total volume of construction was about $\$ 900$ billion, which is 12 percent of U.S. GDP. U.S. construction accounts for more than six million jobs. More than 60 percent of the nation's wealth is invested in constructed facilities. Since constructed facilities shelter and support human activities, their quality and economy is vital to the competitiveness of all industry and the quality of life of its citizens.

BFRL's research is focused and linked with collaborative private- and publicsector activities to help achieve the National Construction Goals (NCGs) developed with industry by President Clinton's National Science and Technology Council's Subcommittee on Construction and Building (C\&B). This Subcommittee coordinates the federal construction-related $R \& D$ to enhance the competitiveness of U.S. industry, public and worker safety, and environmental quality. BFRL is a co-chair of this 14 Federal agency body. During the past 3 years, $C \& B$ has had major interactions with construction industry leaders; together they have defined the NCGs. The goals are to provide cost-effective technologies and practices by 2003 that will achieve the following improvements in the life cycle performance of constructed facilities over average 1994 practices:

o $\quad 50$ percent reduction in delivery time.

o 50 percent reduction in operation, maintenance, and energy costs.

o $\quad 30$ percent increase in productivity and comfort.

o $\quad 50$ percent fewer occupancyrelated illnesses and injuries.

o $\quad 50$ percent less waste and pollution.

- $\quad 50$ percent more durability and flexibility.

o $\quad 50$ percent fewer construction illnesses and injuries.

In 1996 groups of industry leaders representing the residential, industrial, public works, and commercial/institutional sectors developed industry strategic plans for achieving the National Construction Goals in cooperation with Federal agencies. These industry plans and direct discussions with industry leaders have helped to the direction of BFRL research.

This annual report, Project Summaries 1997, presents BFRL's research during 1997. BFRL focuses its research in three principal thrusts:

1. High Performance Construction Materials and Systems,

2. Automation in Construction and Constructed Facilities, 
In high performance construction materials and systems, BFRL's projects include: high performance concrete, building life cycle cost computer program, high performance mechanical systems, finishes, and furnishings, "natural" alternative refrigerants for heat pumps, and our search, with industry, for alternative fire suppressants.

Within the automation thrust, research is addressing development of new techniques and standards for real-time construction metrology and a national standard for kinematic modeling of construction site machinery and displaying graphical representations. With U.S. industry, BFRL is developing the capability to represent and exchange information supporting the design and construction of structural systems using internationally accepted protocols. Conformance tests are being developed for products complying with standards for the open exchange of information between equipment from different control vendors and between different levels of control in hierarchal and distributed building management systems.

In the loss reduction thrust, BFRL research includes next generation design standards for wind loads to develop key elements of an improved wind load design standard that will use existing databases and state-of-the-art computational methods for establishing site-specific design wind speeds and the corresponding steady and fluctuating structural loads. BFRL is constructing a user-friendly version of its CFAST model (FASTLite) which can be used by fire protection engineers and fire service personnel with a minimum of training, and developing protocols to quantify the accuracy of computer-based predictive fire models.

In meeting these thrusts, BFRL's research addresses structural engineering, materials engineering, mechanical and environmental systems, fire safety engineering, fire science, and applied economics. Each of the BFRL research summaries is formatted by project title, the BFRL point of contact, sponsor, description of the research, and recent results.

BFRL's laboratory facilities are an important resource. Facilities include: six-degree-of-freedom structural testing facility; large-scale structural testing facility with the $53 \mathrm{MN}$ universal structural testing machine; environmental chambers; guarded hot-plate; calibrated hot-box; plumbing tower; building materials imaging and modeling laboratory; fire suppression test facilities; and a fire simulation laboratory. The large burn facility for conducting experimental fires in full-scale large industrial fire test facilities is currently undergoing renovation.

BFRL works closely with its international peer organizations to maintain awareness of foreign research developments, assure that generic research efforts are complementary, and represent U.S. interests in the preparation of international standards and practices. BFRL cooperates closely with other U.S. and foreign laboratories in the conduct of its research. More than 90 research associates from U.S. industry, guest researchers from foreign laboratories, and faculty members from universities worked at BFRL during 1996 for periods averaging about a year. BFRL has direct linkages with industry through its 45 Cooperative Research and Development Agreements (CRADAs). 
BFRL participates in more than 130 national and international standardization activities; provides leadership in these national and international standardization organizations and chairs more than 20 voluntary standardization activities. Annually BFRL publishes over 220 reports, articles for research journals and for professional and trade journals, and computer model software packages. BFRL staff annually makes hundreds of presentations at professional and technical meetings of building community organizations, is host to more than 1700 visitors to its facilities, and responds to more than 19000 requests for information. BFRL conducts symposia in cooperation with other organizations concerned with building research and practice and hosts biweekly Fire Research Seminars for NIST staff and colleagues from the fire community. These meetings are effective means of transferring the latest knowledge to practitioners and peer researchers. The Fire Research Information Service (FRIS) consisting of national and international fire research literature and FIREDOC, the automated database of fire research literature, is the only comprehensive national library resource for the fire community.

At the beginning of FY1997, BFRL's staff was about 220 persons of which 129 are professional staff, 71 have Ph.D.s, and 26 are registered engineers. BFRL's budget for FY 1997 is \$31 million. Funding comes from direct appropriations (\$19 million), from other Federal agencies (\$10 million) and from the private sector (\$2 million).

For further information about BFRL, its facilities, opportunities for Guest Researcher assignments, collaborative programs, and contracted research, may be reached through BFRL's Home Page at: http://www.bfrl.nist.gov or contact BFRL's Office of Cooperative Research Programs, Building 226, Room B250, NIST, Gaithersburg, MD 20899.

Persons requesting information may want to contact BFRL using facsimile number 301-975-4737 or E-mail noel.raufaste@nist.gov. 



\section{CONTENTS}

Foreword $\ldots \ldots \ldots \ldots$ iii

\section{EARTHQUAKE ENGINEERING}

Performance Requirements for Passive Energy Dissipation Systems for Buildings and Lifeline

Geotechnical Characterization for Lifelines and Buildings .............. 4

Cyclic Lateral Load Tests and Digital Database of Reinforced Concrete Bridge

Columns ............... 5

Seismic Performance of Precast Concrete Connections ..............

Seismic Resistance of Partially-Grouted Masonry Shear Walls ........... 8

Seismic Performance of Cladding

Systems ................ 8

Seismic Strengthening Methodologies for Existing Lightly RC Frame Buildings . . . .

Guidelines for the Repair/Rehabilitation of Welded Steel Moment Frames ...... 10

Implementation of National Lifeline

Plan .................. 11

Management of the Interagency Committee on Seismic Safety in Construction

(ICSSC) ................. . 12

Technical Assistance to FEMA Project

Officer (Existing Buildings) . . . . . . . 14

Technical Assistance to FEMA Project

Officer (New Buildings) ......... 15

Support Implementation of EO 12699 . 15

Secretariat U.S.-Side Panel on Wind and

Seismic Effects . . . . . . . . . . . 16

\section{STRUCTURAL EVALUATION}

Construction Automation . . . . . . . . . 19

High-Performance Concrete: Design and Construction Practices ........ 20
Fire Resistance of High-Strength

Concrete ............... . . 22

Fiber Reinforced Polymer Composites in Construction ............. . 24

Next Generation Design Standard for Wind Loads ................. . . 25

\section{COATINGS AND COMPOSITES}

Computer-Integrated Knowledge Systems (CIKS) for High-Performance Construction Materials and Systems ........ 29

Computer-Integrated Knowledge Systems (CIKS) for High Performance Coatings . . 30

Coatings Service Life Prediction Consortium - Task I: Quantification of Photodegradation Effects of UV-radiation in the Field and Laboratory . . . . . . . . . . . . . . 32

Coatings Service Life Prediction Consortium - Task II: Interactive Research Program With Industry .............. 33

Coatings Service Life Prediction Consortium - Task III: User-Friendly Software System for Experimental Design and Data

Analysis ...................... 33

Advanced Models and Measurements of Optical Reflectance of Materials . . . . . 34

Spectral Ultra Violet-B Radiation

Database . . . . . . . . . . . . . . 35

Highway Structures Expert System for the Selection of Coating Materials . . . . . 36

Effects of Environmental and Mechanical Stresses on Fiber-reinforced Polymeric Composites .............. 37

Interface/Interphase Characterization of Polymeric Building Materials . . . . . . . 38

Standards for Abatement of Hazards from Lead in Buildings . . . . . . . . . 39

Method for Evaluation of Performance of Lead-in-Paint Measuring Devices Under Simulated Field Conditions . . . . . . . 40 
Factors Affecting the Leaching of Lead from Lead-based Paint Films ......... . 41

International Standards for Design Life of

Buildings ............... . . 42

\section{CONCRETE}

Three-Dimensional Microstructural/Kinetic Model of Cement Hydration . . . . . . . . 47

Microstructure-Property Relationships in Random Porous Materials . . . . . . . 48

Microstructure and Moisture-Driven Size Changes of Cement-Based Materials . . . 49

Development of Microstructure and Transport Properties of Concrete . . . . 50

Transport Properties of High-Performance

Concrete ............... 51

Computer-Integrated Knowledge Systems (CIKS) for High-Performance Concrete . . 52

Processing of High-Performance

Concrete ................ 53

Cementitious Materials Modeling Laboratory

$(\mathrm{CMML}) \ldots \ldots \ldots \ldots . \ldots . . . . . . .54$

Characterization of Clinker, Cement, and Flaws in Cement Paste and Concrete . . 54

Durability of Highway Concrete

Pavements .............. 55

\section{QUALITY ASSURANCE}

Cement and Concrete Reference

Laboratory . . . . . . . . . . . . . . . . 59

AASHTO Materials Reference

Laboratory . . . . . . . . . . . . . . . . . 60

Performance of Tape-Bonded Seams in

EPDM Roofing Membranes . . . . . . . . 61

\section{COMPUTER INTEGRATED}

CONSTRUCTION

STEP for the Process Plant Industries . . 65

Object Oriented Implementation of STEP
Protocol Testing for Process Plant

Representations ........ . . . . 67

Architecture and Modeling Issues for Computer Integrated Knowledge Systems

for Materials .............. . 68

\section{HEAT TRANSFER}

Advanced Thermal Insulation Panel

Testing ................ . 71

Low-Temperature and High-Temperature

Thermal Insulation Reference

Materials ................ . 72

Development of 2-Dimensional Heat and Moisture Transfer Model . . . . . . . . .73

A Photovoltaic Solar Water Heating

System ............. . . . . 74

\section{INDOOR AIR QUALITY}

Indoor Air Quality Modeling with

Computational Fluid Dynamics . . . . . . 79

Development of IAQ Model for

Designers ............... . 80

VOC Emission Measurements in Office

Buildings ................ 81

IAQ Analysis of Residential Ventilation

Systems ... . . . . . . . . . . . 82

Infiltration and Ventilation in Large

Buildings ................ 83

Demonstration of Residential Ventilation

Systems ............... . . 84

Combined Thermal and Airflow Analysis in Multizone Buildings . . . . . . . . . 85

\section{MECHANICAL SYSTEMS AND} CONTROLS

Communication Protocols for Building

Controls ................. . 89

Real Time Fault Detection and

Diagnostics .............. . 90

Test Procedures for Furnaces, Boilers, and Integrated Appliances ............991 
Test Procedures for Commercial

Furnace/Boilers, Central Air Conditioners,

Heat Pumps, and Hot Water

Heaters . . . . . . . . . . . . 992

Test Procedures for Heat Pumps and Air

Conditioners ...........99

Test Procedures for Compact

Refrigerators ............ 94

Test Procedures for Plumbing Systems . 95

Test Procedures for Lighting Fixtures and

Systems .............996

Revised Test Procedures for Ranges and

Ovens . . . . . . . . . . . . . . . 97

Revised Test Procedures for Water

Heaters . . . . . . . . . . . . . . . . 97

Revised Test Procedures for Pool

Heaters . . . . . . . . . . . . . . 98

Revised Test Procedures for Clothes

Washers ................ 99

Revised Test Procedures for Clothes

Dryers . . . . . . . . . . . . . . . . 99

Revised Test Procedures for

Dishwashers ............. 100

\section{THERMAL MACHINERY}

Calorimetric and Visual Study of Heat

Transfer Enhancements with Alternative

Refrigerants .............. 103

Thermodynamic Performance of Natural

Fluids as Alternative Refrigerants . . . 104

Development of MicroElectro Mechanical Systems (MEMS) Sensors for Refrigeration

Machinery ............... 106

Impact of Air-Side Maldistribution on the

Performance of Finned-Tube

Evaporator . . . . . . . . . . . . . 107

Procedure for Determining the Energy Efficiency Ratio of DOE $95{ }^{\circ} \mathrm{C}$ Rating Point for Mixed Unitary Air Conditioners . . 108
FIRE MODELING AND

\section{APPLICATIONS}

Fire Performance Design of High-

Performance Materials Used in

Construction ............. 111

Implementation of Fire on the Web

CD ROM ............... 112

Zone Fire Modeling . . . . . . . . 113

Enhanced Fire Safety Evaluation

System . . . . . . . . . . . . . . . 114

Manufactured Housing Fire Safety . . 114

Experimental Application of Fire Hazard

Analysis for U.S. Passenger Train

Systems . . . . . . . . . . . . 116

Performance Fire Codes . . . . . . . . 117

Study of Heat and Smoke Movement and

Their Influence on Detector Response in

Enclosed Spaces . . . . . . . . . 117

BACnet Support . . . . . . . . . . 118

Fire Research Information Services

(FRIS) . . . . . . . . . . . . . . 119

Fire Forum . . . . . . . . . . . 119

\section{RECENT GRANTS - FIRE MODELING AND APPLICATIONS}

Review and Evaluation of Thermal Sensors for Use in Testing Firefighter Protective

Clothing .............. 120

Enhanced PC-Based Building Fire

Assessment System . . . . . . . . 121

Evaluation of Alternative Methods for Fire

Rating Structural Elements . . . . . . . 123

Assessment of the Technological

Requirements for the Realization of

Performance-Based Fire Safety Design in

the United States - Phase I: Fundamental

Requirements . . . . . . . . . . . 124

Interactive Virtual Environments for Fire

Simulation ... . . . . . . . . . . 125

An Analysis of Performance Requirements 
for an International Building Code

Evaluation of the HDR Fire Test Data and Accompanying Computational Activities with Conclusions from the Aspects of Present Code Capabilities . . . . . . 128

\section{LARGE FIRE RESEARCH}

In situ Burning of Oil Spills

Demonstration of Water Based Fire Fighting

Agents . . . . . . . . . . . 134

Quantitative Evaluation of Fire Safety

Features .............. 135

Office Building Fire Research Program . 136

Modification of Fire Protection Requirements

for NRC . . . . . . . . . . . . 137

Firefighter Thermal Environments and

Protective Clothing and Equipment

Performance ............. 137

Participation in Non-Project Committees and

Standards .............. 138

Large Fire Research Facility . . . . . . 139

\section{RECENT GRANTS - LARGE FIRE RESEARCH}

Characterization of Sprinkler Sprays and

Their Interaction with Fire Induced

Flows . . . . . . . . . . . . . 139

Fire Protection in Large Industrial

Fires ................. 141

A Study of Two Phase High Liquid Loading

Jet Fires . . . . . . . . . . . . 143

Measurements of Heat Release Rates and Vorticity Distributions in Pool Fires for the Calculation of Fire Induced Flow

Field . . . . . . . . . . . . . . . . . 144

Large Fire Analysis . . . . . . . . . . 146

\section{FIRE SENSING AND}

EXTINGUISHMENT

Advanced Fire Detection
Next Generation Fire Suppression

Program ............... 152

Dispersed Liquid Agent Fire Suppression

Screen ... . . . . . . . . . . 153

Fire Suppression Chemistry . . . . . . 154

Suppression of Engine Nacelle Fires . . 155

Chemical Inhibitor Effects on Diffusion

Flames in Microgravity . . . . . . 156

Payload Specialist on STS-83 . . . . . 157

Low Environmental Impact Fire

Suppression . . . . . . . . . . . 157

Analysis of High Bay Hangar Facilities for

Detector Sensitivity and Placement . . . 158

Smoke Movement in High Bays . . . . 159

Research in Fire Protection Technologies - A Resource Allocation and Impact

Study . . . . . . . . . . . . . . 160

High Heat Flux Measurement

Standards ... . . . . . . . . . . 161

\section{RECENT GRANTS - FIRE SENSING}

\section{AND EXTINGUISHMENT}

Fire Detection Using Reflected Radiation and Source Temperature

Discrimination . . . . . . . . . . . . 162

Water Mist Penetrations Through Complex Openings of Compartments . . . . . 164

A Theoretical and Experimental Investigation on Physical, Thermal, and Chemical Effects of Condensed Phase Fire Suppressants . . . . . . . . . . . . 165

\section{MATERIALS FIRE RESEARCH}

Fire Safe Materials . . . . . . . . . 169

Development of Environmentally-Friendly, New Flame Retardants Consortium . . 170

Flammability of Automotive Materials and Components ............ 171

Vehicle Fire Initiation and Propagation . 171 
Evaluation of Potential Fire Intervention

Materials and Technologies

Quantitative Evaluation of Fire Safety

Features ............... 173

Combustion of Silicone . . . . . . . . 174

Production and Certification of Cone

Calorimeter SRMs . . . . . . . . . . 175

Radiative Ignition and Subsequent Flame

Spread in Microgravity . . . . . . . . 176

Combustion of a Polymer (PMMA) Sphere in Microgravity ............. 177

\section{RECENT GRANTS - MATERIALS FIRE RESEARCH}

Cross-Linking of Polystyrene by FriedelCrafts Chemistry to Enhance Resistance to Thermal Degradation ........... 178

A Fire Growth Simulation Model for Materials ............... 179

The Development of Novel Low Flammability Siloxane-Based Impact Modifiers for Cyanate Ester Resins . . . 180

\section{ADVANCED FIRE MEASUREMENTS} Improvement and Development of Fire

Diagnostics .............. 183

Particle Measurement in Support of the

Semiconductor Industry . . . . . . . . 183

Carbon Monoxide Production and

Prediction ................. 184

Lean Flammability Limit as a Fundamental

Refrigerant Property, Phase III . . . . . 185

Laminar Flame Speeds in Refrigerant/Air

Mixtures ............... 186

A Numerical Model for Combustion of Bubbling Thermoplastic Materials in Microgravity ........... . 187

Flammability of Structural Composites . 188

Fire Safe Aircraft Interior Materials . . 189
RECENT GRANTS - ADVANCED FIRE MEASUREIMENTS

Mixing and Radiation Properties of Buoyant

Luminous Flame Environments . . . . . 191

Experimental and Modeling Studies of Soot and Polycyclic Aromatic Hydrocarbon

Oxidation in Post-Flame Gases . . . . . 192

Dynamics, Transport and Chemical Kinetics of Compartment Fire Exhaust Gases . . 193

\section{OFFICE OF APPLIED ECONOMICS}

Building for Environmental and Economic Sustainability (BEES) . . . . . . . . . . 197

Purchasing Environmentally Preferable

Products .............. . . 198

Economics of New-Technology

Materials ............... 199

How to Select Research Projects and

Measure Their Impacts ....... . 200

Baseline Measures for National Construction Goals . . . . . . . . . . . . . . . . 201

Life-Cycle Costing Methodology ... . 202

Minimizing Compliance Costs of the Life Safety Code for Correctional Facilities . 204

Decision Support Software for Hospitals Financed by HUD-Guaranteed Loans . . 205

Allocating Capital Improvement Budgets Among Historic Buildings . . . . . . . . 206

Economic Support to NIST Manufacturing Extension Partnership . . . . . . . . 207

Economic Support to NIST Advanced Technology Program ... . . . . . . 208

Economic Support for the NIST Office of Law Enforcement Standards ...... 209

Cost-Effective Decisions for Police Patrol Vehicle Disposal ............ 210 
BFRL Headquarters

Performance Standards System for

Housing . . . . . . . . . . 215

Subcommittee on Construction and

Building . . . . . . . . . . . . . 216

Computing and Network Resources . . 217 


\section{STRUCTURES DIVISION}

\section{EARTHQUAKE ENGINEERING}



Performance Requirements for Passive Energy Dissipation Systems for Buildings and Lifeline

\author{
Principal Investigator \\ Riley M. Chung \\ Structures Division \\ 301-975-6062
}

\section{Sponsor \\ National Institute of Standards of \\ Technology \\ Objective}

To develop and verify guidelines for pre-qualification, prototype and quality control testing of seismic isolation systems.

\section{Problem}

Seismic isolation has been proven to be an effective method of reducing the response of structures during strong earthquakes. In practice, the components of the isolation system undergo an extensive series of prototype and quality control tests before installation. However, there are no commonly accepted testing standards for base isolation devices. Consequently, designers of base isolated structures do not know how to specify testing of systems or interpret test results. Furthermore, without standard testing procedures, it is nearly impossible to compare the performance of competing isolation systems.

Recently BFRL published an extensive set of guidelines for conducting these tests: Guidelines for Pre-Qualification, Prototype and Quality Control Testing of Seismic Base Isolation Systems NISTIR 5800, June 1996. The guide is, for now, the leading available test guidelines for testing base isolation systems. Presently, ASCE is using the guidelines as the basis for development of an ANSI national consensus standard. BFRL is supporting this effort through participation in the ASCE standards development committee.

To develop further confidence in the guidelines, and to foster wider adoption of the proposed testing procedures, the guidelines must be evaluated by conducting tests on typical isolation components. These tests will expose any inconsistencies, omissions of important data, or other unforeseen problems with the procedures.

\section{Approach}

During FY1997, BFRL will perform a two part experimental program: The project involves the following tasks:

\section{Support of Development of a}

National Consensus Standard. As an ongoing component of this project, BFRL will provide the secretariat of the ASCE standards committee on testing of base isolation systems. The committee was formed in August of 1995. Meetings will take place approximately every 6 months

\section{Test Program for Assessing and} Evaluating Guidelines.

- Design and Construction of Lateral Load Test Frame. The current configuration of the BFRL's Large Scale Testing Facility permits concentric axial loads to be applied to base isolation devices. However, the most critical design condition for isolators is when simultaneous axial load and lateral load are applied. Several tests in BFRL's guidelines require such loading. Therefore, a lateral loading frame is needed for the $53 \mathrm{MN}$ capacity universal testing machine. This frame could make use of the existing reaction wall and $4.4 \mathrm{MN}$ long-stroke hydraulic actuator. Two faculty members of the United States Military Academy (West Point) are designing the lateral loading frame.

- Test Plan: A detailed plan has been developed for the experimental program, through consultations with researchers at the University of Delaware, the University of Maryland, Southern Methodist University, and Dynamic Isolation Systems, and Furon (two major manufacturers of elastomeric isolation bearings). The objectives of the experimental program is to evaluate BFRL's testing guidelines, and to study 
three other issues which affect test methods: the ultimate capacity of seismic isolators; the effects of bi-lateral loading on isolator performance; and improved methods for detecting flaws in elastomeric bearings.

\section{Recent Results}

Shenton III, H.W., Guidelines for

Pre-Qualification, Prototype and Quality Control

Testing of Seismic Base Isolation Systems,

NISTIR 5800, National Institute of

Standards and Technology, June 1996.

Shenton, H.W. and Taylor, A.W., Guidelines and Benchmarks for Analysis of Isolated Buildings, Proceedings, 1996 ASCE structures Congress, April 15-18, 1996.

Shenton, H.W., Summary and Results of the NIST Workshop on Proposed Guidelines for Testing and Evaluation of Seismic Isolation Systems, July 25, 1994, San Francisco, California, NISTIR 5785, National Institute of Standards and Technology, January 1996.

Taylor, A.W., Shenton, H.W., and Chung R.M., Standards for Testing and Evaluation of Seismic Isolation System, Seismic, Shock, and Vibration Isolation, 1995 ASME/JSME PVP Conference, Honolulu, July 23-27, 1995, PVP-Vol 319, pp. 39-43.

Shenton H.W., Taylor A.W., and Lew, H.S., "Test Requirements for Base Isolation," Proceedings, 27th Joint Meeting on Wind and Seismic Effects, U.S.-Japan Panel on Wind and Seismic Effects, UJNR, Tsukuba, Japan, May 1995.

\section{Geotechnical Characterization for Lifelines and Buildings}

\author{
Principal Investigators \\ Ronald D. Andrus \\ Structures Division \\ 301-975-605 I \\ Riley M. Chung \\ Structures Division \\ 301-975-6062
}

\section{Sponsor \\ National Institute of Standards and Technology}

\section{Objective}

To develop methodologies for rapidly assessing liquefaction potential and characterizing ground deformations of soil deposits supporting lifelines and buildings.

\section{Problem}

A major cause of lifeline and building damage in past earthquakes is ground deformations caused by liquefaction. Since lifeline corridors can be many kilometers in length, rapid screening of large areas is required. Screening techniques based on geology, hydrology, and soil conditions show promise for identifying areas along lifeline corridors requiring more rigorous analyses. However, even these areas requiring further analyses can be quite large.

\section{Approach}

During FY1997, BFRL will continue the development of rapid techniques for evaluating liquefaction resistance based on small-strain shear wave velocity, VS. The use of VS as a field index of liquefaction resistance is justified since both are influenced by void ratio, effective confinement, stress history, and geologic age. Its application to liquefaction assessment before and after ground improvement will also be examined. In addition, this project will begin work on refining/developing methodologies for predicting magnitude and spatial extent of liquefaction-induced ground deformations. The work will be performed in 
collaboration with academia and industry; it is divided into four tasks:

1. Conduct field demonstration of the Spectral-Analysis-of-Surface-Waves (SASW) method for rapid determination of layer thickness and VS.

2. Develop simplified liquefaction assessment procedures based on VS from available field performance data.

3. Refine/develop practical approaches to predicting ground deformations for lifeline risk assessment through a review of the physical attributes of lateral spreads in past earthquakes.

4. Prepare guidelines for using the SASW method to evaluate liquefaction potential of soils supporting lifelines from results of Tasks 1 and 2.

\section{Recent Results}

Andrus, R. D., and Chung, R. M., "CostEffective Ground Improvement Techniques for Liquefaction Remediation Near Lifelines," Wind and Seismic Effects, Proceedings, 27th Joint Meeting of the U.S.-Japan Cooperative Program in Natural Resources Panel on Wind and Seismic Effects, Public Works Research Institute, Japan, 1995.

Andrus, R. D., and Chung, R. M., "Liquefaction Remediation Near Existing Lifeline Structures," Technical Report NCEER-96-00 12, Lifeline Facilities and Countermeasures Against Soil Liquefaction, 6th Proceedings, Japan, June I I-13, 1996.

Andrus, R. D., and Stokoe, K. H., II, Preliminary Guidelines for Liquefaction Assessment Using Shear Wave Velocity, NIST SP 904, National Institute of Standards and Technology, Gaithersburg, MD, August 1996.

Andrus, R. D., Surface Wave Method - A Tool for Lifeline Earthquake Engineering, Proceedings, Earthquake Engineering Site Characterization Workshop, Vicksburg, MS, June 27-28, 1995.

\section{Cyclic Lateral Load Tests and Digital Database of Reinforced Concrete Bridge Columns}

\author{
Principal Investigator \\ William C. Stone \\ Structures Division \\ 301-975-6075
}

\section{Sponsors}

National Center for Earthquake Engineering Research and

\section{California Department of Transportation}

\section{Objective}

To investigate experimentally the effect of varying cyclic lateral load paths on damage to circular reinforced concrete columns and to develop a comprehensive digital database of cyclic lateral load tests on rectangular reinforced concrete columns.

\section{Problem}

In earthquake engineering studies of reinforced concrete columns, a controlled, cyclic lateral load pattern with gradually increasing amplitude has traditionally been applied to columns tested in the laboratory. However, in an actual earthquake a bridge column is exposed to a random cyclic lateral loading pattern, which is much different from the laboratory loading pattern. Current American Association of State Highway and Transportation Officials (AASHTO) and Caltrans design provisions are based almost exclusively on tests in which traditional, controlled laboratory loading patterns have been applied to the specimens, rather than realistic earthquake loading patterns. The differences between these types of loading have never been explored systematically. Furthermore, to develop confidence in inelastic analysis algorithms for reinforced concrete structures, the algorithms must be calibrated against laboratory data from tests on reinforced concrete members. Without such a calibration, the inelastic analysis algorithms are essentially useless. There is currently no comprehensive, world-wide database of results from cyclic lateral load 
experiments on rectangular columns.

\section{Approach}

During FY1997, BFRL will test 12 column specimens. The specimens will be approximately one-fourth scale versions of prototype bridge columns designed using current Caltrans standards. The 12 specimens will be nominally identical: approximately $300 \mathrm{~mm}$ in diameter by $1800 \mathrm{~mm}$ long, with the same material properties for all specimens. The specimens will be cast integrally with a reinforced concrete base block to simulate a bridge column footing.

The main variable in the test program will be the type of cyclic lateral load pattern applied to the specimen. The first specimen will be loaded with a monotonic lateral load to failure (pushover test) to determine basic specimen stiffness and strength. The next four specimens will each be loaded with cyclic lateral displacements of a constant amplitude for as many cycles as are necessary to cause complete failure of the specimen. The amplitude of displacement applied to each specimen will be a multiple of the yield displacement determined from the first test specimen. The fourth specimen will be loaded with a "standard" laboratory load pattern, which consists of cyclic lateral displacements with gradually increasing amplitudes. The final six specimens will be loaded with simulated earthquake displacement patterns. The earthquake displacement patterns will be selected to simulate a range of earthquake types. The effects of applying multiple damaging earthquakes to the same column will also be investigated.

The data and visual observations obtained from these tests will be correlated with several analytical damage models which have been proposed by other researchers. The accuracy of the damage models will be evaluated in light of the test data, and recommendations will be made regarding the best methods for analytically modeling earthquake damage to circular reinforced concrete bridge columns. Recommendations will also be made regarding the appropriateness of using results from "standard" laboratory tests of columns, rather than simulated random earthquake motions, to develop codes and standards for the seismic design of reinforced concrete bridge columns.

\section{Recent Results}

New project. 


\section{Seismic Performance of Precast Concrete Connections}

\section{Principal Investigator}

Geraldine S. Cheok

Structures Division

301-975-6074

\section{Sponsor}

National Institute of Standards and

Technology

\section{Objective}

To develop technical data and to recommend rational and consistent seismic design provisions for moment resistant precast concrete beam-column connections.

\section{Problem}

Careful attention to connection detail is required to ensure ductility and no premature yielding of connections. In order to exploit the benefits that exist in precast construction, ATC-8, the Proceedings of Workshop on Design of Prefabricated Concrete Buildings for Earthquake Loads, identified research on moment resistant joints between precast beam and column element as the top priority item.

Strength and ductility of joints of precast beam-column connections can be achieved by post-tensioning the precast elements, special reinforcing arrangement, and fiber reinforced grout in the joints. Technical data are needed to establish provisions for code and standards, thereby promoting precast construction in seismically active regions.

\section{Approach}

During FY1997, BFRL will complete cooperative work with Charles Pankow Builders on the debond tests of reinforcing bars. BFRL will continue to provide the necessary input to $\mathrm{ACI}$ and SEAOC to aid them in their consideration of code changes which would allow the construction of the hybrid connections in high seismic regions.

\section{Recent Results}

Cheok, G. S., Stone, W. C., and Nakaki, S.
D., Simplified Design Procedure for Hybrid

Precast Concrete Connections, NISTIR 5765,

National Institute of Standards and

Technology, Gaithersburg, MD, February, 1996.

Stone, W. C., Cheok, G. S, and Stanton, J. F., "Performance of Hybrid

Moment-Resisting Precast Beam-Column

Concrete Connections Subjected to Cyclic

Loading," ACI Structural Journal, Vol. 92, No. 2, American Concrete Institute, Detroit, MI, March-April, 1995, pp. 229-249. 
Seismic Resistance of Partially Grouted Masonry Shear Walls

\author{
Principal Investigator \\ Geraldine Cheok \\ Structures Division \\ 301-975-6074
}

\section{Sponsor}

National Institute of Standards and

Technology

\section{Objective}

To define the strength and deformation of partially grouted masonry shear walls at the cracking and ultimate limit states and to develop semi-empirical, simplified design expressions for predicting shear strengths and deformations of partially grouted masonry shear walls.

\section{Problem}

The behavior of masonry shear walls has been the subject of increased attention during the past 15 years. However, this effort has been aimed at fully grouted, reinforced walls. Due to the lack of physical data on the response of partially grouted masonry walls to in-plane lateral loads, no acceptable design formulas are available for predicting shear strength of such walls. The limited data available also suggests that empirical formulas for shear strength of fully grouted, reinforced walls have very limited applicability for determination of the shear strength of partially grouted, lightly reinforced shear walls.

\section{Approach}

During FY1997, BFRL will complete the tests of the masonry walls that were started at the end of FY1996. Data reduction and analyses also will be conducted.

\section{Recent Results}

Chang, P. and Love, A., Finite Element Modeling of Masonry Shear Walls, Project No. 43NANB5 12479, University of Maryland, College Park, 1996.

\section{Seismic Performance of Cladding Systems}

\author{
Principal Investigator \\ Andrew W. Taylor \\ Structures Division \\ 301-975-6078
}

\section{Sponsor \\ National Institute of Standards and Technology}

\section{Objective}

To evaluate seismic performance of exterior architectural cladding elements during the Northridge earthquake, and develop energy dissipating cladding systems for seismic retrofit and design of new buildings.

\section{Problem}

Although many cladding elements are not specifically designed for seismic forces, they participate in resisting lateral loads as they deform with the framing system. Cladding systems sustained damage during the Northridge earthquake, particularly those on steel frame structures. The seismic performance of buildings could be improved by effectively using the cladding system to dissipate energy. Energy-dissipating cladding can be applied to new construction and seismic retrofit.

\section{Approach}

During FY1997, BFRL will document the performance of architectural cladding systems during the Northridge and other earthquakes. Current design criteria and code requirements will be critically evaluated based on observed cladding performance.

The performance of energy dissipating cladding connector hardware will be studied. This will be primarily an experimental investigation, making use of existing test fixtures at Georgia Institute of Technology. The goal of this phase will be to determine how different types of energy dissipating connectors behave (e.g., elastomeric connectors, steel clip angles, and other specially designed steel connectors). The 
hysteretic properties of the connectors will be established, and desirable modes of connector performance will be defined.

The contributions of cladding to the stiffness and damping of the overall structural system will be determined. This work follows naturally on the connector performance studies described above, since the energy dissipating properties of connectors have a major influence on the interaction between the cladding system and the structural frame. This task will be carried out by comparing analytical models of buildings with observed experimental full-scale and scale-model building performance data.

Based on the results of the steps above, seismic design guidelines for building cladding systems will be developed.

\section{Recent Results}

Literature review on Seismic Performance of building Cladding Systems, prepared by Cladding Research Institute, Emeryville, CA, NIST GCR 95-681, National Institute of Standards and Technology, February 1995.

\section{Seismic Strengthening Methodologies for Existing Lightly RC Frame Buildings}

\author{
Principal Investigators \\ Geraldine S. Cheok \\ Structures Division \\ 301-975-6074 \\ Long T. Phan \\ Structures Division \\ 301-975-6077
}

\section{Sponsor}

National Institute of Standards and

Technology

\section{Objective}

To develop guidelines for strengthening lightly reinforced concrete (LRC) frames using concrete infill walls.

\section{Problem}

There are some research results available to give limited guidance in the design of concrete infill walls to strengthen LRC frames. However, gaps exist in the database which need to be filled. Some of these gaps were identified in a BFRL sponsored workshop in 1995. One of the issues identified was the connection of the infill wall to the frame. This is an important issue as the predicted behavior of a frame could be made more accurately if the behavior of such connections were better understood.

\section{Approach}

During FY1997, BFRL will perform an experimental program involving the tests of anchors subjected to tension and shear. The variables to be examined include anchor type, different combination of tension and shear load, embedment depth, anchor configuration - number of rows, number of anchors, spacing, and concrete strength. The results from this test program and other available test data will serve as the basis for the development of the load-deformation relationship for post-installed anchors. 


\section{Recent Results}

Phan, L. T., Cheok, G. S., Todd, D. R. and

Lew, H. S., Strengthening Methodology for

Lightly Reinforced Concrete Frames: Recommended

Design Guidelines for Strengthening with Infill

Walls, NISTIR 5682, National Institute of

Standards and Technology, July 1995.

Cheok, G. S., Editor, Proceedings, Workshop on the Seismic Rehabilitation of Lightly Reinforced Concrete Frames, June 12-13, 1995, NISTIR 5741, National Institute of Standards and Technology, November 1995.
Guidelines for the Repair/Rehabilitation of Welded Steel Moment Frames

Principal Investigator

John L. Gross

Structures Division

301-975-6068

Sponsor

National Institute of Standards and

Technology

Objective

To develop guidelines for the repair and/or rehabilitation of welded steel moment frame buildings damaged in the Northridge earthquake.

\section{Problem}

On February 12, 1994 Public Law 103-22 1 was passed authorizing BFRL to conduct post-earthquake investigations of structural failures resulting from the January 17, 1994 Northridge earthquake in Los Angeles, California. The BFRL investigative team, as well as other investigators, found severe and unexpected damage to welded steel moment frame structures. While none of the steel frame structures damaged in the Northridge earthquake collapsed or caused serious injury to their occupants, their damaged condition leaves them vulnerable to future earthquakes and or aftershocks. Additionally, thousands of buildings built to the same specifications as those that suffered severe damage in the Northridge earthquake are vulnerable to an earthquake of similar or greater magnitude.

\section{Approach}

During FY1997, BFRL will perform experimental investigations of full-scale beam-to-column connections to evaluate three different repair/rehabilitation strategies. These repair/rehabilitation strategies, found from SAC Phase I investigations to hold the most promise, include: welded haunch, bolted bracket and section reduction. The BFRL tests extend previous work conducted for SAC by considering two-sided connections and the effect of the floor slab. 
Results of the BFRL tests, combined with previous results from tests of one-sided, bare steel connections, will be used to validate design procedures for the three repair/rehabilitation procedures. Design guidelines will then be prepared with participation from the American Institute of Steel Construction.

\section{Recent Results}

Gross, J., and Kaufman, E. J., Failure Analysis of Welded Steel Moment Frames Damaged in the Northridge Earthquake, NISTIR 5944, National Institute of Standards and Technology, January 1997.

Gross, J., and Nabih Y., A Survey of Steel Moment-Resisting Frame Buildings Affected by the 1994 Northridge Earthquake, NISTIR 5625, National Institute of Standards and Technology, April 1995.

\section{Implementation of National Lifeline Plan}

\author{
Principal Investigators \\ Bijan Mohraz \\ Structures Division \\ 301-975-6079 \\ Riley M. Chung \\ Structures Division \\ 301-975-6062

\section{Sponsor \\ National Institute of Standards and Technology}

\section{Objective}

To assess the Lifeline Plan and proceed with its implementation for developing seismic safety guidelines for rehabilitation and design of lifeline systems.

\section{Problem}

In September 1995, FEMA submitted to Congress a "Plan for Developing Seismic Guidelines and Standards for Lifelines," FEMA 27 1, 5/96, referred to as the "Lifeline Plan." Among the recommendations was a cost effective approach that will result in near-term implementation activities to reduce the current vulnerability of existing lifelines. The Plan also recommended establishment of a Lifeline Seismic Safety Executive Board (LSSEB) to manage and coordinates the development of the guidelines.

\section{Approach}

The project will support the implementation of the "Lifeline Plan" and examine how best the Plan can be implemented through partnership between the private/public sectors and the federal government. It will provide technical and managerial support for the formation of the LSSEB. The project will include the following tasks:

1. Conduct a workshop in collaboration with ASCE to support the development of seismic safety guidelines and assess the Lifeline Plan and its implementation through partnership between the private/public sectors and 
Federal Government.

2. Assess the need and proceed with establishing LSSEB based on the recommendations to be developed by the workshop participants and provide technical and managerial support to the Board for the implementation of the Plan.

3. Formulate development of guidelines for liquid fuel systems based on the outcome the two current efforts conducted by others through NIST's external research program and begin recommended studies, if needed.

\section{Recent Results}

Dikkers, R. D., Chung, R. M. Mohraz, B., Lew, H. S., and Wright, R. N., Proceedings of the 1991 Workshop on Developing and Adopting Seismic Design and Construction Standards for Lifelines NISTIR 5907, National Institute of Standards and Technology, October 1996.

\section{Management of the Interagency Committee on Seismic Safety in Construction (ICSSC)}

\author{
Principal Investigator \\ Ann Bieniawski \\ Structures Division \\ 30I-975-6065

\section{Sponsor \\ Federal Emergency Management Agency Mitigation Directorate}

\section{Objective}

To facilitate and expedite the work of the Interagency Committee on Seismic Safety in Construction (ICSSC) by providing the Chair and Technical Secretariat.

\section{Problem}

The National Earthquake Hazard Reduction Program (NEHRP) established the ICSSC to assist Federal departments and agencies develop, improve, and maintain seismic safety programs for all types of construction. Thirty-three Federal departments and agencies currently participate in the ICSSC. The National Earthquake Hazard Reduction Act (amended by Public Law I0 I-6I 4) designates the director of NIST, or his deputy, as the chair of the ICSSC. BFRL provides the Technical Secretariat to the ICSSC, to facilitate, document, and disseminate the work of the committee.

The ICSSC has published and distributed implementation guidance for Executive Order I 2941, Seismic Safety of Existing Federally Owned or Leased Buildings. Section 2 of the Order requires all building-owning agencies to develop a seismic inventory and an estimate of the cost of achieving adequate seismic safety in their buildings. The information that is collected on the Federal Government's half-million owned buildings will be used to examine potential rehabilitation programs, and to recommend to Congress an economically feasible way to upgrade the seismic safety of the Federal building population. 
The ICSSC guidance is aimed at ensuring that the data collected by the agencies is consistent in content and format, so that an effective seismic rehabilitation program, based on reliable and defensible data, will be proposed to Congress. The ICSSC guidance was published in two volumes including a "how-to" handbook. Continued efforts are needed on the part of the ICSSC to encourage consistent data collection, interpretation, and reporting by the agencies. The information collected by the agencies will be submitted to the ICSSC between now and 1998, for incorporation into a government-wide database, with entries on all the half-million owned buildings. The government-wide database will serve as the primary source of information for the examination of potential rehabilitation programs and the report to Congress.

\section{Approach}

During FY1997, BFRL will continue serving as the ICSSC Technical Secretariat and will continue to carry out the basic day-to-day management of the full committee and the five subcommittees: organizing and documenting meetings, maintaining rosters, disseminating information. The ICSSC will encourage consistency of implementation of EO 12941 by:

1. Developing cost estimating tools and methodologies. Submitted data will be used to assess vulnerability of a wide variety of building types. The Second Edition - Typical Costs cost estimating methodology will be adapted for use in sub-dividing cost estimates into the cost reporting categories called for in the ICSSC guidance. Other potential tools and methodologies that could aid the agencies will be identified and developed.

\section{Holding twice-yearly workshops to} provide a forum for agencies to share successes and difficulties in implementing the order. Agency personnel will be trained in the use of the ICSSC-developed methodologies.

3. Providing additional agency-specific technical support upon request, in the form of explanation, interpretation and/or training in the use of the ICSSC guidance documents, distribution of ICSSC documents, presentations at meetings, review and comment on proposed methodologies, and similar efforts.

4. Serving as Database Manager who will develop the basic framework for the government-wide database, and begin working with agency personnel to test protocols for transmitting data.

\section{Recent Results}

No recent publications. 


\section{Technical Assistance to FEMA Project Officer (Existing Buildings)}

Principal Investigator

Ann Bieniawski

Structures Division

301-975-6065

\section{Sponsor}

Federal Emergency Management Agency

Office of Earthquakes and Natural Hazards

\section{Objective}

To provide technical review of FEMA-funded projects aimed at developing design and construction guidance documents for seismic rehabilitation of existing buildings.

\section{Problem}

FEMA supplements the capabilities of their own staff by using the technical expertise of BFRL personnel.

\section{Approach}

During FY1997, BFRL will assist FEMA

perform the following:

1. Implement Section 2 of Executive Order 12941, "Seismic Safety of Existing Federally Owned or Leased Buildings";

2. Complete "Guidelines for Seismic Rehabilitation of Buildings," and supporting documentation, being prepared by BSSC/ATC/ASCE;

3. Complete "Existing Buildings 2005," development of a strategy for improving seismic rehabilitation tools between now and 2005;

4. Investigation of the seismic rehabilitation of Federally assisted and regulated buildings; and

5. Update FEMA 178, the NEHRP Handbook for the Seismic Evaluation of Existing Buildings.

\section{Recent Results}

Bieniawski, A. S., "Executive Order 12941: Mitigating Seismic Risk in the Federal Inventory," Proceedings of EERI New Madrid Zone regional Seminar on Seismic Engineering Issues, September 1996. 


\section{Technical Assistance to FEMA Project Officer (New Buildings)}

\author{
Principal Investigator \\ H. S. Lew \\ Structures Division \\ 301-975-6061
}

\section{Sponsor}

Federal Emergency Management Agency

Mitigation Directorate

\section{Objective}

To provided technical review of

FEMA-funded projects on development of improved building codes for seismic design of new construction.

\section{Problem}

FEMA supplements the capabilities of it's staff by using BFRL's technical expertise.

\section{Approach}

During FY1997, BFRL will participate in technical subcommittees of the BSSC Update Project including the NEHRP Recommended Provisions for the Development of Seismic Regulations for New Buildings. All ballot submittals from the Provisions Update Committee will be reviewed. At the request of the FEMA Project Officer, BFRL staff will participate in proposal evaluation panels and selected technical seminars and meetings.

\section{Recent Results}

No published results.

\section{Support Implementation of EO 12699}

\author{
Principal Investigator \\ Ann Bieniawski \\ Structures Division \\ 301-975-6065
}

\section{Sponsor}

Federal Emergency Management Agency Mitigation Directorate

\section{Objective}

To support implementation of Executive Order 12699 on seismic safety of new Federal construction by providing technical assistance when requested by affected agencies, and by producing appropriate technical studies.

\section{Problem}

Federal Government Agencies may lack knowledge of seismic design and construction principles, and content and use of building codes. As model codes and source documents are updated, agencies may need guidance on which codes are appropriate for Federal use.

\section{Approach}

During FY1997, BFRL will upon request of an affected Federal agency:

1. Provide a speaker knowledgeable on EO 12699 and implementation issues, for meetings in the Washington, DC area;

2. Provide multiple copies of existing literature, published by NIST, supporting implementation of the EO;

3. Review proposed implementation procedures or regulations for appropriateness of technical content; and

4. Duplicate and disseminate materials produced by affected agencies for purposes of information-sharing with other agencies (only at request of the producing agency).

\section{Recent Results}

Provided ongoing technical assistance to Federal agencies. 


\section{Secretariat U.S.-Side Panel on Wind and Seismic Effects}

\author{
Principal Investigator \\ Noel J. Raufaste \\ BFRL Headquarters \\ 301-975-5905
}

\section{Sponsors}

National Institute of Standards and

Technology

Nine Federal Agency Members

\section{Objective}

To provide the U.S. Secretariat of the U.S.-Japan Panel on Wind and Seismic Effects.

\section{Problem}

Loss of life and property result from insufficient knowledge to adequately design and construct buildings and other structures cost-effectively against high winds and seismic loads. Improved mitigation practices are in early stages of development. Technical collaboration between experts in the United States and Japan continue to produce findings that improve natural hazard mitigation practices. Such improvements are possible through joint working relations with experts from the United States and Japan through performing joint research projects and exchanges of research personnel, technical data and information, and research equipment. [This Panel is part of the U.S.-Japan Natural Resources Development Program under the aegis of the U.S.-Japan Cooperative Science Program of 196I.]

\section{Approach}

During FY1997, BFRL will:

1. Plan U.S.-side activities (19 Agency membership) for scheduling U.S.-side efforts in participating in the 29th Joint Panel Meeting, Japan and hosting two U.S. Panel's domestic meetings.

2. Manage the U.S. delegation's technical contributions to Annual Joint Meetings.

3. Plan and coordinate technical activities of the 11 Task Committees.

4. Manage U.S. delegation to Japan-side hosted Meetings and Workshops and developing technical programs for U.S. hosted meetings.

5. Maintain liaison with U.S. and Japan Panel members and other experts associated with the Panel's activities.

6. Plan Japan Panel member visits to the U.S. under the auspices of the Panel, e.g., post disaster investigations, special studies, data gathering.

7. Maintain administrative and technical records.

8. Prepare and distribute periodic activities reports, and other materials as appropriate to U.S.-side Panel and Task Committee members.

9. Participate in Joint Panel meetings and Task Committees.

10. Prepare and publish annual Proceedings.

\section{Recent Results}

Raufaste, N., J., Wind and Seismic Effects, Proceedings of the 28th Joint Panel Meeting, NIST SP 904, National Institute of Standards and Technology, 1996. 


\section{STRUCTURES DIVISION}

\section{STRUCTURAL}

EVALUATION 



\section{Construction Automation}

\author{
Principal Investigators \\ William C. Stone \\ Structures Division \\ 301-975-6075
}

Lawrence E. Pfeffer

Structures Division

301-975-6067

\section{Sponsor \\ National Institute of Standards and Technology}

\section{Objective}

To develop new techniques and standards for real-time construction site metrology and to develop a national standard for kinematic modeling of construction site machinery and displaying robust graphical representations which depict the real time state of the machine to a remote node on the information superhighway.

\section{Problem}

The emergence of high speed computer communication networks (the "information superhighway") and the rapid advance of real-time, immersive, computer graphics (virtual reality) technologies presage the imminent ability to manage remote construction sites from central offices; to automate certain portions of the tasks performed by common construction machines; and to provide information on the state of such machines to operators (on-site or remote) that would greatly enhance their productivity. Limited demonstrations of this type of technology, largely relating to the control of robotic spacecraft and, more pertinently, to the tele-operation of simple machines for the handling of nuclear waste, have been conducted.

In order to achieve acceptance in the construction industry, a standard means of rapidly interfacing any piece of machinery to a construction-site database must be developed. The development of this standard may not be fully addressed by the construction industry itself, where corporate research budgets are limited. Nor will it be developed by equipment manufacturers who, develop proprietary systems which inhibit data exchange with other systems that might be operational at a construction site. The underpinning to the above technology is the ability to know the real-time position of any piece of equipment and component on the construction site. Present surveying tools suffer from many shortcomings; the most important is they must operate under line-of-sight (LOS) conditions. The development of a non-line-of-sight surveying system, which can in effect "see through walls," represents the ultimate pinnacle of construction site metrology and has guided the focus of BFRL's research in NLS metrology.

\section{Approach}

During FY1997, BFRL will establish an initial version of a Construction Automation Test-bed.

1. Acquire, develop, characterize, and integrate sensors (and wireless

communications equipment) into a real-time computer system for the test-bed. The information from these sensors should be sufficient to determine the kinematic state of a representative construction vehicle and (if possible) the state of objects being handled by the vehicle.

2. Investigate methods for representing kinematic data for both rigid bodies and for simple mechanisms (e.g., construction vehicles.) Investigate how functionality/interface aspects will influence future construction-site database development. Develop an initial specification, and implement in the test-bed. Evaluate the specification, and plan for future extensions.

3. Extend the existing virtual site simulator toward the functionality of a construction automation test bed. Integrate wireless communications system from vehicle to graphical simulator. Incorporate object and vehicle models into the site model, animated by real-time sensor data. Improve the 3-D graphic fidelity; make provisions for extension from passive monitoring to 
tele-operation/control.

BFRL will develop a range-error compensation model based on non-dispersive ray tracing techniques, which heretofore have largely been used for computer graphics rendering. In the proposed research, CAD models of simulated construction sites will be developed and material characteristics, based on the extensive empirical EM material propagation data acquired in FY96, will be attached to various entities in the CAD model - e.g. this panel is concrete; that one is glass etc. This model will then be used to estimate range error in calculated position determined using the NLS system, and will thus allow conclusions to be drawn concerning the accuracy achievable through NLS and its limitations and possibly will identify avenues for further resolution enhancement. The more complex phenomenon of EM wave propagation in dispersive media will be addressed in FY98.

\section{Recent Results}

Stone, W. C., NIST Construction Automation Program Report No. 3: Electromagnetic Signal Attenuation in Construction Materials, NISTIR 6055, National Institute of Standards and Technology, September 1997.

Stone, W. C., NIST Construction Automation Program Report No. 2: Proceedings of the NIST Construction Automation Workshop, March 3031, 1995, NISTIR 5856, National Institute of Standards and Technology, June 1996.

\section{Stone, W. C., NIST Construction Automation} Program Report No. I: Non-Line-of-Sight (NLS) Construction Metrology, NISTIR 5825, National Institute of Standards and Technology, April 1996.

\section{High-Performance Concrete: Design and Construction Practices}

Principal Investigators

Nicholas J. Carino

Structures Division

301-975-6063

Dat Duthinh

Structures Division

301-975-4357

\section{Sponsor}

National Institute of Standards and

Technology

\section{Objective}

To enhance the application of high-performance concrete in the construction of new facilities and the rehabilitation of existing ones.

\section{Problem}

The benefits of high-performance concrete are given in CERF Report \#94-501 1 "High-Performance Construction Materials and Systems: An Essential Program for America and Its Infrastructure." The report, developed by a cooperative effort of key individuals from industry, academe, and the Federal Government, identifies research related to high-performance concrete to enhance the competitiveness of the U.S. construction industry and reduce the life-cycle costs of constructed facilities. The report notes that there are impediments preventing exploitation of the unique properties and advantages of high-performance concrete. This multi-year project aims to remove some of the critical barriers through research in structural behavior, testing standards, and construction practices.

High-strength concrete offers the potential for cost savings in construction due to reduced member dimensions, the capability to accommodate rapid construction schedules, and enhanced service life. However, from a structural perspective, high-strength concrete is inherently more 
brittle than normal strength concrete (NSC). Therefore, failure mechanisms in structural members need to be understood before appropriate design criteria can be developed. Lacking the necessary knowledge, design codes have taken a conservative approach and limit the concrete strength that can be used to compute member resistance to tensile failure modes. For example, current ACI provisions for shear strength are limited to concrete with strength less than $70 \mathrm{MPa}$. For higher strength concrete, code provisions require an increase in minimum shear reinforcement, but otherwise provide no guidance in dealing with higher strength concrete. Limitations such as these place barriers on the exploitation of the potential properties of high-strength concrete. This project aims to provide the technical basis for design criteria applicable to structural members made with high-strength concrete.

Curing concrete is a critical step in the construction process. Sufficient curing is needed to ensure that the concrete properties will develop and that the finished product serves its intended function. Unnecessary prolonged curing adds to construction costs. Curing standards are based on information from normal concrete mixtures. These concretes contained portland cement as the only binder and did not have set controlling admixtures. High-performance concrete typically contains a blend of cementitious materials and often includes chemical admixtures that affect early-age hydration. Thus current prescriptive curing requirements, which are over 50 years old, may not be applicable to high-performance concrete mixtures. In addition, current standards make no distinction between curing to obtain adequate strength and curing to obtain adequate durability. Because durability is influenced highly by the near-surface layer, whereas strength is influenced by the concrete mass, different curing methods may be needed depending on the objective. A new look at the subject of curing is critical to ensure that the potential benefits of high-performance concrete can be realized economically. Current research practice is to study the effects of curing on small specimens, such as $100 \mathrm{~mm}$ x $200 \mathrm{~mm}$ cylinders. However, the properties measured on such specimens may not be indicative of those in a structure because of differences in moisture movement.

\section{Approach}

During FY1997, BFRL will focus on the shear friction behavior of high-strength concrete across cracks. This shear friction contributes significantly to the shear-carrying mechanism of reinforced concrete beams. Shear crack surfaces are smoother in high-strength concrete than in normal-strength concrete because cracks propagate though the aggregates in HSC as opposed to going around them as in NSC. Thus a significant reduction in the shear friction of HSC is expected compared with NSC. "Push-off" type specimens will be used to investigate the influences of factors such as aggregate size and shape, aggregate strength, aggregate volume and compressive strength. The results of these tests will add to the database on shear friction behavior of cracked concrete which is limited for concrete strength above $60 \mathrm{MPa}$. Results will be made available to ACI Committee 445 on shear and torsion and to ACI Committee 318 on the building code.

A cooperative study will be performed to investigate the applicability of unbonded polymeric caps to testing high-strength specimens. The use of these caps is increasing because of the labor reduction compared with sulfur capping or grinding. However, there are few data from well-controlled experiments to show that the unbonded caps do not reduce the measured strength of the specimens. Results will be synthesized and developed into recommendations for ASTM Committee C9.

BFRL will provide the basis for rational curing criteria that will ensure the required strength and durability. An important question that will be addressed by this research is the efficacy of moist curing when mixtures with low water to cementitious materials ratios are used. When these mixtures reach a fraction of their ultimate 
level of hydration, the capillary pores in the paste become discontinuous and water movement into and out of the concrete becomes controlled by diffusion through the cement gel. Results will be synthesized into a suitable form for presentation to ACI Committees 308, 318 and 363 for incorporation into reports and standards.

\section{Recent Results}

Duthinh, D., and Carino, N. J., Shear Design of High-Strength Concrete Beams: A Review of the State-of-the-Art, NISTIR 5870, National Institute of Standards and Technology, August 1996.

Carino, N. J., Guthrie, W. F., Lagergren, E. S., and Mullings, G. M., "Effects of Testing Variables on the Strength of High-Strength (90 MPa) Concrete Cylinders" Proceedings of the ACI International Conference on High-Performance Concrete, Singapore, November 15-18, 1994, ACI SP-149, pp. 589-632.

Carino, N. J., Guthrie, W. F., and Lagergren, E. S., Effects of Testing Variables on the Measured Compressive Strength of High-Strength (90 MPa) Concrete, NISTIR 5405, National Institute of Standards and Technology, October 1994.

\section{Fire Resistance of High-Strength Concrete}

\author{
Principal Investigator \\ Long T. Phan \\ Structures Division \\ 301-975-6077
}

\section{Sponsor}

National Institute of Standards and

Technology

\section{Objective}

To understand performance characteristics of high-strength concrete (HSC) when exposed to high temperatures, develop analytical tools for assessing fire performance of HSC, and implement research results into code provisions for fire design of HSC.

\section{Problem}

For its economic (carry a compression load at less cost than lower-strength concrete) and architectural (allow smaller columns to be used) advantages and its availability, HSC is being used more widely in structural applications such as columns of high-rise buildings, prestressed concrete members, and offshore structures. However, HSC is a state-of-the-art material and little is known about its fundamental behavior (damage mechanism) when subjected to rapid heating as in the case of fire. To address this issue, in FY1996 BFRL assessed the body of knowledge about the fire performance of HSC.

The review indicates that a limited number of experimental studies concerning fire performance of concrete (both normal and high-strength) have been conducted to date. Of these studies, only the more recent ones considered HSC. Furthermore, most of these recent studies were done in Europe and involved siliceous aggregates that have different thermal expansion properties than those used in the United States Because these studies are limited in number (relative to the number of variables that influence the fire endurance of HSC), they can not be used to develop a behavioral model of the effect of 
high temperature on HSC with statistical confidence. However, they confirm important behavioral differences between HSC and normal strength concrete (NSC). These include:

- The tendency of HSC to spall explosively when subjected to high temperature (above $\left.300^{\circ} \mathrm{C}\right)$.

- The larger decrease in compressive strength and modulus of elasticity of HSC in the temperature range of $100^{\circ} \mathrm{C}$ to $300^{\circ} \mathrm{C}$ compared with NSC.

\section{Approach}

During FY1997, BFRL will perform three phases:

1. Experiments will consist of materials testing (elevated temperature tests of specimens) and element testing (tests of beams, columns, slabs, walls). This phase is designed to gain an understanding of the fundamental behavior of HSC at high temperature and, more importantly, to develop data necessary for the development and validation of predictive models which can account for the moisture transport and the sudden spalling of HSC when subjected to fire.

2. The experimental data obtained from this and other studies will be used to develop a material model to predict damage of HSC due to high temperature. The basis for the model may be adopted from the pore pressure models by Bazant or Ahmed, but including the measured properties (permeability, moisture content, rate of moisture loss, etc.) characteristic of HSC. Data obtained from element tests in Phase 1 will be used for model validation. The material model will then be implemented in a computer program (possibly University of Liege's SAFIR, which has been acquired as part of the work in FY1996) and used in parametric studies to aid in assessing the fire performance rating for HSC structural elements.

3. The experimental and analytical data will be synthesized and tabulated into a useable form, such as a practical constitutive relationship for HSC at various temperatures, suitable for design purposes, and presented to code writing organizations for implementation.

\section{Recent Results}

Phan, L. T., "Fire Performance of High-Strength

Concrete, A Report of the State-of-the-Art,"

NISTIR 5934, National Institute of

Standards and Technology, December 1996. 


\section{Fiber Reinforced Polymer Composites in Construction}

\author{
Principal Investigators \\ John L. Gross \\ Structures Division \\ 301-975-6068 \\ Dat Duthinh \\ Structures Division \\ 301-975-4357

\section{Sponsor} \\ National Institute of Standards and \\ Technology
}

\section{Objective}

To develop guidelines for the use of Fiber Reinforced Polymer (FRP) composites in repair and rehabilitation of infrastructure facilities; to develop the technical basis for the application of FRP to new structural forms for replacing infrastructure facilities.

\section{Problem}

Much of the U.S. infrastructure is in need of repair or replacement as a result of damage caused by heavy use and exposure to the environment. Additionally, some of the Nation's infrastructure facilities are in need of rehabilitation to either increase their capacity or to improve their seismic performance. Fiber Reinforced Polymer (FRP) composites have been demonstrated to provide an economical solution to these repair and rehabilitation problems. In addition, FRP composites show promise for new construction as alternatives to traditional materials.

The ease of handling and application, the minimal disruption to the structure's function, and the versatility of the materials have all contributed to the widespread use of FRP in repair and rehabilitation of damaged and decaying structures. The extent to which FRP will be used depends on 1) the resolution of outstanding technical issues such as fire performance and durability, 2) the extent to which automation in the manufacturing process can reduce cost, and
3) the availability of validated codes, standards and guidelines which can be used as design references and tools by the civil engineering profession.

\section{Approach}

During FY1997, BFRL will perform worldwide search of FRP related products, research results, available test methods, and successful applications. They will be synthesized to assess the current state of practice in applying FRP to repair and rehabilitation of infrastructure facilities. A workshop will be convened to determine the specific needs for standards and to identify areas where the technical basis for such standards is insufficient. Guided by the workshop recommendations, analytical and/or experimental research will be conducted to provide the technical basis for the development of guidelines and draft standards for the repair and rehabilitation of structures using FRP. The guidelines and draft standards developed by NIST will be proposed to the industry for consideration in the consensus standards process.

At the same time, applications of FRP in new construction will be investigated. Possible areas include innovative systems for short-span vehicular bridges. An expert panel will be assembled to establish potential applications where the unique characteristics of FRP composites can be used to advantage to reduce the life-cycle costs of new construction. At the same time, the technical barriers to widespread use of FRP composites will be identified. Based on this information, a research plan will be formulated to address these barriers.

\section{Recent Results}

New project 


\section{Next Generation Design Standard For Wind Loads}

\author{
Principal Investigator \\ Emil Simiu \\ Structures Division \\ 30I-975-6076
}

\section{Sponsor}

National Institute of Standards and

Technology

\section{Objective}

To develop key elements of a

knowledge-based improved wind load design standard that will make extensive use of site and building-specific databases and state-of-the-art computational methods for establishing site-specific design wind speeds and the corresponding steady and fluctuating structural loads.

\section{Problem}

There are a number of significant deficiencies in the wind load design provisions of current U.S. codes and standards. They include 1 ) crude simplifications of loading models due to the need in traditional standards to summarize a wide range of information in one table or even one number; 2 ) extreme winds and corresponding load factors derived from outmoded estimation methods; 3 ) exposure coefficients that cannot deal with complex wind exposures (the normal case); 4) gross simplifications of extreme pressures and loads that ignore the directional effects of wind; and 5) no distinction between design for safety and design for serviceability.

\section{Approach}

During FY1997, BFRL will 1. develop "peaks over threshold" extreme value estimation approach to hurricane load estimation, taking wind directionality into account; 2 . develop aerodynamics databases for a pilot module of the new type of standard; 3 . acquire information on typical frame design, development of corresponding influence line plots for the pilot module, testing of the conceptual approach to a new standard, and assessing its benefits; 4 . coordinate the BFRL computational fluid dynamics researchers group to explore potential of CFD methods to supplant wind tunnel testing for loads on wind-force resisting systems; 5 . monitor the incorporation of updates to ASCE 7-95 into the BFRL develop interactive software; and 6. work with insurance workers and standards groups on improvement of current design methodologies for hurricanes and tornadoes.

\section{Recent Results}

Simiu, E., Hackert, N. A. And Whalen, T. M., Estimates of Hurricane Wind Speeds by the Peaks Over Threshold Method, NIST TN 1416, National Institute of Standards and Technology, February 1996.

Whalen, T. M., Probabilistic Estimates of Design Load Factors for Wind Sensitive Structures Using the Peaks Over Threshold Approach, NIST TN 1418, National Institute of Standards and Technology, April 1996. 

BUILDING MATERIALS DIVISION

COATINGS AND COMPOSITES 

Computer-Integrated Knowledge Systems (CIKS) for High-

Performance Construction

Materials and Systems

\author{
Principal Investigator \\ Lawrence Kaetzel \\ Building Materials Division \\ 301-975-5912
}

\section{Sponsor \\ National Institute of Standards and Technology}

\section{Objective}

To develop and demonstrate ComputerIntegrated Knowledge Systems (CIKS) for High-Performance Construction Materials and Systems (HPCMS).

\section{Problem}

The President's National Science and Technology Council has developed, with strong endorsement by the industries of construction, a set of National Construction Goals that focus on better constructed facilities and health and safety of the construction workforce. They include a call for significant reduction in delivery time; reduction in operation, maintenance, and energy costs; increase in productivity and comfort; reduction in occupant related illnesses and injuries; reduction in waste and pollution; increase in durability and flexibility; and reduction in construction work illnesses and injuries. At the same time, the Civil Engineering Research Foundation (CERF), working with the construction materials industry, has drawn attention to the need for creating a computer-integrated knowledge system for HPCMS that is planned, built, and maintained at a national level and will serve as the corner stone of its technology development strategy. The highly fragmented nature of the industries of construction makes it difficult for all stakeholders -- owners, architects, designers, specifiers, construction planners, site managers, facilities managers, materials suppliers, equipment suppliers, the labor force, trade/professional organizations, standards development organizations, public/private technology transfer centers, universities and research institutes, and government/private laboratories -- to access and use the data, information, and knowledge necessary for widespread deployment of HPCMS. Such deployment will contribute to the realization of the National Construction goals and the specific economic and commercial benefits that derive from them.

\section{Approach}

During FY1997, BFRL will develop a meta model on knowledge sources, processes, and requirements for CIKS. The CIKS testbed will be used to test the meta model using NIST HPCMS knowledge, information, and data, in addition to that provided by other construction industry organizations. Coordination will be necessary among all HPCMS projects that deal with computerized knowledge bases on construction materials. Input from CERF CONMAT Council and the CIKS Construction Materials Working Group groups will be used in the design and requirements for CIKS. Efforts by private industry, academia, and government organizations will be evaluated for possible use and interfaces for ClKS. Workshops will be held to determine user needs. User needs will be compared against new and innovative enabling information technologies and standards activities. Opportunities for establishing consortia and CRADA's between BFRL and construction industry organizations will be explored. Collaboration with leading universities such as Stanford and Carnegie-Mellon Universities who are engaged in knowledge management and information modeling will be sought. An Internet presence via the World Wide Web will be available to disseminate information and application systems related to the HPCMS program. Examples of information that will be available via CIKS includes; material property databases, manuals, published reports, decision-support systems, computer-based models (service-life prediction), and economic analysis software. 


\section{Recent Results}

Kaetzel, L., Kurihara, T. Y., Computer

Integrated Knowledge Systems (CIKS) for

Construction Materials, Components and Systems:

Proposed Framework, NISTIR 6071, National

Institute of Standards and Technology,

October 1997. (www.ciks.nist.gov)

\section{Computer-Integrated Knowledge System, (CIKS) for High \\ Performance Coatings}

\author{
Principal Investigators \\ Lawrence Kaetzel \\ Building Materials Division \\ 301-975-5912 \\ Thomas Kurihara \\ Building Materials Division \\ 301-975-3876 \\ Mary McKnight \\ Building Materials Division \\ 301-975-6714
}

\section{Sponsor \\ National lnstitute of Standards and Technology}

\section{Objective}

To develop an architecture, information models and operational computerized systems for the representation and dissemination of knowledge concerning high performance organic coating used for protecting steel structures.

\section{Problem}

Coatings provide a versatile and cost-effective means for protecting steel structures against adverse environmental conditions, but, because of the large number of factors which need to be considered, and the inaccessibility of data, decisions concerning coating systems having a long service life in their intended service environment are often difficult to make. Currently, users of coating systems must rely on information that is represented in many different forms and in many diverse ways. These include manuals, guides, photographs and drawings, videos, databases, and other references. In addition, the advice of the human expert is often needed in reaching a decision. An integrated knowledge system that includes different forms of knowledge and is presented in a coherent format will help to overcome these obstacles and improve the specification, selection, and use of coatings systems for protecting steel, 
thus improving the performance and extending the service life of structures.

\section{Approach}

During FY1997, BFRL will develop a CIKS based decision-making process and knowledge bases on coating materials will be identified or generated, as necessary. The research involves identifying the data elements used in the decision-making process, defining and establishing an information model or activity model that describes the knowledge, information, and data flows for testing within the CIKS testbed, and developing computerized prototypes and operational systems for distribution. BFRL will work with the CIKS Coatings Working Group setup under the auspices of the Civil Engineering Research Foundation CONMAT Council and the Steel Structures Painting Council Committee C.4.10 on "Knowledge Based Systems for Coatings." During the first phase of the interaction, an activity model will be developed that describes the information requirement and processes used by highway engineers in determining the appropriate coating system for recoating highway steel bridge structures. This project contributes to the development of Knowledge Systems for High Performance Construction Materials and Systems and will be disseminated by the HPCMS World Wide Web server and other networks. The architecture and methods developed in this project will be applicable to other construction materials and will have broad application within the construction industry.

New methods for improved dissemination and access to geographically distributed knowledge bases will be investigated, including the intelligent agents that allow more efficient commuter-computer and human-computer interactions. The CIKS testbed (computerized system and software development tools) being developed in BFRL will provide a framework for the development and testing of the methods. The testbed will be accessible through high-speed data links to other organizations including the University of Kansas, NIST Radiometric Physics
Division, Steel Structures Painting Council, and the Infrastructure Technology Institute at Northwestern University. Standards activities such as STEP, Electronic Data Exchange, Knowledge Query Language will be evaluated and implemented if they apply.

\section{Recent Results}

The COEX (Coatings Expert Advisory System) was reviewed by coatings industry personnel. Capabilities to distribute decision support systems via the Internet, including COEX were installed at the CIKS testbed.

The coating product data format ballot was approved in SSPC and a National Association of Corrosion Engineers (NACE) task group was established at NACE to review the format. Implementation of databases using the format was performed. 
Coatings Service Life Prediction

Consortium - Task I:

Quantification of

Photodegradation Effects of

UV-radiation in the Field and

Laboratory

Principal Investigator

Jonathan Martin

Building Materials Division

301-975-6717

Sponsors

National Institute of Standards and

Technology and

FHWA and industry partners

\section{Objective}

To develop methodologies for mathematically predicting from the photodegradation response of the materials exposed to UV-radiation, the service lives of organic coatings and other polymer materials.

\section{Problem}

UV-radiation, along with the wetness and temperature of a material, are usually the prime weathering factors determining the service lives of organic coatings and other polymeric systems exposed outdoors in most non-industrial environments. The inability to control or adequately characterize temporal changes in these weathering factors is one of the major challenges which must be overcome before establishing a connection between the degradation response of polymeric materials exposed in the laboratory and the field. This project is directed at establishing the linkage between the degradation effects of UV-radiation in the field and the laboratory needed in predicting service life from the results of laboratory tests.

\section{Approach}

During FY1997, BFRL will refine a mathematical model that mathematically relates photodegradation results obtained from field and laboratory exposure experiments. This model requires knowledge of a material's spectral UV-absorbency and its spectral quantum yield along with knowledge of the spectral UV-irradiance to which it is exposed.

\section{Recent Results}

Floyd, F.L. and Martin, J.W.

"Forschungsplanung mit Hilfe der

Reliabilitätstheori," Farbe und Lack 102: 28.

Saunders, S.C. and Martin, J.W. "Statistical Models for Cumulative Damage in Coatings Due to Photolytic Degradation," J. of Polymer Science, 1996.

Frohnsdorff, G. J. and Martin, J.W. “Toward Prediction of Building Service Life-The Standards Imperative," Proceedings of the 7 th International Conference on the Durability of Building Materials and Components, Stockholm, Sweden, May, 1996.

Pommersheim, J. Nguyen, T., and Kotterer, D., "The Effects of Diffusion Osmosis and Applied Potential On the Growth of Cathodic Blisters Beneath Organic Coatings," American Chemical Society Symposium Series, January 1995. 
Coatings Service Life Prediction Consortium- Task II: Interactive Research Program with Industry

\author{
Principal Investigator \\ Jonathan Martin \\ Building Materials Division \\ 301-975-6717
}

\section{Sponsor}

Industrial Consortium

\section{Objective}

To reduce the time required for the implementation of reliability-based methodologies into the industrial community.

\section{Problem}

Implementation of reliability-based service life prediction procedures have led to improvements in the service life of a wide range of products. Coupled with design of experiment and data analysis technologies, these techniques could lead to significant reductions in test times. A major impediment to implementing and accepting these techniques is this method is different from the current one. This "hands-on" experimental program is designed to facilitate the transfer of this methodology to industry, to identify problems in its implementation, and establish a dialogue between industrial and government researchers.

\section{Approach}

During FY1997, BFRL will meet with representatives from each member company of the industrial consortium to discuss their service life prediction problems. A life test program will be designed and data requirements specified. The experiments will be conducted at the representatives facility. BFRL staff will consult with the company representative throughout the experiment in analyzing and interpreting the collected data and in using software.

\section{Recent Results}

New project.
Coating Service Life Prediction Consortium - Task III:UserFriendly Software System for Experimental Design and Data Analysis

\author{
Principal Investigators \\ Jonathan Martin \\ Building Materials Division \\ 301-975-6717
}

\section{James J. Filliben \\ Information Technology Laboratory 301-975-2855 \\ Sponsor \\ National Institute of Standards and Technology}

\section{Objective}

To develop a menu-driven, user-friendly software system for 486/Pentium-class PC's for designing experiments, analyzing resulting data, fitting assumptions, and modeling data.

\section{Problem}

The use of modern experimental design and data analysis techniques has resulted in savings of time, materials, and money in many industries. It is likely to be at least as useful in the coatings industry, in developing a good relationship between field and laboratory testing, which will be useful in substituting specific, short-term laboratory experiments for lengthy field tests. Software is needed to expedite the introduction and use of these techniques.

\section{Approach}

During FY1997, BFRL will build on NIST's DATAPLOT engineering data analysis software system, by incorporating the appropriate approaches and methods. Work includes experimental design and data analysis for lifetime tests and techniques for distributional model fitting based on accelerated testing.

\section{Recent Results}

New project. 


\section{Advanced Models and Measurements of Optical Reflectance of Materials}

\author{
Principal Investigator \\ Mary E. McKnight \\ Building Materials Division \\ 30 I-975-67 I 4
}

\section{Objective}

To develop improved methods for measuring and models for predicting the reflectance properties of materials

\section{Problem}

The optical reflectance properties of an object can be of vital importance. They can greatly influence judgments of the quality of object through its appearance or affect the visibility of a warning sign or a camouflaged object. To provide the physical tools needed in the development and implementation of new products in which reflectance properties are critical, it is essential that the industry have the physical tools necessary to accurately quantify the optical reflectance properties and the modeling capability to predict them. Current metrology is unable to accurately quantify some important reflectance properties. The challenge is to develop evaluate, demonstrate and implement the use of new measurement and modeling methods, filling the knowledge gaps as needed and coordinate efforts among the experimental, modeling, and computer rendering activities.

\section{Approach}

During FY1997, BFRL will 1) prepare a set of materials having a desired range of surface morphology, 2) collaborate with NIST's Physics, Manufacturing Engineering, and Information Technology Laboratories to characterize their optical reflectance properties and their surface morphology, model their reflectance properties and render their appearance, and 3) initiate activities with industry, university and other government researchers to form a group to address research needed to develop and implement the use of advanced technologies (measurement, modeling and computer rendering). The experimental and modeling data obtained in FY1997 will contribute to the long-term goal of improved fundamental understanding of the relationships between material properties and reflectance properties.

\section{Recent Results}

New project 


\section{Spectral Ultra Violet-B Radiation Database}

Principal Investigator

Lawrence Kaetzel

Building Materials Division

301-975-5912

Sponsor

National Institute of Standards and

Technology

\section{Objective}

To develop a computerized database system of solar ultra-violet $\mathrm{B}$ radiation data for dissemination as a 1997 NIST Standard Reference Data Program product.

\section{Problem}

Spectral UV-B radiation (solar) data is important to a wide range of scientific disciplines including materials (e.g., color changes in coatings, textiles, fabrics, and degradation of composites, plastics and coatings). The data in the database will be invaluable input into models for predicting the service life of building material and in assessing the relative severity of different exposure environments throughout the United States Currently, the Smithsonian Institution, several universities, and NIST's Physics Laboratory are collecting UV-B spectral irradiance data at several locations throughout the United States. The NIST site BFRL is the largest UV-radiation network in the United States.

\section{Approach}

During FY1997, BFRL will; 1) characterize the data, 2) evaluate the quality control measures for data accuracy (e.g., calibration, transformations), 3) develop database formats to use data from different sources, and 4) build the database representing outdoor weathering factors, specifically, solar spectral UV-B radiation data. A geographical user interface will be developed. The NIST Optical Physics Division effort on the calibration of solar spectroradiometers and generation of inter-comparison data sets will be used to develop criteria for establishing guidelines for data set quality. Databases on the performance of coating materials will be used to develop the user interface and to test the use of the computerized database system for measuring the environmental effects on materials performance. BFRL's Coatings Service Life Consortium activities will be used to obtain feedback for the user interface and to test prototype systems.

\section{Recent Results}

The solar ultra-violet B data network became fully operational during fiscal year 1997.

Remote sites included in the network are: Phoenix, Arizona, Miami, Florida, Edgewater, Maryland. Data from Ocean City, New Jersey and Rockville, Maryland and the above referenced sites will constitute the database produced as a NIST Standard Reference Data Product. 


\section{Highway Structures Expert System for the Selection of Coating Materials}

\author{
Principal Investigator \\ Lawrence Kaetzel \\ Building Materials Division \\ 301-975-5912
}

\section{Sponsor}

Department of Transportation

Federal Highway Administration

\section{Objective}

To develop a computerized expert system on coatings performance (decision-support system) that assists FHWA's district staff and sate DOT engineers by providing easy access to FHWA research results for the selection of coatings systems for highway structures.

\section{Problem}

Conventional methods (e.g., published research reports) used to disseminate knowledge about coating system performance often fail to reach their intended audience of coating users, and coating system users often lack systematic ways of interpreting and applying research results in practice. Also, obstacles such as incompatible or diverse knowledge formats may hinder access to relevant coating materials knowledge.

\section{Approach}

During FY1997, BFRL will perform four tasks in developing an expert system for coating selection:

1. Identify and acquire the knowledge base for the system, FHWA reports and Technical Summaries will be the primary source of knowledge to be incorporated into the system. Rules will be developed from the reports and from standards and guides to accepted practice. The rules will be included in a framework that will permit users to obtain recommendations. Other knowledge in areas such as corrosion control for highway structural components, and maintenance coating of weathering steel, will be included in the system.

2. Interpret knowledge and develop the reasoning process (question-response dialogue) that will guide the user while interacting with the system, coatings domain experts will define the system scope, systematic approaches to solutions based upon the FHWA reports and user specifications for the computerized system. $3 . \quad$ Computerize the knowledge developing a prototype for review, then refine the system to achieve an operational status, multiple forms of knowledge will be used. These will include: a) rules developed by the domain experts, and video clips to demonstrate proper procedures for inspection, surface preparation and the application of coatings systems, b) digitized photographs of coating failures, and c) bibliographic references to support the conclusions and recommendations made by the system. A group of users will be selected to evaluate and provide feedback to the system during its development. This process will ensure that a useful system is developed. Upon completion of the operational system it will be delivered to FHWA for distribution. 4. Develop a reference document and train users. The method for distribution of the system will depend on the computing platforms available among the user audience. While it is probable that a CD-ROM will be used, other methods such as using the Internet will also be explored.

\section{Recent Results}

A prototype decision support system was developed for use by Federal Highway District Engineers and State Transportation Department Engineers. 
Effects of Environmental and

Mechanical Stresses on

Fiber-reinforced Polymeric

Composites

\author{
Principal Investigator \\ Joannie W. Chin \\ Building Materials Division \\ 301-975-6815
}

\section{Sponsor \\ National Institute of Standards and Technology}

\section{Objective}

To provide the technical basis for predicting changes in the performance of polymer matrix composites following exposure to UV, moisture and mechanical loading.

\section{Problem}

The polymer matrix in a fiber-reinforced composite binds and orients reinforcing fibers to carry the intended loads, protects them from handling and environment, and provides all of the interlaminar shear strength of the composite. However, the matrix is often considered to be the weak link in a fiber-reinforced composite system, since it may undergo physical damage (in the form of crazing and cracking) and chemical degradation during environmental exposure and stress application.

The durability of polymer composites in outdoor environments is the primary concern limiting the acceptance of these materials in infrastructural applications. In a June 1996 meeting of Federal Agencies, the performance of composite materials was cited as a major concern. Specifically of interest was the long-term durability of these materials when subjected to temperature cycling, humidity, freeze/thaw, ultraviolet (UV) radiation, alkaline and saline immersion, and both static and dynamic loading.

At present, few studies have been conducted on the photodegradation of composite materials combined with moisture, temperature and mechanical loading. It is necessary to understand the mechanisms which govern polymer degradation, not only to be able to develop methods for predicting service life and other aspects of performance, but also to devise reliable accelerated degradation tests.

\section{Approach}

During FY1997, BFRL will subject polymer films, and model composites, to static and cyclic loads, to moisture, alkaline, environments, sea water, UV radiation and combinations of these parameters. A novel weathering device is being designed to perform the above exposure conditions. Chemical changes which take place in commonly used composite matrix resins, e.g., vinyl ester and isophthalic polyester, will be characterized with Fourier transform infrared spectroscopy (FTIR), x-ray photoelectron spectroscopy (XPS) and differential scanning calorimetry (DSC). Changes in viscoelastic response, stiffness and strength will be evaluated with dynamic mechanical thermal analysis (DMTA) and tensile testing. Each of these techniques is critical to material characterization at the molecular to the macroscopic scales as a function of environmental exposure and mechanical loading. Exposures will be carried out at room temperature as well as elevated temperature to assess acceleration of environmental damage. Scanning electron microscopy (SEM), atomic force microscopy and image analysis will be used to quantify microcracking and other changes in polymer surface morphology.

Because degradation processes may be different in a fiber-reinforced polymer composite versus the neat polymer, model composite systems will be employed in assessing physical and chemical properties as a function of environmental exposure and mechanical stress. These model systems will involve well-defined fiber orientations and architectures, a minimum number of plies and low fiber volume fractions. Fibers of interest include carbon, glass, and/or aramid. This stage of the study will be undertaken when the matrix resin study is completed, so that polymer-related factors which lead to 
decreased composite durability can first be isolated. This study is being coordinated with a complementary study on the durability of the interface between composite matrix resins and reinforcing fibers, so that this important component of a composite system will also be included in assessment of overall durability.

Collaboration with potential users of polymer matrix composites, in industry as well as other federal agencies will be sought.

Planning for a Federal Working Group in Composite Materials is currently underway. Interactions with the Polymers Division of NIST will continue to be actively pursued. Links to industrial manufacturers and users of composite materials will also be initiated so that relevant areas of research can be identified and the appropriate technical assistance provided.

\section{Recent Results}

Chin, J. W., Nguyen, T., and Aouadi, K., "Effects of Environmental Exposure on FRP Materials Used in Construction," Journal of Composites Technology and Research, vol. 19, no. 4, October 1997.

\section{Interface/Interphase \\ Characterization of Polymeric Building Materials}

\author{
Principal Investigator \\ Tinh Nguyen \\ Building Materials Division \\ 301-975-6718
}

\section{Sponsor \\ National Institute of Standards and Technology}

\section{Objective}

To identify methods for quantitatively characterizing chemical and physical properties of interfaces and interphases in aged and unaged polymeric composite materials and provide the technical basis for performance tests and predictions of service life and other aspects of performance.

\section{Problem}

The use of polymeric composite materials in the construction industry is increasing. Polymeric composite materials, like paints, painted plastics, adhesives, and fiber-reinforced composites, are comprised of a polymer matrix in which other materials are dispersed causing the existence of an interface/interphase region; the materials in this region, have chemical and morphological properties that are different from the bulk polymer and, the interphase often includes impurities, unreacted molecules, or additives. The interphase is a complex structure which is not easily analyzed or modeled. The interface/interphase is believed to control many of the properties of polymeric composite materials. It may also be a weak link in that the interface/interphase region is often the location of failure initiation.

\section{Approach}

During FY1997, BFRL will:

1. Develop methods to characterize the interface/interphase and its changes with external stresses.

2. Develop models for describing interface/interphase regions. 
3. Develop models for predicting how the interface/interface changes under stress.

4. Conduct experiments to provide data for elucidating interfacial/interphasial formation and failure mechanisms, and for validating models.

5. Conduct experiments to determine the role of interface/interphase properties on the performance and service life of polymeric composite systems.

6. Relate interfacial/interphasial failure data obtained under laboratory conditions to data from exposures of polymeric composites under typical service conditions.

Since interface/interphase properties are matrix/substrate specific, three distinct polymer/substrate systems will be selected and investigated to demonstrate the techniques. The techniques developed and the knowledge learned should be applicable to all polymeric composite materials.

Work will focus on identifying and developing techniques to characterize the molecular interactions and microstructure (including defects) in the interface regions, determine the role of interfacial molecular interaction and microstructure on the adhesion of polymeric systems, and assess the effects of process variables on the interfacial microstructure and composite performance.

\section{Recent Results}

New project.

\section{Standards for Abatement of Hazards from Lead in Buildings}

\author{
Principal Investigator \\ Mary McKnight \\ Building Materials Division \\ 301-975-6714
}

\section{Sponsor \\ Department of Housing and Urban \\ Development \\ Office of Lead-Based Paint Abatement and \\ Poisoning Prevention}

\section{Objective}

To expedite development of standards needed for abatement of hazards from lead in buildings and related structures.

\section{Problem}

An estimated 57 million homes in the United States contain some lead-based paint. Although there are increasing numbers of standards for characterizing the lead concentrations in paint, dust, soil and air particulates, and for carrying out lead abatements, additional standard procedures are still needed. For example, there is a need for an overall standard practice or guide for abating hazards from lead in buildings and related structures that includes assessment and analysis of the problem, design of an abatement strategy, abatement procedures, and post-abatement management procedures. ASTM Subcommittee, E06.23, chaired by BFRL, was organized to meet the need for development of all the needed standards; it has already established 19 standards, but the most complex ones have yet to be completed.

\section{Approach}

During FY1997, BFRL will work with ASTM E06.23 in developing basic standards to support an overall practice for abatement of hazards from lead in buildings and related structures. To maintain the subcommittee's vitality, additional knowledgeable members will be recruited, results of applicable research will be provided to task groups, and liaisons with related ASTM committees, including D22, D1, E50, E1 and D18, will be 
maintained.

\section{Recent Results}

Prepared the texts which ASTM is to publish is a volume containing 19 full consensus standards and one provisional standard.

\section{Method for Evaluation of \\ Performance of Lead-in-Paint \\ Measuring Devices Under \\ Simulated Field Conditions}

\author{
Principal Investigator \\ Mary McKnight \\ Building Materials Division \\ 30 I-975-67 I 4
}

\author{
Sponsor \\ U.S. Department of Housing and Urban \\ Development \\ Office of Lead Based Paint Abatement and \\ Poisoning Prevention
}

\section{Objectives}

To identify and quantify factors affecting the field performance of portable x-ray

fluorescence (XRF) devices for measuring of lead in paint using a range of simulated field conditions.

\section{Problem}

Recent legislation (Housing and Community Development Act of 1992, PL102-550) will phase in requirements for lead-based paint testing for all housing built before 1978 . These requirements are expected to result in several new $\mathrm{x}$-ray fluorescence (XRF) devices. Because of both health and financial liabilities associated with these measurements, it is essential to have reliable estimates of the field performance parameters of the measurements (e.g., detection limit, precision, bias). For some XRF devices, research results have shown that estimates of these performance parameters obtained using existing laboratory evaluation procedures do not agree with estimates obtained using field-acquired data. Currently, field studies are being used to characterize additional devices. However, field studies are limited in several ways - sites having parameters in the necessary ranges are difficult to find; systematic variation of the parameters is usually not possible; implementation of new technologies may be impeded; and fundamental understanding of the measurement procedures is complete. 


\section{Approach}

During FY1997, BFRL will characterize and model the scientific principles controlling the performance of portable XRF devices, design and carry out laboratory experiments to simulate significant field conditions, as determined by modeling and other information, carry out a limited field study to determine whether the laboratory results are consistent with field results, and prepare a standard protocol for laboratory evaluation of portable XRF devices and present it to ASTM E06.23 for standardization. Upon completion of the experimental study, a draft standard test method for evaluating the performance of portable XRF equipment will be written and presented to ASTM E06.23.

\section{Recent Results}

No published results.

\section{Factors Affecting the Leaching of Lead from Lead-based Paint Films}

\section{Principal Investigators}

Eric Byrd

Building Materials Division

301-975-6701

Mary McKnight

Building Materials Division

301-975-67 14

\section{Sponsor}

U.S. Department of Housing and Urban

Development

Office of Lead-Based Paint Abatement and Poisoning Prevention

\section{Objective}

To determine the relative importance of $\mathrm{pH}$, acid type, acid concentration, surfactant concentration, lead concentration and immersion time on the leaching of lead from lead-based paint films, and to recommend to ASTM E06.23 encapsulant performance tests and criteria for incorporation in encapsulant specifications.

\section{Problem}

According to a recent U.S. Department of Housing and Urban Development (HUD) report to Congress, an estimated 57 million homes in the United States contain lead-based paint. The hazards of lead-based paint may be abated by painting the lead-based paint with an encapsulant. However, questions remain as to under what conditions lead can be leached from a lead-based paint film and transported through an encapsulant film. Previous HUD-sponsored BFRL research results indicated that essentially no lead is leached from lead-based paint films immersed in dilute nitric acid ( $\mathrm{pH} 2$ or $\mathrm{pH} 4$ ) or from paint films immersed in $\mathrm{pH} 10$ or 12 sodium or ammonium hydroxide solutions. On the other hand, practically all the lead was leached from paint films immersed in 20-percent acetic acid, while a much smaller amount was leached from vinegar ( 5 percent acetic acid). These results demonstrate that 
leaching of lead depends greatly upon the type and concentration of liquid acid to which the lead-based paint is exposed. Therefore, information is needed on the lead-leaching effects of other acids and household cleaners.

\section{Approach}

During FY1997, BFRL will conduct a two-level, fractional, factorial experiment to determine the relative importance of $\mathrm{pH}$, acid type, acid concentration, surfactant concentration, lead concentration and immersion time on the leaching of lead from lead-based paint films. The transport of lead through three encapsulants will be determined for at least two exposure conditions that caused lead to be leached from the lead-based paint films. Exposure conditions will be selected in consultation with members of E06.23 and HUD. The results will be reported and recommended performance tests and criteria drafted and presented to ASTM E06.23 for standardization.

\section{Recent Results}

No published results.

\section{International Standards for Design Life of Buildings}

\author{
Principal Investigator \\ Geoffrey Frohnsdorff \\ Building Materials Division \\ 301-975-6706
}

\author{
Sponsor \\ National Institute of Standards and \\ Technology
}

\section{Objective}

To lead the development of an ISO standard for assuring that the designed life of a building under anticipated environmental actions will be achieved and to chair the ISO Working Group on Design Life of Buildings.

\section{Problem}

As building technology advances, there is an increasingly strong desire to minimize the risks associated with innovation, whether due to premature deterioration resulting from the materials and components used, or the way they are incorporated into the building design. In a partial response to the need, standard methodologies for assessing the service lives of individual materials and components have been developed in ASTM Committee E06, Performance of Buildings.

Now, methodologies for assessing the service lives of individual materials and components are to e incorporated into a methodology for assessing whether a building of a given design will perform satisfactorily over its intended life, the service life. The standard is needed to provide guidance to: designers and planners on methods for assessing the expected life of a building and assuring that its design life will be met; construction engineers on how to construct a building to assure the intended life; materials and product manufacturers on information they should provide to assist assessment of the life of a building; maintenance engineers and building owners on information they will need to carry out the maintenance required to achieve the design life; and standards and code bodies and legislators on the need for improved standards and codes. To prepare 
the standard, ISO Technical Committee TC59, Building Construction, established a Working Group (WG9) on the Design Life of Buildings, with ASTM Committee E06, Performance of Buildings as the Convener (chairman); the WG was established in 1993 in response to a request made by ASTM E06, through ANSI, to ISO TC59. To advise the Convener on the U.S. position, ASTM set up a U.S. TAG (Technical Advisory Group) which the Convener chairs. An executive committee has been established in the WG to plan the WG's work between annual meetings.

\section{Approach}

During FY1997, BFRL will coordinate, as chair of the ISO Working Group, the development of Part I, General Principles of Building - Service Life Planning. The scope of the guide will be limited to the building envelope, partitions and surface finishes. British, Canadian, and Japanese documents on service life planning of buildings are being used as working documents.

\section{Recent Results}

A new draft of Part 1 , prepared in the UK under contract from the British Standards Institution, was completed in September 1996. 



\section{BUILDING MATERIALS DIVISION}

CONCRETE 



\section{Three-Dimensional \\ Microstructural/Kinetic Model of Cement Hydration}

\author{
Principal Investigator \\ Dale P. Bentz \\ Building Materials Division \\ 301-975-5865
}

\section{Sponsor \\ National Institute of Standards and Technology}

\section{Objective}

To develop and validate a comprehensive model for cement hydration and microstructure development in three dimensions.

\section{Problem}

Prediction of the properties and performance of cement-based materials is hindered by a lack of a basic understanding of microstructural development and hydration kinetics. Progress in this area has been slow due to the complexity of the starting materials, water and a multi-size, multi-phase cement powder, and the number and the complexity of the reactions which occur during hydration. A comprehensive model incorporating both microstructural and kinetic considerations should allow a priori prediction of the behavior of these materials under a variety of processing conditions, which is of great interest to the concrete construction community.

In the first 2 years of this 3 year project, BFRL concentrated on the development of an integrated computer model and experimental techniques to be used in model validation. Computational techniques were developed for the critical step of generating representative 3-D starting microstructures of cement particles in water to be used in the hydration model. Research considers the effects of temperature and hydration under sealed conditions (self-desiccation). In all cases, good agreement between the results of the computer model and experimental measurements (degree of hydration, heat release, chemical shrinkage, and compressive strength of mortar cubes) has been observed.

\section{Approach}

During FY1997, BFRL will extend the model to incorporate silica fume, and eventually other mineral admixtures, by calibrating against experimental thermogravimetric measurements to quantify both the normal hydration and pozzolanic reactions. In addition, a report detailing the final version of the model and its usage will be developed, so other research groups may employ the model in their hydration studies. Currently, the model is being used by researchers at the U.S. Army's Waterways Experiment Station in Vicksburg, MS, in a collaborative effort. Ultimately, the model and its real-time simulation capabilities will be part of the Integrated Knowledge-Based System for High Performance Construction Materials and Systems (HPCMS) and will be distributed electronically to industry and academia through the HPCMS world-wide-web servers and other means. The incorporation of mineral admixtures into the model will assist the cement and concrete industries in their production and use of blended cements and the development of a new generic performance-based cement standard. The model also should find use in studies of the effects of processing parameters such as degree of grinding and w/c ratio, and curing on the resultant microstructure and properties of cement-based materials.

\section{Recent Results}

Bentz, D. P. “Three-Dimensional Computer Simulation of Portland Cement Hydration and Microstructure Development," Journal of the American Ceramic Society, volume 80, No. 1, pp. 3-21, 1997. 


\section{Microstructure-Property \\ Relationships in Random Porous Materials}

\author{
Principal Investigator \\ Edward J. Garboczi \\ Building Materials Division \\ 301-975-6708
}

Sponsor

National Institute of Standards and Technology

\section{Objective}

To develop new, more accurate relationships between microstructure and properties of random porous materials, using computer models and analytical theory as validated by experiments and make these relationships available in mathematical form to the cement-based materials community.

\section{Problem}

The degradation of the concrete infrastructure, worth on the order of $\$ 6$ trillion, is a national problem. The basic physical and chemical mechanisms of degradation processes in concrete need to be understood in order for scientifically sound, nonempirical service life predictions to be made. Most of the degradation processes that affect cement-based materials involve microstructure-related properties like diffusivity, permeability, elastic moduli, and viscoelastic properties like stress relaxation and creep. Fundamental computer-based models are necessary in order to quantitatively relate such properties to the complex microstructure of cement-based materials. Such quantitative relationships will serve to put existing and future standard test measurements of transport and other properties on a firm scientific foundation, needed to enable reliable production of high-performance concrete and other cementbased materials.

\section{Approach}

During FY1997, BFRL will use a digital-image-based approach, along with Monte Carlo techniques, to simulate the formation of cement-based and ceramic materials at the fundamental level. Using efficient numerical techniques, BFRL will develop the software necessary to simulate and compute physical processes and parameters as needed. These new microstructure and property simulation algorithms will feed into the other modeling projects that are focused on the solution of specific problems. Experimental measurements will be made as necessary, either at BFRL or in collaboration with other institutions (Northwestern University and Imperial College) to validate the model results. Also, BFRL will be 1) developing new capabilities in understanding viscoelastic properties like stress relaxation and creep, which couple to many degradation processes like alkali-silica reaction and sulfate attack, and 2) completing a monograph summarizing the last 8 year's modeling work and incorporating it into the ComputerIntegrated Knowledge Based System.

\section{Recent Results}

Ferraris, C., Clifton, J., Stutzman, P., and Garboczi, E. J., "Mechanistic Studies on Sulfate Attack of Cement-Based Materials," Mechanisms of Chemical Degradation of CementBased Systems, London, England, 1997.

Bentz, D. P., Garboczi, E. J., Lagergren, E. S., "Multi-scale Microstructural Modeling of Concrete Diffusivity: Identification of Significant Variables," ASTM Cement and Aggregate, 1997.

Garboczi, E. J., and Bentz, D. P., "Multi-scale Analytical/Numerical Theory of the Diffusivity of Concrete," Journal of Advanced Cement-Based Materials, 1997. 
Microstructure and

Moisture-Driven Size Changes of Cement-Based Materials

\author{
Principal Investigator \\ Edward J. Garboczi \\ Building Materials Division \\ 301-975-6708
}

\section{Sponsor}

National Science Foundation

Center for Advanced Cement-Based

Materials

Northwestern University

\section{Objective}

To predict the moisture-driven size changes of cement-based materials as a function of moisture state and microstructure.

\section{Problem}

Concrete has often been called a living material, in that it can shrink or grow in response to its moisture state and induced stresses. It is a viscoelastic material, whose applied stress can reduce itself at a fixed strain (stress relaxation) or which can increase its apparent strain for a given applied stress (creep). This viscoelasticity also applies at the microstructural level, where stresses built up from various degradation reactions (sulfate attack, corrosion of rebars, alkali-silica reaction, etc.) induce local viscoelastic movement in the microstructure that are accompanied by moisture changes. The macroscopic viscoelastic properties of concrete have been known and studied for many years. However, the local microstructural basis of this viscoelasticity have not been well studied. Research at this level is necessary for correctly modeling chemo-mechanical degradation reactions, and interpreting the results of standard tests designed to measure these effects.

\section{Approach}

During FY1997, BFRL will develop microstructure-based understanding of viscoelastic processes in cement-based materials, based on viscoelastic theory and numerical simulations using viscoelastic finite elements developed to apply to BFRL microstructure models. Also, BFRL will collaborate with an expert at Northwestern University (NWU), in analyzing strain maps generated with the Environmental Scanning Microscope (NWU) for cement paste undergoing drying shrinkage, by comparing these with microstructure and modeling simulations.

\section{Recent Results}

Bentz, D. P., "A three-phase model of the elastic and shrinkage properties of mortar," Journal of Advanced Cement-Based Materials, 4, 6-20 1996.

Bentz, D. P., Garboczi, E. J., and Duenard, P. A., "Modeling Drying Shrinkage in Reconstructed Porous Materials: Application to Porous Vycor Glass," Materials Science and Engineering, 1997. 


\section{Development of Microstructure and Transport Properties of Concrete}

\author{
Principal Investigator \\ Edward J. Garboczi \\ Building Materials Division \\ 301-975-6708 \\ Sponsor \\ National Science Foundation \\ Center for Advanced Cement-Based \\ Materials \\ Northwestern University
}

\section{Objective}

To use multi-scale microstructure models, in conjunction with transport property experiments, to predict the transport properties of concrete.

\section{Problem}

Understanding the properties of concrete on the basis of microstructure means that a multi-scale approach must be taken, as the microstructure is different at different length scales, but all length scales contribute to overall properties. Such a multi-scale approach also needs to be extended to other properties like elastic moduli.

\section{Approach}

During FY1997, BFRL will systematically apply a multi-scale model for concrete diffusivity to understanding the concrete conductivity measurements being carried out at Northwestern University. BFRL will use finite element techniques, at the micrometer (cement paste) scale, to study the relationship between dynamic elastic moduli and microstructure at this length scale. This study is one key ingredient of a multi-scale approach to the elastic moduli of concrete.

\section{Recent Results}

Schwartz, L. M., Garboczi, E. J., Bentz, D. P., "Interfacial Transport in Porous Media:

Application to D.C. Electrical Conductivity of Mortars," Journal of Applied Physics, pp. 5898-5908, 1995
Garboczi, E. J., Bentz, D. P., Schwartz, L. M., "Modeling the Influence of the Interfacial Zone on the D.C. Electrical Conductivity of Mortar," Journal of Advanced Cement-Based Materials, 1995.

Coverdale, R. T., Christensen, B. J., Mason, T. O., Jennings, H. M., Garboczi, E. J., and Bentz, D. P., "Interpretation of the Impedance Spectroscopy of Cement Paste via Computer Modeling I: Bulk Conductivity and Offset Resistance," Journal of Materials Science, pp. 7 12-719, 1995.

Coverdale, R. T., Christensen, B. J., Mason, T. O., Jennings, H. M., Garboczi, E. J., "Interpretation of the Impedance Spectorscopy of Cement Paste via Computer Modeling II: Dielectric Response," Journal of Materials Science, pp. 4984-4992, 1994.

Christensen, B. J., Mason, T.O., Coverdale, R. T., Jennings, H. M., Olsen, R. A., and Garboczi, E. J., "Impedance Spectroscopy and the Electrical Properties of Hydrating Cement-Based Materials: A Review," Journal of the American Ceramic Society, pp. 2789-2804, 1994. 


\section{Transport Properties of High-Performance Concrete}

\section{Principal Investigator}

Nicos S. Martys

Building Materials Division

301-975-5915

\section{Sponsor}

National Institute of Standards and

Technology

\section{Objective}

To provide the technical basis for standards for the prediction of the service life of high-performance concrete (HPC), by developing analytical and simulation models that can predict transport properties of HPC and develop improved test methods for measuring the important transport properties that are needed for service life prediction of HPC.

\section{Problem}

Before reliable service life predictions can be made for HPC structures, a fundamental understanding of the transport processes controlling degradation of HPC is needed. Although diffusion of ionic species and gases in uncracked concrete has received some attention, much knowledge is needed about all the important transport properties (e.g., permeability, diffusion, and capillarity) that control the invasion of HPC by aqueous media. In addition, experimental methods and standard procedures are needed to form a basis for reliable characterization of transport properties.

\section{Approach}

During FY1997, BFRL will employ parallel computers for large-scale simulations of the flow of complex fluids including multi-component and multi-phase fluids in porous media such as cements. Results of these simulations will be compared with experiments of capillary transport in partially-saturated concrete. In addition, BFRL will use these methods to study diffusion in partially-saturated concrete. Measurement techniques will be further improved to more reliably and accurately measure chloride diffusivity in concrete. In FY 1998, the most promising of these experimental methods will be submitted to ASTM for consideration as a standard test method. The final product of this project will be an integrated model, to predict ingress of matter and chemical species in HPC, for use in developing a service life design methodology for HPC.

\section{Recent Results}

Martys, N. S., and Chen, H., "Simulation of Multi-Component Fluids in Complex Three Dimensional Geometries by the Lattice Boltzman Method," Physical Review E, pp. 743-750, June 1996.

Martys, N. S., and Ferraris, C. F., "Sorption of Water in Mortars and Concrete," Proceedings of the Materials Science of Concrete ASCE, Washington, DC, October 1996.

Martys, N. S., Survey of Concrete Transport Properties and Their Measurement, NISTIR 5592, National Institute of Standards and Technology, February 1995. 


\section{Computer-Integrated Knowledge Systems (CIKS) for High-Performance Concrete}

\author{
Principal Investigators \\ James R. Clifton \\ Building Materials Division \\ 301-975-6707 \\ Dale P. Bentz \\ Building Materials Division \\ 30I-975-5865
}

\section{Sponsor}

National Institute of Standards and Technology

\section{Objective}

To develop and demonstrate an operational prototype for a national computer integrated knowledge system (CIKS) for

high-performance concrete (HPC).

\section{Problem}

A major need for exploiting the benefits of HPC is making reliable information about these advanced concretes (composition and mix design, properties, performance, and economics) quickly available to the construction and building community. Owners, designers, material suppliers, and contractors will all benefit from access to information and knowledge about HPC that can be quickly retrieved. This can be accomplished by incorporating and integrating the information and knowledge in a CIKS. The CIKS for HPC will consist of knowledge bases including databases, mathematical models, artificial intelligence systems, standard practices and test methods, and guidelines. It will assist decision makers in using the most reliable and advanced knowledge in selecting and using HPC. When fully developed, this system is likely to become the leading problem solver for HPC.

\section{Approach}

During FY1997, BFRL will perform four tasks:

1. Continue developing the CIKS prototype, accessible through the Internet, for designing concrete mixtures to give specific service lives for reinforced concrete members and considering corrosion induced by chloride ions from an external source (e.g., de-ionizing salts). BFRL will further develop the mix design program for HPC in the CIKS, based on an optimization approach. Knowledge of other major degradation processes will be incorporated into the CIKS, including sulfate attack, leaching,

alkali-aggregate reactions, and frost attack. The proceedings of the CIKS Workshop held in FY 96 will be published.

\section{Development of other HPC}

knowledge bases will be undertaken including a knowledge-base dealing with the processing of HPC. Also, the electronic monograph on modeling of cement-based materials, developed within the HPCMS program, will be added to the CIKS system.

\section{Establish a test bed for CIKS in} collaboration with the construction industry. BFRL will work with the concrete and metals (aluminum, steel, and stainless metals) CONMAT working groups in their participation in the CIKS test bed development. By chairing ACI Committee 235, "Knowledge Based Systems for Concrete," and organizing a session on CIKS, members of the American Concrete Institute will become exposed to the benefits of CIKS technology.

4. Continue disseminating information to the construction industry on the application of CIKS.

\section{Recent Results}

Ferraris, C. F., Guide to a Format for Data on Chemical Admixtures in a Material Property Database, NISTIR 5796, National Institute of Standards and Technology, March 1996.

Bentz, D. P., Clifton, J. R., and Snyder, K. A., "A Prototype Computer-Integrated Knowledge System for Service Life Prediction of Steel-Reinforced Concrete Exposed to Chloride Ions," Concrete International, August 1996. 


\section{Processing of High-Performance Concrete}

\section{Principal Investigator}

Chiara F. Ferraris

Building Materials Division

301-975-67 l l

\section{Sponsor}

National Institute of Standards and

Technology

\section{Objective}

To develop methods for measuring and predicting the effects of formulation, curing and processing on the performance of high-performance concretes.

\section{Problem}

After many years of relatively slow advances in concrete technology, a worldwide awareness has arisen that the performance of concrete in areas such as ease of placement, strength development and durability can be significantly improved. This is evident from the program plans of the CEB (Commission Euro-International de Beton) and the high-performance concrete research activities in Japan, Norway, and Canada. In the United States, programs such as the concrete and structures program of the Strategic Highway Research Program(SHRP) and the establishment of the NSF Center for Advanced Cement-Based Materials (ACBM) were in response to the need for improved concretes and the recognition of the possibility of the development of high-performance concrete (HPC). The Civil Engineering Research Foundation (CERF) and the American Concrete Institute (ACI) have been leading the U.S. efforts in developing a comprehensive program on HPC and have proposed a program that deals with high-performance construction materials (High-Performance Construction Materials and Systems: An Essential Program for America and Its Infrastructure, CERF Technical Report 93-5011, April 1993). The technology of HPC is sufficiently different from that of conventional concrete that existing test methods and processing practices (e.g., mixing, consolidating and curing) may not be applicable to HPC.

\section{Approach}

During FY1997, BFRL will perform studies on the prediction of the rheological properties of HPC, and the effect of curing practices on the performance of HPC. In the study of rheology of concrete, the main emphasis is on developing methods to measure and predict the flow parameters of HPC. The approach includes simulation modeling and experimental measurements. The modeling will focus on simulating the flow of particles (cement) in a fluid (water) while sheared between two surfaces (aggregates). This model will be validated by measurements conducted using a new fluid rheometer. A methodology will be developed to predict the rheology of concrete from measurements on cement paste orland mortar. The results will be used in developing a method for predicting the rheological properties of HPC based on more rapid tests performed on cement pastes or mortars.

BFRL will examine the influence of silica fume on the curing of the paste fraction in a high-performance concrete. The knowledge of the relationship between the curing conditions and degree of hydration will lead to the development of guidelines for the field curing of HPC. The results will provide an essential input to the development of the Computer Integrated Knowledge System of HPCMS through an expert system for the curing of HPC.

\section{Recent Results}

Bentz, D. P., Snyder, K. A., and Stutzman, P. E., "Hydration of Portland Cement: The Effects of Curing Conditions," Proceedings of the 10th International Congress on the Chemistry of Cement, vol. 2, p. 8, 1997.

Ferraris, C. F., Clifton, J. R., Garboczi, E. J., Davis, F. L., "Stress Due to Alkali-Silica Reactions in Mortars," Proceedings of the 4th ASCE Materials Engineering Conference, pp. 1379-1387, 1996. 


\section{Cementitious Materials Modeling Laboratory (CMML)}

Principal Investigator

Edward J. Garboczi

301-975-6708

\section{Sponsor}

National Science Foundation

Center for Advanced Cement-Based

Materials

Northwestern University

\section{Objective}

To advance the science of cement-based materials through the electronic availability of models and the transfer of modeling knowledge through workshops and documentation.

\section{Problem}

Many cement-based materials models that have proved themselves in research applications need to be effectively transferred to the general materials science of concrete research public, in order to be of wider use. Many researchers have the skill to use such models, but not the time and ability to develop them. Such models also need to be documented so others can use them.

\section{Approach}

During FY1997, BFRL will make available a hypertext monograph on cement-based material modeling. Those who need further training in the modeling techniques used in the models can attend the annual Computer Modeling Workshop. Cooperation is maintained with RILEM Committee I23-MME, ACBM faculty, and other computer modelers around the nations.

\section{Recent Results}

Garboczi, E. J., Finite Element and Finite Difference Codes for Computing the Linear Electric and Elastic Properties of Digital Images of Modern Materials, NIST TN, National Institute of Standards and Technology, 1997.
Characterization of Clinker, Cement, and Flaws in Cement Paste and Concrete

\author{
Principal Investigator \\ Paul Stutzman \\ Building and Fire Research Laboratory \\ 301-975-6715
}

\section{Sponsor \\ National Institute of Standards and Technology}

\section{Objective}

To apply modern computational and imaging methods to analysis of cementitious materials, and hydration products, and provides the technical basis for standards for use in determining their composition at any stage of their service life.

\section{Problem}

The development of standard tests and application of new analytical methods are necessary to provide measures of quality, and tools for predicting their performance and for evaluation of the influences of deleterious physical and chemical processes. In addition to portland cement, supplementary cementitious materials such as fly ash, ground granulated blast furnace slag, and silica fume are becoming increasingly important in the production of concrete, yet performance of all these materials in concrete is difficult to predict. The development of standard test methods using x-ray powder diffraction and microscopy addresses these difficulties. X-ray powder diffraction offers a rapid, direct means for phase compositional analysis of portland and blended cements. Microscopy provides means for a direct examination of materials, but has traditionally been subjective. Both of these methods offer the potential for quantitative characterization of phase composition and texture, features important in determining quality and optimizing materials production.

\section{Approach}

During FY1997, BFRL will model x-ray

diffraction patterns of cementitious materials, 
pozzolanic materials, and hydration products and perform analysis of cements through calculation of the best-fit set of reference patterns based on a refined structure model. The compilation of a structure database will be a key to the success of this method. The potential of the Rietveld method as a basis of an ASTM standard test method will be explored through analysis of the NIST Reference Material clinkers and supplementary cementitious materials.

Petrographic analysis by optical and electron microscopy provides high-resolution, high-contrast images of microstructures and a means for quantitative image analysis. The development and application of techniques to characterize phase abundance and distribution will enhance the utility of these methods. X-ray diffraction and microscopy will facilitate a greater understanding of cementitious materials by providing a means to study composition-performance relationships and through study of the changes in hydration products upon curing and degradation.

The improved methods for determining the compositions of clinker, cements, and blended cements will form the basis for new standard test methods in ASTM which will facilitate the development of performance-based standards for cement and concrete.

\section{Recent Results}

Stutzman, P. E., Guide for X-ray Powder Diffraction Analysis of Portland Cement and Clinker, NISTIR 5755, National Institute of Standards and Technology, November 1995.

\section{Durability of Highway Concrete Pavements}

\author{
Principal Investigators \\ James R. Clifton \\ Building Materials Division \\ 301-975-6707 \\ Paul E. Stutzman \\ Building Materials Division \\ 301-975-6715
}

\section{Sponsor}

Iowa State Department of Transportation

\section{Objective}

To identify probable processes responsible for premature deterioration of the concrete pavement of a major state highway in Iowa.

\section{Problem}

A major highway concrete pavement in Iowa has exhibited premature deterioration. The Iowa Department of Transportation (DOT) has responsibility for determining the cause of the deterioration and implementing measures for avoiding similar future problems. The cause(s) of the deterioration has not been identified definitively Investigators using different methods to characterize the processes have arrived at different conclusions. The deterioration has been variously attributed to effects of ettringite formation (including delayed ettringite formation), alkali-silica expansive reactions, and to frost attack, or some combination of them. Evidence for all three processes has been reported. Thus, there is a need to establish if one or more of these processes is the prime cause of the deterioration, or if some other deleterious process is the cause.

\section{Approach}

During FY1997, BFRL will perform three tasks in collaboration with the Iowa State DOT.

1. Perform a field inspection of deteriorated concrete and collect information on the pavement such as the concrete mixture 
designs and constituent materials, the mixing, consolidation and curing of the concretes, test records, and inspection reports. Also, samples of the concretes' constituents will be obtained. Specimens of both deteriorated and un-distressed pavement, constructed from the same concrete, will be collected.

2. Subject concrete specimens to petrographic examination, using visible light microscopy and scanning electron microscopy coupled with image analysis, and x-ray powder diffraction analysis. These investigations will identify the major degradation process(es) causing the premature deterioration of the pavement and, if more than one major process is identified, assess their relative contributions.

3. Perform microstructure simulation, hydration simulation, and micro-mechanical models developed at BFRL. Through a combination of back-scattered electron and $x$-ray imaging, the microstructure of the distressed concretes will be established. Modeling of deterioration processes will involve the selective expansion of phases in accordance with proposed deterioration mechanisms. Analysis of the stress fields after a series of expansion cycles will form a basis for predicting the crack patterns associated with the different modes of deterioration. Comparison of the predicted stress fields and resulting crack patterns will provide additional information regarding the mode(s) of deterioration.

The products will include the development of a database, in collaboration with Northwestern University, in which data from Tasks 1 and 2 are entered. The format will adhere to the recommendations developed by ACI Committee 126 on Database Formats for Concrete Materials Properties. The database, along with the modeling of Task 3 , will initiate the development of the first step towards a computer-integrated knowledgebased system (CIKS) for concrete pavements. BFRL will publish the results of the studies.

\section{Recent Results}

New project. 
BUILDING MATERIALS DIVISION

\section{QUALITY ASSURANCE}



Cement and Concrete Reference Laboratory

Principal Investigator

James H. Pielert

Building Materials Division

301-975-6704

Sponsor

American Society for Testing and Materials (ASTM) and

Department of the Army

U.S. Army Corps of Engineers

\section{Objective}

To inspect cement and concrete testing laboratories, distribute proficiency test samples, and support the voluntary standards development process.

\section{Problem}

The infrastructure represents a substantial portion of the nation's wealth. Construction of such facilities is one of the nation's largest industries usually amounting to about 10 percent of the Gross Domestic Product. Over $\$ 4$ billion of hydraulic cement is produced in the United States each year with the value of the concrete construction estimated to be in the order of $\$ 20$ billion. Standardization of testing to enhance the reliability of quality assurance measurements is of paramount concern. The productivity of the testing community in the cement and concrete fields can be increased by the use of correct procedures and apparatus which reduce testing errors and provide a sound basis for the acceptance of cement on mill certificate. More efficient use of long-established construction materials are facilitated by dependable quality assurance programs.

With the support of ASTM Research Associates working under BFRL supervision, services are provided to both public and private cement and concrete testing laboratories on a voluntary basis. These services include the laboratory inspection program and the distribution of proficiency test samples. Equipment and procedures used in performing conventional quality assurance tests are evaluated for conformance to applicable national standards. Related test apparatus is checked with inspection equipment calibrated by BFRL personnel.

\section{Approach}

During FY1997, BFRL will continue to produce proficiency test samples of portland cement, pozzolan, concrete, blended cement and masonry cement and distribute at regular intervals to obtain information on laboratory performance. Specific products of this work include: (1) detailed inspection reports; (2) report on each round of proficiency sample testing; (3) input to the work of standards committees such as draft standards and precision data; and (4) reports on results of technical studies. Additionally, technical studies are conducted in areas related to these programs; often in conjunction with other NIST units. NIST technical reports, papers in outside journals, and oral presentations are used as appropriate.

\section{Recent Results}

Inspected over 290 cement and concrete laboratories; distributed over 3000 proficiency samples; quality system for laboratory inspection program in place with first annual review completed in January 1995; recognition of 29 laboratories who have participated in all CCRL inspection tours. 


\section{AASHTO Materials Reference Laboratory}

\author{
Principal Investigator \\ James H. Pielert \\ Building Materials Division \\ 301-975-6704
}

\section{Sponsor}

American Association of State Highway and Transportation Officials

\section{Objective}

To inspect soil and bituminous testing laboratories, distribute proficiency test samples, and support the voluntary standards development process.

\section{Problem}

The quality of testing in construction materials laboratories is an important concern when considering the overall question of quality construction. The importance of the testing function is demonstrated by The Strategic Highway Research Program (SHRP), a \$150-million highway and bridge research program, which was completed in 1994. Standardization of testing to enhance the reliability of quality assurance measurements is of paramount concern. The productivity of the testing community can be increased by the use of correct procedures and apparatus which reduce testing errors and provide a sound basis for the acceptance of materials on certificate. More efficient use of long-established construction materials and broader use of new materials are facilitated by dependable quality assurance programs.

\section{Approach}

With the support of AASHTO Research Associates working under BFRL supervision, services are provided to public and private laboratories on a voluntary basis. During FY1997, BFRL will continue to provide services such as on-site inspection of the laboratory and the distribution of proficiency test samples. The current scope of the laboratory inspection program includes the testing of soils, bituminous materials, and plastic pipe, and the measurement of roughness and frictional properties of highways. Equipment and procedures used in performing conventional quality assurance tests are evaluated for conformance to applicable national standards. Proficiency test samples of asphalt, soils, paint, aggregates and bituminous concrete are distributed at regular intervals. Additionally, technical studies are conducted in areas related to these programs, often in conjunction with other NIST laboratories.

Specific products of this work include: (1) detailed inspection reports; (2) report on each round of proficiency sample testing; (3) input to the work of standards committees such as draft standards and precision data; and (4) reports on the results of technical studies. The AMRL programs provide the following benefits to construction materials testing laboratories and others involved with the nation's transportation systems: (1) improves the quality of laboratory testing; (2) provides data to quantify standard measurement techniques; and (3) provides direct communications between testing laboratories and standards-writing committees.

\section{Recent Results}

Inspected over 322 bituminous and soil labs; distributed over 5600 proficiency samples;

SHRP Asphalt binder and Gyratory Compactor samples distributed; informal inspection of SHRP equipment provided in sponsor labs.

Kandhal, P.S., Wu, Y., Parker, F., and Spellerberg, P. A., "Precision of Marshall Stability and Flow Test Using 6-in Diameter Specimens." ASTM Journal of Testing and Evaluation, April 1996. 


\section{Performance of Tape-Bonded Seams in EPDM Roofing Membranes}

\author{
Principal Investigator \\ Walter J. Rossiter \\ Building Materials Division \\ 301-975-6719
}

\section{Sponsors \\ National Institute of Standards and \\ Technology}

Adco Products

Ashland Chemical Company

Carlisle SynTec Systems

Firestone Building Products

GenFlex Roofing Systems

National Roofing Contractors Association

Roof Consultants Institute

\section{Objective}

To develop a test protocol and recommended criteria for evaluating the long-term performance of tape-bonded seams in EPDM roofing membranes.

\section{Problem}

EPDM is a non-polar elastomeric material with excellent weathering properties, but care must be taken in adhesively bonding EPDM with itself, as required in the formation of a roofing seam. Liquid-applied butyl adhesives have been extensively and successfully used in forming EPDM roofing seams since the mid-1980's. However, liquid-applied adhesives contain a large volumetric fraction of volatile solvents, which are increasingly becoming environmentally unacceptable. An alternative to these liquid-applied adhesives is butyl-based tapes. Users of EPDM roofing such as contractors and consultants have expressed concern that the rheological properties of adhesive tapes be properly evaluated and data be developed to characterize their long-term performance and compare it with that of liquid-applied adhesives.

\section{Approach}

During FY1997, BFRL will conduct investigations of the rheological properties of EPDM roofing seams bonded with butyl-based tapes and their performance will be compared against seams bonded with liquid-applied adhesives. The technical approach has been developed in concert with the EPDM industry. The outcome is an industry-government consortium. Eight collaborators have entered into CRADAs and are participating in the consortium; they include three manufacturers of EPDM roofing, two manufacturers of seam tapes, and two trade associations.

The research is divided into three sequential phases in which statistically-designed laboratory experiments will be complemented by field investigations. In the field, roofs are inspected and tape-bonded seam samples are obtained. Mechanical properties of the field seam specimens are determined and compared with those of

liquid-adhesive-bonded seams. In the laboratory, the experimentation focuses on subjecting tape-bonded EPDM seam specimens to testing of the rheological performance under a range of application and environmental conditions. The seam specimens are prepared using currently available EPDM membrane material and tape/primer systems. Additionally, seam specimens fabricated with a solvent-based butyl adhesive are prepared as controls and included in some experiments. The three laboratory phases are:

Phase I (FY1995) Investigation of the rheological performance of butyl-tape systems as a function of applied load. The results were compared against similarly stressed liquid-applied adhesive systems.

Phase 2 (FY1996) Investigation of the effect of various application variables and environmental factors on the rheological performance of butyl-tape systems. The 
variables included temperature, pressure, rubber surface condition, and tape thickness.

Phase 3 (FY1997) Investigation of the effect of elevated test temperatures and specimen configuration on rheological performance and preparation and publication of a final report.

\section{Recent Results}

Rossiter, W. J., Vangel, M. G., Embree, E., Kraft, K. M., Seiler, J. F., Performance of

Tape-Bonded Seams of EPDM Membranes:

Comparison of the Peel Creep-Rupture Response of Tape-Bonded and Liquid-Adhesive-Bonded Seams, BSS 175, National Institute of Standards and Technology, 1996. 
BUILDING ENVIRONMENT DIVISION

COMPUTER INTEGRATED

CONSTRUCTION 

STEP for the Process Plant

\section{Industries}

\author{
Principal Investigator \\ Mark E. Palmer \\ Building Environment Division \\ 30I-975-5858
}

\section{Sponsor \\ National Institute of Standards and Technology}

\section{Objective}

To assist the U.S. process plant industries in developing the STEP application protocols needed for exchanging and sharing information during the design, construction and maintenance of process plants.

\section{Problem}

The U.S. process plant industries seek to improve their use of computerized systems through integration of information systems, e.g., automation of the exchange and sharing of information among systems. The many computerized systems in use can be integrated only at great cost because of their incompatible proprietary representations of information; information exchange today is accomplished largely through manual methods. Standard, neutral information representations and exchange methods are needed that allow system vendors to be innovative and yet allow system users to exchange and share information about process plants automatically. The evolving international standard ISO 10303 -Product Data Representation and Exchange, known as STEP, is providing the base technology.

STEP application protocols must be developed that meet the needs of the process plant industries.

\section{Approach}

During FY1997, BFRL will work with the industry, standards development organizations, and international programs to ensure the delivery of a harmonized suite of STEP APs that meet the requirements of the process plant industries. In collaboration with pdXi (Process Data eXchange Institute of
AIChE), BFRL will complete the Committee Draft of the Process Engineering AP (AP 231). This will include conducting industry reviews of the AP 231 requirements specification, defining the data structures and conformance classes for AP 231, and developing usage scenarios and test cases for AP 231. In collaboration with PlantSTEP, Inc., BFRL will update the Plant Spatial Configuration AP (AP 227) to resolve the issues from the ISO Committee Draft ballot on AP 227. NIST will develop the Abstract Test Suite for AP 227

BFRL will review, test, and comment on the Functional Data and Schematic Representation AP (AP 221) and will define necessary alignments between AP 221 standard classes and the plant concepts and process concepts included in AP 227 and AP 231. NIST will co-lead the ISO TC184/SC4 Process Plant AP Planning Project and will work with PIEBASE (Process Industry Executive for achieving Business Advantage using Standards for data Exchange) to develop a roadmap for delivering needed data exchange standards and to provide global coordination of industry programs to develop, demonstrate, and standardize needed data exchange standards.

\section{Recent Results}

Established PlantSTEP, Inc. and in collaboration with PlantSTEP developed the first STEP AP for the process plant industries, Plant Spatial Configuration (AP 227) which was approved by ISO TC184/SC4 for Draft International Standard in August 1996. 


\section{Object Oriented Implementation of STEP}

\section{Principal Investigator}

Kent A. Reed

Building Environment Division

301-975-5852

\section{Sponsor}

National Institute of Standards and

Technology

\section{Objective}

To work with U.S. industry to ensure the proper deployment of STEP in emerging software scenarios.

\section{Problem}

The U.S. construction industry seeks to improve its use of computerized systems through integration, e.g., automation of the exchange and sharing of information among systems. Some industrial sectors have pursued the development of ISO 10303, Product Data Representation and Exchange, known as STEP, to enable integration at the information level. Recently the members of the general building and construction industry have formed the International Alliance for Interoperability to pursue the development of object class libraries, known as IFCs, to enable integration at the application programming interface level. Careful liaison is required to ensure these approaches are compatible.

\section{Approach}

During FY1997, BFRL will continue to participate on the Research-Advisory Committee of the International Alliance for Interoperability, working to define the relationship between IFCs and STEP. BFRL will prepare position papers on STEP technologies as appropriate to aid the IAI deliberations and will bring IAI issues to appropriate STEP committees for resolution. BFRL will build experimental object-oriented implementations of selected portions of STEP technology to compare ideas evolving in the IAI. This is the second year of a project envisioned to take 4 years to complete.

\section{Recent Results}

Participated in IAI discussions to resolve the representation of measured quantities.

Developed a software translator for generating VRML models from 3D models represented according to STEP Application Protocol 227 for use in the exploration of geometry representation issues in the IAI. 

Protocol Testing for Process Plant
Representations

Principal Investigator

Kent A. Reed

Building Environment Division

301-975-5852

\section{Sponsor}

National Institute of Standards and

Technology

\section{Objective}

To verify and demonstrate the standard protocols being developed for the representation and exchange of life-cycle information supporting the design,

construction, and operation of process plants.

\section{Problem}

BFRL is working with U.S. industry in several projects to develop information exchange standards for the process plant industries. The need was identified early in these projects for a neutral, open testbed in which developers, users, and vendors could come together to test and demonstrate software solutions based on these standards. A principal standard in development is STEP Application Protocol 227 "Plant Spatial Configuration." Recently, STEP Application Protocol 221 "Plant Functional Data and Schematic Representation" has been advanced by projects in Europe to the point that it must be considered as well. Validated test-case data and testing scenarios are needed by the commercial implementers of these protocols. Verification of the protocols is needed by the process plant industries. Harmonization of the various related protocols needs to be tested and demonstrated.

\section{Approach}

During FY1997, BFRL will continue to work in collaboration with the industry members of the PlantSTEP, Inc., consortium to develop and verify needed protocol test and demonstration datasets, introducing a focus on STEP AP221. BFRL will continue to develop software programs for the creation of datasets and the analysis of experimental STEP exchange files created by vendor-implementers. This is the third year of a 5-year project.

\section{Recent Results}

Created with the collaboration of PlantSTEP, Inc., partners, and maintained on-line testcase data files representing elements of a chemical solvent recovery plant. These data files were verified in the BFRL Testbed and subsequently used in public demonstrations by PlantSTEP implementors of STEP AP227, the most recent occurring at the Daratech Plant Design/Plant Management Automation Strategy Workshops '97 in Houston, Texas. 


\section{Architecture and Modeling Issues for Computer Integrated Knowledge Systems for Materials}

\section{Principal Investigator}

William F. Danner

Building Environment Division

301-975-5855

\section{Sponsor}

National Institute of Standards and

Technology

\section{Objective}

To harmonize the development of computer integrated knowledge systems for materials with other information technology developments in the construction industry.

\section{Problem}

BFRL is leading a national effort to develop multiple Computer Integrated Knowledge Systems (CIKS) for the capture and dissemination of information about building and construction materials. As currently envisioned, a CIKS would integrate knowledge and programs from multiple sources but function essentially as stand-alone information "warehouses" that are accessed by humans, albeit via the Internet. While this approach addresses the immediate needs of the U.S. construction industry, it should be harmonized with other information technology developments if it is to remain as useful in the future environment of distributed, interoperating information systems.

\section{Approach}

During FY1997, BFRL will initiate a study of information technology issues related to CIKS. BFRL will apply the methods developed in the ISO/STEP community and in other major system integration efforts such as the U.S. DoD/CALS program to the CIKS program. BFRL will select a specific materials domain and study the information requirements identified by industry, for example, by the appropriate working group of the CONMAT Council and will explore the applicability of the information structures contained the ISO Standard 10303-45, "STEP Integrated Resource: Materials." The CIKS approach will be compared to the approach taken in BFRL's: "Electronic Commerce of Scientific and Engineering Data" (ECSEA) project. This is the first year of a project that is envisioned to take 3 years to complete.

\section{Recent Results}

New project. 


\section{BUILDING ENVIRONMENT}

DIVISION

\section{HEAT TRANSFER}





\section{Advanced Thermal Insulation Panel Testing}

\author{
Principal Investigator \\ A. Hunter Fanney \\ Building Environment Division \\ 301-975-5864
}

\section{Sponsor}

National Institute of Standards and Technology

\section{Objective}

To evaluate thermal measurement techniques applicable to advance insulation systems.

\section{Problem}

Advanced insulation products are being developed and introduced into the U. S. market. Examples of these products are aerogels, powder filled panels, and evacuated panels. These products offer extremely high insulating capabilities. For example, theoretical calculations reveal that an R-value approaching 100 may be achieved in a 25.4 $\mathrm{mm}$ thick evacuated panel. Current test procedures for measuring thermal conductivity are applicable to materials that are homogenous, have planar surfaces, and have, compared to advanced insulation materials, relatively poor insulating capabilities. Appropriate measurement techniques and measurement apparatus are needed that will allow an accurate determination of the overall thermal conductance of advanced insulation materials.

\section{Approach}

During FY1997, BFRL will collaborate the modified calorimeter apparatus for a range of mean specimen temperatures. The results will be compared to measurements made using the NIST's one-meter guarded hot plate. An extensive finite element model will be formulated for the revised calorimeter facility. This model will include geometric details that were not previously considered. The resulting model will be extensively exercised to pinpoint deficiencies, if any, in the modified apparatus. A CRADA will be established and tests will be conducted under the terms of this Cooperative Research and Development Agreement (CRADA) to evaluate the performance of prototype advanced insulation panels.

\section{Recent Results}

Fanney, A. H., Saunders, C. A., Hill, S. D., "Test Procedures for Advanced Insulation Panels." Superinsulations and the Building Envelope, Symposium Proceedings, Environment and Thermal Envelop Council and the National Institute of Buildings Sciences, November 14, 1995, pp.149-161.

Fanney, A. H., Saunders, C. A., and Hill, S. D., Test Procedures for Advanced Insulation Panels, National Institute of Standards and Technology, Gaithersburg, MD. Alliance for Responsible Atmospheric Policy; U.S. Environmental Protection Agency; Environment Canada and United National Environmental Program. International CFC and Halon Alternatives Conference, 1994. Stratospheric Ozone Protection for the 90's. October 24-26, 1994, Washington, DC 1994. 


\section{Low-Temperature and High-Temperature Thermal Insulation Reference Materials}

\author{
Principal Investigator \\ Robert R. Zarr \\ Building Environment Division \\ 301-975-6436
}

\section{Sponsor \\ National Institute of Standards and \\ Technology}

\section{Objective}

To establish a low- and high-temperature guarded hot plate laboratory for thermal insulation Standard Reference Materials (SRMs) over an extended temperature range.

\section{Problem}

NIST's Materials Evaluation Division decommissioned several apparatus for the measurement of thermal conductivity. Two apparatus were used to develop and establish thermal insulation SRMs at low and high temperatures. For example, one apparatus provided SRMs $1450 \mathrm{~b}$ and 1451 with certified values of thermal resistance from $100 \mathrm{~K}$ to $330 \mathrm{~K}$. Recognizing the necessity for these apparatus, the American Society of Testing Materials (ASTM) Committee C-16 on Thermal Insulation requested of NIST to re-establish these measurement capabilities.

\section{Approach}

During FY1997, BFRL will re-assemble the apparatus to previous configurations. The apparatus will be extensively evaluated in assess its accuracy. The evaluation will be based on a series of experiments, as well as theoretical analysis. If required, the primary individual measurement sensors will be calibrated. A benchmark at room temperature will be provided by cross-checking with BFRL's one-meter guarded hot plate. The low-temperature guarded hot plate apparatus will available for development of SRM 1450c. A final report will be prepared describing the evaluation of the apparatus.

\section{Recent Results}

Zarr, R. R., Glass Fiberboard SRM 1450c for

Thermal Resistance From $280 \mathrm{~K}$ to $340 \mathrm{~K}$, NIST SP 260-130, National Institute of Standards and Technology, April 1997.

Zarr, R. R., Insulation Materials Testing and Applications, Vol. 3 ASTM Committee C-16; Proceedings. ASTM STP 1320, May 15-17, 1997, Quebec, Canada, ASTM, West Conshohocken, PA, 1997.

Zarr, R. R., and Hahn, M. H., Line Heat Source Guarded Hot Plate Apparatus, National Institute of Standards and Technology, ASTM Designation C1043; PCN 12-31043061; 33 p. 1996.

Zarr, R. R., Expanded Polystyrene Board as a Standard Reference Material for Thermal Resistance Measurement Systems, ASTM STP 1320, National Institute of Standards and Technology, October 1996. 
Development of 2-Dimensional Heat and Moisture Transfer Model

Principal Investigator

Douglas M. Burch

Building Environment Division

301-975-6433

\section{Sponsor}

National Institute of Standards and Technology

\section{Objective}

To develop a 2-dimensional personal computer model that predicts the combined transfer of heat and moisture in building construction.

\section{Problem}

BFRL has developed a "one-dimensional" personal computer model, called MOIST, that predicts heat and moisture transfer in building construction. This model inputs hourly outdoor weather data, and predicts the moisture content and temperature of the construction layers as a function of time of year. The algorithms of the program include moisture transfer by diffusion and capillary flow. A user of MOIST is able to investigate the effect of various parameters on moisture movement and accumulation within the building envelope. These parameters include climate, building materials, the use and placement of vapor retarders, and the relative placement of building materials. The capability of MOIST to predict the moisture accumulation within each building material as a function of time allows the user to select the most appropriate building materials and construction for a given climate. BFRL has released version 2.1 of the MOIST Software to over 1000 persons. A significant limitation of the MOIST model is that it is onedimensional and does not address many building applications (e.g., rising dampness in earth-coupled foundation walls, water leakage into basements, the effect of framing members on heat and moisture transfer, etc.).

\section{Approach}

During FY1997, BFRL will develop a 2-dimensional personal computer program will run from a Windows 95 operating system. It will have the following elements:

Input processor. An input processor will be developed that permits the program user to draw the building construction on the computer screen using a calibrated cursor. Boundary conditions along various segments of the exterior boundary of the construction will be assigned by dragging the cursor along that segment of the boundary. It will be possible to assign hourly ASHRAE Weather Year for Energy Calculations (WYEC) weather to one or more segments of the boundary. The program will come equipped with a considerable database of heat and moisture property data. Property data will be assigned by clicking with the mouse on a particular region and then selecting the material type from the material property data base. The user may create a new material in the database with unique property values. The nodal spacing for the finite-difference solution will be established by clicking the mouse at various locations within the construction. All data entry will be accomplished in a Windows environment. The program will solve for the temperature and moisture content at the specified finite-difference nodes as a function of time.

Finite-Difference Solution. A set of equations will be developed that perform a heat balance at the finite-difference nodes and calculate the nodal temperatures at each time step of the analysis. A separate set of equations will be developed that perform a moisture balance at the finite-difference nodes and calculate the nodal moisture contents at each time step of the analysis. The moisture transport equations will include both molecular diffusion and capillary transfer in the materials. Latent heat (i.e., the effect of water evaporating from one place and condensing in another place) will be distributed within the materials. The above two sets of finite-difference equations will be solved using an alternating-direction implicit method.

Output Processor As the program executes, it 
will display a color-coded image depicting the moisture content of various parts of the construction as it changes with time. After execution, the user will be able to send to the printer either color-coded or gray-tone snapshot images showing the moisture content of the construction at selected time intervals.

\section{Recent Results}

Burch D. M., and Chi, J., MOIST: A PC

Program for Predicting Heat and Moisture

Transfer in Building Envelopes. Version 3.0,

NIST SP 917, National Institute of

Standards and Technology, September 1997.

Burch, D. M., Tsongas, G. A., and Walton,

G. N., Mathematical Analysis of Practices to

Control Moisture in the Roof Cavities of

Manufactured Houses, NISTIR 5880, National

Institute of Standards and Technology,

September 1996.

TenWolde, A., and Burch, D. M., Ventilation, Moisture Control, and Indoor Air Quality in Manufactured Houses, A Review of Proposed Changes in the HUD Standards and a Proposal for Revised Standards. National Institute of Standards and Technology, Department of Housing and Urban Development, Interagency Agreement, 1996.

Tsongas, G. A., Thronton, B. A., Burch, D. M., and Walton, G. N., Computer Analysis of the Moisture Perofrmance of Roof Constructions in the U.S., DOE Moisture Control Handbook, NISTIR 5919, National Institute of Standards and Technology, December 1996.

\section{A Photovoltaic Solar Water Heating System}

Principal Investigator

A. Hunter Fanney

Building Environment Division

301-975-5864

\section{Sponsor}

National Institute of Standards and Technology

\section{Objective}

To develop computer simulation capabilities for photovoltaic solar water heating systems

\section{Problem}

Photovoltaic simulation models have not been adequately validated with experimental data for many of the photovoltaic technologies. Models do not exist that characterize the performance of photovoltaic systems that use direct current at the end application rather than utilizing a dc to ac inverter and its associated maximum power tracking circuitry. Additionally, the conversion efficiency of photovoltaic integrated building products has not been documented.

\section{Approach}

During FY1997, BFRL will work with the University of Wisconsin to develop simulation tools to predict the performance of photovoltaic solar systems that utilize direct current. The model will provide predictions of solar array performance and displaced electrical energy. Predictions of electrical demand reductions and the impact on the environment through the widespread use of these systems will be modeled.

Detailed experimental data will be collected for systems at the BFRL, the Florida Solar Energy Center, and the Great Smoky Mountains National Park. A single-tank photovoltaic solar water heating system will be developed and fabricated to provide data for single-tank model development and validation. The system will utilize components that maximize performance 
while providing an adequate supply of hot water during extended periods of poor weather conditions. The photovoltaic array at the Florida Solar Energy Center will be reconfigured to provide additional experimental data for model verification.

Samples of photovoltaic residential roof shingles will be obtained. The voltage, current, and efficiency characteristics of this amorphous-silicon-based product will be measured for various ambient temperature and solar irradiance levels. The resulting data will be used to determine the validity of a four node lumped parameter model.

\section{Recent Results}

Fanney, A. H., Dougherty, B. P.,

"Photovoltaic Solar Water Heating System," ASME Journal of Solar Energy Engineering, pp. 126-133, May 1997.

Fanney, A. H., Dougherty, B. P., Photovoltaic Solar Water Heating System at Great Smokey Mountains National Park, National Institute of Standards and Technology, Pamphlet, 1997.

Fanney, A. H., Dougherty, B. P., Kramp, K. P., "Field Performance of Photovoltaic Solar Water Heating Systems," Proceedings, Solar Engineering 1997, American Society of Mechanical Engineers, April 27-30, 1997. 

BUILDING ENVIRONMENT DIVISION

INDOOR AIR QUALITY 



\section{Indoor Air Quality Modeling with Computational Fluid Dynamics}

\section{Principal Investigator}

Steven J. Emmerich

Building Environment Division

301-975-6459

\section{Sponsor}

National Institute of Standards and

Technology

\section{Objective}

To apply the large eddy simulator computational fluid dynamics (CFP) model (LES3D) to investigate mixing of air and contaminants within rooms, and investigate the application of computational fluid dynamics in the design process.

\section{Problem}

During FY1996, the potential for using a large eddy simulation computational fluid dynamics model (LES3D) developed by BFRL's Fire Science Division to analyze building indoor air quality and ventilation problems was investigated. Based on a literature review of the use of CFD modeling in indoor air quality and ventilation, the application of the LES3D model to a test case, and discussions with a number of individuals in the private sector, it was determined that this model offers several unique capabilities compared to other available CFD models and could be use to make a unique contribution in studying several issues of current interest to the building indoor air quality and ventilation field.

\section{Approach}

During FY1997, BFRL will perform CFD simulations of air and contaminant mixing in a single room using LES3D. This work will demonstrate the unique capabilities of LES3D and to further explore the use of this model to study contaminant transport in ventilated spaces. These simulations will focus on the relative merits of different turbulence models and the predictive accuracy of the model.
BFRL will work with industry to develop a strategy for industry to employ CFD modeling techniques in the design process. A series of industry visits to BFRL will be arranged to demonstrate the LES3D program, to discuss design problems of interest that could be analyzed with the program, and to explore the possibility of cooperative efforts between BFRL and industry.

\section{Recent Results}

Emmerich, S. J., Use of Computational Fluid Dynamics to Analyze Indoor Air Quality Issues, NISTIR 5997, National Institute of

Standards and Technology, April 1997. 


\section{Development of IAQ Model for Designers}

Principal Investigator

W. Stuart Dols

Building Environment Division

301-975-5860

\section{Sponsor}

National Institute of Standards and

Techriology

\section{Objective}

To develop an indoor air quality design tool in cooperation with the National Research Council of Canada.

\section{Problem}

Multizone airflow and contaminant models were developed at BFRL, including AIRNET and CONTAM86 through CONTAM96.

These models were unique at the time of their development and have been useful for the study of airflow and indoor air quality in multizone building systems. However, most indoor air quality models, including CONTAM, have been used primarily by researchers, consultants and sophisticated designers. The design community still needs an indoor air quality analysis program that meets their needs and is appropriate to their technical level.

During FYI 996, NIST entered into a three-year agreement with the National Research Council of Canada (NRCC) to develop an indoor air quality design tool. A general framework for the model was developed, and BFRL began the development of their primary contribution to the effort, a Windows-based multizone airflow and contaminant dispersal model based on the latest version of CONTAM. Software was developed which will enable the use of many of the approaches currently contained within CONTAM in the Windows version.

\section{Approach}

During FY1997, BFRL will continue to work with NRCC to develop the indoor air quality design tool. The Windows version of
CONTAM will be completed and then incorporated into the general program interface being developed at NRCC. Software will be developed with NRCC to link this program with the other components of the NRCC model, specifically the VOC emission database and the single-zone room airflow model. A working version of the program will be developed to enable testing and refinement during the final year of the agreement between NIST and NRCC.

\section{Recent Results}

Walton, G. N., CONTAM96 User Manual, NISTIR 6065, National Institute of Standards and Technology, September 1997. 


\section{VOC Emission Measurements in Office Buildings}

Principal Investigator

Andrew K. Persily

Building Environment Division

301-975-6418

\section{Sponsor}

National Institute of Standards and

Technology

\section{Objective}

To develop and demonstrate advanced methods to measure VOC emission rates in office buildings.

\section{Problem}

Volatile Organic Compounds (VOC) emission rates employ a number of simplifying assumptions and do not consider all important mass transport mechanisms. These approaches assume the indoor VOC concentration is at equilibrium; there is no loss of indoor VOC other than through dilution by ventilation air, and there is no loss of outdoor VOC when they enter the building. During FY1996, the approaches that have been used to estimate VOC emission rates in the field, and the theory behind these approaches, were examined. An analysis of the measurement errors that might be encountered in the field based on the assumptions used in these approaches was conducted, and preliminary estimates of these errors were in the range of 25 percent to 100 percent.

\section{Approach}

During FY1997, BFRL will develop alternative approaches to estimate VOC emission rates in the field and demonstrate the approaches in a number of office buildings. These new methods will account for the transient nature of indoor VOC concentrations and the potential for adsorption/desorption interactions with indoor surfaces. Initially, these methods will be based on real-time measurements of VOC concentrations employing a portable gas chromatograph; ultimately they will employ more conventional measurement technology based on integrated air sampling using solid sorbents and off-site analysis of the samples. Based on the results of these measurements, a draft ASTM standard will developed to provide guidance on the measurement of VOC emission rates in the field. In addition, more precise determinations of the measurement uncertainty associated with VOC emission rate measurements will be performed, for both existing approaches and the new approaches that are developed as part of this project.

\section{Recent Results}

Dols, W.S., Persily, A.K., and Nabinger,

S.N., "Indoor Air Quality in Green

Buildings," Proceedings of ASHRAE IAQ'96, 1996.

Persily, A.K., Issues in the Field

Measurement of VOC Emission Rates,

Proceedings of Indoor Air '96, pp. 49-54, 1996. 


\section{IAQ Analysis of Residential Ventilation Systems}

\author{
Principal Investigator \\ Andrew K. Persily \\ Building Environment Division \\ 301-975-6418

\section{Sponsor} \\ Electric Power Research Institute
}

\section{Objective}

To assess the indoor air quality and ventilation performance of residential ventilation systems using multizone airflow and contaminant modeling.

\section{Problem}

A variety of approaches to mechanical ventilation in residential buildings exist, which are intended to control indoor contaminant levels while maintaining thermal comfort and controlling energy consumption. BFRL recently completed a project for the U.S. Consumer Product Safety Commission where a number of single-family residential buildings were modeled using the multizone airflow and indoor air quality program CONTAM. Simulations were performed to predict indoor pollutant levels due to a variety of sources and to assess the impact on these pollutant levels of a limited number of indoor air quality control technologies. The technologies considered were modifications of conventional forced-air distribution systems and included enhanced particulate filtration, heat recovery ventilator installed on the return side of the system, and an outdoor air intake duct connected to the system return. The effectiveness of these controls was a function of the source characteristics, building factors, and the outdoor pollutant concentrations. In some cases, pollutant concentrations were reduced by as much as 70 percent. In other cases, the reductions were lower and even resulted in increased indoor concentrations. This effort contributed a significant amount of insight to issues of residential indoor air quality. However, a number of indoor air quality control approaches, including several promising approaches to residential ventilation that are currently being used in the field, were not considered in this project.

\section{Approach}

During FY1997, BFRL will use the multizone airflow and indoor air quality model CONTAM to assess the indoor air quality and energy impacts of a number of approaches to residential ventilation. The residential ventilation approaches will include infiltration balanced mechanical ventilation, and mechanical exhaust ventilation with passive air supply inlets. The indoor air quality analysis will consider emissions of carbon dioxide, water vapor, carbon monoxide, particles and volatile organic compounds from typical indoor sources. Annual simulations will be performed for a base building case with a moderate level of envelope airtightness and for a building with an increased level of airtightness typical of homes built under energy efficiency programs. Short-term simulations will also be performed to examine other issues of interest including the impacts of forced-air fan operation, wood stoves as an indoor pollutant source, closed intake vents during cold weather, and window opening during shoulder seasons.

\section{Recent Results}

New Project. 


\section{Infiltration and Ventilation in Large Buildings}

\author{
Principal Investigator \\ Andrew K. Persily \\ Building Environment Division \\ 301-975-6418
}

\section{Sponsor}

Department of Energy

Office of Building Technologies

\section{Objective}

To analyze energy impacts of large building infiltration and ventilation system airflows employing integrated building thermal analysis and network airflow analysis, and to participate in industry consensus standards development activities.

\section{Problem}

Previous research and field investigations have shown that despite current design goals, the envelopes of modern office buildings often fall short of design expectations in terms of airtightness performance. In addition, field testing has shown that ventilation system airflows are often quite different from their design values, leading to over- and under-ventilation as well as increasing the pressure differences that drive envelope leakage. The existence of such envelope leakage, as well as ventilation system airflows that are not in accordance with design, will increase the energy loads of a building. In addition to the energy penalties, envelope air leakage can also negatively impact indoor air quality, envelope material durability and occupant comfort. However, the energy implications of envelope leakage and ventilation system airflows are not known, in part due to a lack of ability of thermal analysis models to properly account for the complexities of building airflows in large, multi-zone buildings. Although sophisticated network airflow analysis programs are available, such as AIRNET developed at BFRL, thermal analysis models are currently not able to incorporate the output of such airflow models. Such an integration of thermal and airflow analysis is necessary to properly account for the energy impacts of infiltration and ventilation system airflows.

\section{Approach}

During FY1997, BFRL will perform an analysis of the energy impacts of infiltration in office buildings and participate in industry consensus standards development to provide the HVAC industry with the benefits of DOE-supported research at BFRL. The former activity involves the development of a simplified estimate of the energy impacts of infiltration and the development of a more rigorous approach based on the TRNSYS thermal load model. The simplified estimate of energy impacts will be performed, including an estimate of energy efficiency opportunities through air tightening and improved ventilation system control. Also, the TRNSYS approach in which the AIRNET program for calculating building airflow rates is coupled with the thermal loads analysis capabilities of TRNSYS will be demonstrated. For the latter, BFRL will participate in ASHRAE and ASTM activities, primarily the ASHRAE committee responsible for revising ASHRAE Standard 62 Ventilation for Acceptable Indoor Air Quality. The public review of Standard 62 will be monitored and a draft version of the carbon dioxide standard will be developed for full consensus approval. This work is the second year of a 5-year project.

\section{Recent Results}

ASTM Provisional Standard Guide, PS 40, Using Indoor Carbon Dioxide Concentrations to Evaluate Indoor Air Quality and Ventilation, ASTM.

Emmerich S. J., Persily A. K., Van Bronkhorst D. A., An Analysis of the Energy Impacts of Envelope Airtightness in Office Buildings, NISTIR 5758, National Institute of Standards and Technology, November 1995.

Van Bronkhorst D. A., Persily A. K., Emmerich S. J., "Energy Impacts of Air Leakage in U.S. Office Buildings," 16th AIVC Conference, November 1995. 


\section{Demonstration of Residential Ventilation Systems}

\author{
Principal Investigator \\ Andrew K. Persily \\ Building Environment Division \\ 301-975-6418
}

\section{Sponsor}

Synertech Systems Corporation (Contractor to New York State Energy Research and Development Administration)

\section{Objective}

To evaluate the performance of residential ventilation systems based on multizone airflow and contaminant modeling of houses in a field monitoring program.

\section{Problem}

A variety of approaches to mechanical ventilation in residential buildings exist, which are intended to control indoor contaminant levels while maintaining thermal comfort and controlling energy consumption. The New York State Energy Research and Development Administration recently sponsored a project to identify and analyze the energy and indoor air quality impacts of ventilation approaches to residential construction. This project, performed by the California Institute for Energy Efficiency and Lawrence Berkeley Laboratory, included the collection of cost and performance data for ventilation approaches from past studies and telephone surveys with HVAC contractors. These data formed the basis for detailed analyses of the most promising approaches to evaluate their ventilation characteristics, energy usage impacts and life cycle costs in new and existing buildings. The results of these analyses have identified the most effective systems in New York State and California. A Ventilation Guide discussing the issues associated with ventilation and the most appropriate system for New York State homes was developed from the results of these analyses.

The New York State Energy Research and Development Administration has moved on to the second phase of this effort in which the actual performance of the most promising ventilation systems will be evaluated in a sample of New York State homes. This second phase is being conducted by Synertech Systems Corporation in conjunction with a number of subcontractors, including BFRL. The performance evaluation of this second phase will involve installing ventilation systems in 26 homes and performing detailed monitoring in eight of them. The monitoring will include measurements of airflow rates and selected indoor air quality parameters.

\section{Approach}

During FY1997, BFRL will perform computer simulations of the homes with detailed monitoring with the multizone airflow and indoor air quality model CONTAM, developed by BFRL. The houses will be set-up in CONTAM, with input values determined by site measurements.

Simulations will be performed for the monitoring period to determine the ability to predict the measured values. Once this ability has been established, longer term simulations will be performed to understand the overall performance of the ventilation systems, their impact of several important indoor air quality parameters, and the existence of interactions between the ventilation systems and other building systems. The results obtained from these simulations will be compared with the trends predicted during the first phase of the effort.

\section{Recent Results}

New project. 


\section{Combined Thermal and Airflow Analysis in Multizone Buildings}

\section{Principal Investigator}

George Walton

Building Environment Division

301-975-6421

\section{Sponsor}

National Institute of Standards and

Technology

\section{Objective}

To develop approaches to perform simultaneous thermal, airflow and contaminant dispersal analysis within the framework of the CONTAM model.

\section{Problem}

Multizone airflow and contaminant models have been developed at BFRL, including AIRNET and CONTAM86 through CONTAM96. These models were unique at the time of their development and have been useful for the study of airflow and indoor air quality in multizone buildings. However, these programs have been limited by the zone air temperatures which are specified as constant values, even for transient simulations. In reality, the zone air temperatures are functions of the airflows, and the airflows are functions of the zone air temperatures. This limits the potential accuracy and sensitivity of the CONTAM simulations, and prevents the use of these models to analyze some important issues.

\section{Approach}

During FY1997, BFRL will integrate conductive, convective, and radiative heat transfer models within the existing airflow and contaminant analysis capabilities of CONTAM. These thermal models will be selected to have accuracy and execution time performance characteristics comparable to those of the airflow and contaminant migration models. Models will be provided for a sufficient variety of building features to permit the thermal modeling of most buildings. Potential computational problems in the solution of the simultaneous nonlinear equations will be studied and resolved.

\section{Recent Results}

Walton, G. N., CONTAM 96 Users Manual, NISTIR 6065, National Institute of Standards and Technology, September 1997. 

BUILDING ENVIRONMENT DIVISION

MECHANICAL SYSTEMS AND CONTROLS 



\section{Communication Protocols for Building Controls}

\section{Principal Investigator}

Steven Bushby

Building Environment Division

301-975-5873

\section{Sponsor}

National Institute of Standards and Technology

General Services Administration

Public Buildings Service

Department of Energy

Office of Building Technologies

\section{Objective}

To expand the acceptance of BACnet technology into the areas of lighting control, life safety systems, security, and elevator control; achieve international standardization of the BACnet protocol; and establish an industry-run BACnet certification program based on recognized testing standards.

\section{Problem}

Today's direct digital control (DDC) systems employ proprietary communication protocols which prevent systems supplied by different manufacturers from communicating with each other. This has resulted in "captive customers" who, upon buying a control system, are unable to upgrade or expand it without going back to the same manufacturer. This lack of communication capability between control systems made by different manufacturers also prevents the building owner from obtaining the most capable building service by not allowing him to choose, regardless of the manufacturer, the best EMCS system, the best digital controllers, the best security system, the best fire detection system, or the best telecommunications system.

\section{Approach}

During FY1997, BFRL will administer and participate with industry partners in an BACnet Interoperability Testing Consortium.
The objectives of this consortium are to: 1 ) assist control system manufacturers in verifying the correctness and interoperability of their proprietary BACnet implementations 2 ) verify the technical soundness of the BACnet protocol; 3) identify errors or omissions in the BACnet protocol specification; 4) identify ambiguities in the BACnet protocol which might lead to implementations which cannot interoperate and; 5) develop insight into testing requirements which should be included in the future version of ASHRAE Standard 135 for testing conformance to BACnet.

BFRL will develop tools that can be used to establish an industry-run BACnet certification program. It will assist GSA establish and carry out an BACnet test-bed demonstration project in the Philip Burton Federal Office building in San Francisco. Work will begin on developing on international standard version of BACnet through ISO TC 205. Also, work will be performed in conjunction with ASHRAE SSPC 135 on expanding BACnet to integrated building services, including life safety, security, and transportation.

\section{Recent Results}

Bushby, S. T., "BACnet ${ }^{\mathrm{TM}}$ - A Standard Communication Infratstructure for Intelligent Buildings," Automation in Construction, July 1997.

Bushby, S. T., "Testing the Conformance and Interoperability of BACnet ${ }^{\mathrm{TM}}$ Systems" ASHRAE Journal Vol. 38 No. 11, November 1996. 


\section{Real Time Fault Detection and Diagnostics}

\author{
Principal Investigator \\ John House \\ Building Environment Division \\ 301-975-5874
}

\section{Sponsor}

National Institute of Standards and

Technology and

Department of Energy

\section{Objective}

To develop and demonstrate methods for controlling and performing fault detection and diagnostics (FDD) on mechanical equipment and systems in real time and to participate in the International Energy Agency (IEA) Annex 34 Committee on Computer-Aided Evaluation of HVAC System Performance: The Practical Application of Fault Detection and Diagnosis Techniques in Real Buildings.

\section{Problem}

Heating, ventilating, and air-conditioning (HVAC) systems frequently operate in the presence of faults. Faults can lead to energy waste, occupant discomfort, and can shorten equipment life. Advanced control strategies and FDD methods are needed to help ensure that HVAC systems operate properly.

\section{Approach}

During FY1997, BFRL will: 1) work with industry, participants in Annex 34, and academia to implement and test advanced control strategies and methods for FDD on actual building HVAC systems; 2) work with an industry manufacturer to validate an advanced control strategy developed in FY1996 that is expected to be integrated into new industry controllers; 3) work with an industry manufacturer and Cornell University to demonstrate FDD methods on the Cornell campus; 4) work with Purdue University to develop a model of the chiller system for the Temperature Control Module (TCM) in BFRL's large environmental chamber, and to use the model and chiller system to examine various FDD methods; and 5) explore the possibility of working with the Iowa Energy Center (IEC) to develop and test FDD methods in the IEC Energy

Resource Station.

\section{Recent Results}

Seem J. E., House, J. M., and Klaassen, C. J., "Volume Matching Control: Leave the Outdoor Air Damper Wide Open," ASHRAE Journal, 1997.

House, J. M., Seem, J. E., and Kelly, G. E., "Reverse Airflow Through the Exhaust Air Damper for Variable-Air-Volume AirHandling Units: Part I - Problem Description," International Journal of HVAC\&R Research, 1997.

Seem, J. E., House, J. M., and Klaassen, C. J., "Reverse Airflow Through the Exhaust Air Damper of Variable-Air-Volume AirHandling Units: Part II - Control Solution," International Journal of HVAC\&R Research, 1997.

Lee, W. Y., House, J. M., and Shin, D. R., "Fault Diagnosis and Temperature Sensor Recovery for an Air-Handling Unit,"

ASHRAE Transactions, Vol. 103, pt. 1, 1997.

Seem, J. E., and House, J. M., and Monroe, R. H., "On-Line Monitoring and Fault Detection of Control System Performance," CLIMA 2000, Brussels, 1997. 
Test Procedures for Furnaces, Boilers, and Integrated Appliances

\author{
Principal Investigator \\ Stanley Liu \\ Building Environment Division \\ 301-975-5880
}

\section{Sponsor}

Department of Energy

Office of Energy Efficiency and Renewable

Energy

Office of Codes and Standards Division

\section{Objective}

To provide equitable testing and rating procedures for determining energy performance of furnaces, boilers, and integrated appliances

\section{Problem}

In the DOE test procedure for

furnaces/boilers, procedures are proscribed for single stage and modulating (multiple firing

rate) furnaces. However, there is an discrepancy in the calculated value of the AFUE for gas-fired, two-stage modulating furnaces. The AFUE value based on the two-stage calculation procedure was lower than the AFUE value based on the single stage calculation under the low firing rate condition. The discrepancy between the two AFUE values was from 0.5 to 1 percentage points with the single stage, low firing rate calculation giving the higher value. This was opposite to what was expected. Preliminary investigation at NIST showed that under the average design weather condition assumed in the test procedure, the two-stage furnace would have operated in the low firing mode for over 95 percent of the time. If the furnace is assumed to operate as a single stage furnace but at the low firing rate, the calculated AFUE values of the two cases (two-stage with 95\% time at the low firing rate and single stage with $100 \%$ time at the low firing rate) should be near equal. This discrepancy is believed to be caused by the difference in the calculation procedures for single stage furnaces and modulating furnaces. A study of the calculation procedures is needed to find the cause of the problem and to develop possible corrections to the calculation procedures.

The proposed DOE furnaces/boilers test procedure references the ANSI/ASHRAE Standard 103-1993, and a test procedure for combined space/water heating combination appliances will reference the ANSI/ASHRAE Standard 124-1991. In 1996, ASHRAE sent out notice for its 5-year cycle revision or reaffirmation of both ASHRAE 103-1993 and ASHRAE 124-1991.

\section{Approach}

During FY1997, BFRL will continue to study and develop corrections to conciliate the difference in the AFUE values between the single stage furnace and two-stage modulating furnace. BFRL will continue to conduct tests on the outdoor furnace test unit with different length flue pipe and configurations to develop the needed tracer gas test procedure for incorporation in the DOE furnace/boiler test procedure.

\section{Recent Results}

Assisted DOE evaluate public comments received about proposed revision to test procedures and on the proposed energy cost ratio factor on furnaces/boilers, vented home heating equipment and pool heaters. Final rule for the revised test procedures have been published in the Federal Register Notice on May 12, 1997. 
Test Procedures for Commercial

Furnace/Boilers, Central Air

Conditioners, Heat Pumps, and

Hot Water Heaters

\author{
Principal Investigator \\ Stanley Liu \\ Building Environment Division \\ 301-975-5880
}

\section{Sponsor}

Department of Energy

Office of Energy Efficiency and Renewable

Energy

Office of Codes and Standards

\section{Objective}

To provide equitable testing and rating procedures for determining energy performance of commercial furnace/boilers, central air conditioners, heat pumps, and water heaters.

\section{Problem}

The Energy Policy Act of 1992 (EPACT) requires $\mathrm{DOE}$ to develop test procedures for the energy performance of certain class of commercial heating and cooling equipment and commercial hot water heaters. The Act specifies the ANSU/ASHRAE Standard 90.1-1989 as the reference document for the determination of the energy performance standard. ASHRAE 90.1 in turn referenced several existing industry standards for the testing of a product. For furnaces and boilers, there are some distinct and conflicting differences among these standards (when applied to the same product) with respect to test procedure, test conditions and calculation procedures. For other covered products, there are unspecified or unclear procedures. Some of the unspecified or unclear procedures have been addressed by ASHRAE Standard Project Committee after ASHRAE Standard 90.1-1989 was published. At the present time, ASHRAE 90.1 is being extensively revised to address all types of revisions to the existing standard, and Tables for furnaces, boilers, A/C and heat pump equipment and service water heaters that specified the test standards and performance requirements are all being revised. The revised draft standard 90.1-1989R has been published for public review. In the proposed revision, the ASHRAE Standard 118.1-1993 (Method of Testing for Rating Commercial Gas, Electric, and Oil Water Heaters) has been referenced as the test standard for service water heaters. However, the Standard 118.1 itself is in the process of being revised by ASHRAE SPC I 18.1R. Also, for space heating boilers, ASHRAE 90.1-1989R proposes the adoption of ASHRAE Standard 155P which is itself under development by ASHRAE SPC 155P. All these issues need to be addressed in the development of DOE proposed rules for equitable test and rating procedures for the EPACT-covered commercial products.

\section{Approach}

During FY1997, BFRL will continue to assist DOE in its rulemaking process to develop, revise and finalize the draft DOE test procedures for the EPACT-covered products as required by DOE's proposed rulemaking process. As ASHRAE continues its revision of the ASHRAE 90.1-1989R and 118.1-1993R, BFRL will participate and provide input to the revision processes and will participate in the ASHRAE SPC 155P's effort for the development of test procedure for all type of commercial space heating boilers. When the test methods in ASHRAE 155P are developed, the proposed procedures will require validation. BFRL will participate in the validation tests before the methods are adopted as a DOE test procedure.

\section{Recent Results}

Provided letter reports on the various tasks to DOE. 


\section{Test Procedures for Heat Pumps and Air Conditioners}

\author{
Principal Investigators \\ Brian Dougherty \\ Building Environment Division
}

301-975-6396

Piotr Domanski

Building Environment Division

301-975-5877

\section{Sponsor}

Department of Energy

Office of Energy Efficiency and Renewable

Energy

Office of Codes and Standards

\section{Objective}

To provide equitable testing and rating procedures for determining energy performance of heat pumps and air conditioners

\section{Problem}

The Energy Policy and Conservation Act (PL 94-163) (EPCA), as amended, requires the Department of Energy (DOE) to prescribe test and rating procedures and minimum performance standards for various residential appliances. In addition, the 1987 amendments to EPCA requires analysis of any test procedure amendments to determine their effect on minimum efficiency standards. DOE has, since 1975, relied on BFRL to assist in the development of the test and rating procedures.

\section{Approach}

During FY1997, BFRL will co-sponsor testing of a Nordyne Powermiser combined heat pump-water heating appliance at ETL. The unit will be tested as per the Nordyne waiver, as the BFRL-proposed test procedure for combined appliances, and ASHRAE Standard 137. The results will be used to evaluate the differences between the methods. Based on these results and input from ETL as to the associated testing burden of the different tests, BFRL will generate a generic test procedure that may be based largely on one method or be a combination of all three. This generic test procedure, which will only cover combined appliances that are presently being marketed, will be supplied to DOE for publishing as part of a proposed rulemaking.

\section{Recent Results}

Developed a revised version of DOE's test procedure that covers central air conditioners and heat pumps. 


\section{Test Procedures for Compact Refrigerators}

\section{Principal Investigator}

James Kao

Building Environment Division

301-975-5871

Sponsor

Department of Energy

Office of Energy Efficiency and Renewable

Energy

Office of Codes and Standards

\section{Objective}

To conduct investigation on compact refrigerators to determine if the Department of Energy (DOE) test procedure should be revised.

\section{Problem}

DOE obtained information from some commercial test laboratories in the past that the energy test results on compact refrigerators in volumes of 4 cubic feet or less indicated repeatability problem. However, the accuracy of this information is not certain. Further investigation to confirm or deny its validity is needed.

\section{Approach}

During FY1997, BFRL will perform three tasks:

1. Inquire with manufacturers and test laboratories to determine if repeatability of energy test is a problem for refrigerators in volumes of $0.11 \mathrm{~m}^{3}$ or less.

2. Evaluate the DOE energy test procedure to determine if the test procedure causes reliability problem in energy tests for compact refrigerators.

3. If appropriate, develop a plan to determine the extent of the problem. One approach is to test the same refrigerators at different test laboratories, such as the refrigerator manufacturer, Inchcape, the Canadian Standards Association, and NIST (a round robin approach).

\section{Recent Results}

Drafted test requirements of energy effects of vented refrigerators in the current refrigerator/freezer test procedure.

Investigation of repeatability problem for compact refrigerators indicates that the problem is not caused by the DOE energy test procedure 
Test Procedures for Plumbing Systems

\author{
Principal Investigator \\ Stephen Treado \\ Building Environment Division \\ 301-975-6444
}

\section{Sponsor}

Department of Energy

Office of Energy Efficiency and Renewable

Energy

Office of Codes and Standards

\section{Objective}

To develop test procedures as required for plumbing products covered under EPACT.

\section{Problem}

EPACT, the Energy Policy and and Conservation Act, specifies performance standards for a number of plumbing products, including toilets, urinals, showerheads, and faucets. The American Society of Mechanical Engineers (ASME) test procedures for measurement of hydraulic performance are also specified and are to be adopted by the DOE. While these test procedures are in general sufficient for their intended purpose, the introduction of new plumbing products and designs, and the interpretation and application of the specific testing provisions will require DOE to continuously monitor these changes and their effects on the Department's test procedures for plumbing products.

\section{Approach}

In FY1997, BFRL will continue to provide technical support and liaison with manufacturers, ASME, and other related organizations, and attend industry group meetings as necessary to monitor industry progress on the test procedures for evaluating the performance of water consumption for plumbing products. Specific activities will include supporting the ongoing DOE rulemaking, reviewing and evaluating the revised ASME Al $1218.1 \mathrm{M}-1994$ and the upcoming Al 12.19.6 standard, when published, relating to provisions integral to the measurement of water consumption, and providing general technical support.

BFRL will evaluate comments on proposed test procedures, especially those related to sampling issues, and will participate in public hearings and meetings on proposed rulemakings. BFRL will participate in the development and review of the Tri-Lateral North American Standards 1,2, and 3 to determine their impact on the DOE standards program, water consumption and effect on ASME standards and plumbing codes.

\section{Recent Results}

Provided DOE with a letter report on evaluation of plumbing products. 


\section{Test Procedures for Lighting Fixtures and Systems}

\section{Principal Investigator}

Stephen Treado

Building Environment Division

$301-975-6444$

\section{Sponsor}

Department of Energy

Office of Energy Efficiency and Renewable

Energy

Office of Codes and Standards

\section{Objective}

To provide equitable testing and rating procedures for determining energy

performance of lighting fixtures and systems.

\section{Problem}

The Energy Policy and Conservation Act ( $\mathrm{P}$ 94-163) (EPCA), as amended, required the Department of Energy (DOE) to prescribe test and rating procedures and minimum performance standards for various residential appliances. In addition, the 1987

amendments to EPCA requires analysis of any test procedure amendments to determine their effect on minimum efficiency standards. DOE has, since 1975, relied on BFRL to assist in the development of the test and rating procedures. The Energy Policy Act of 1992 (EPACT) contained many provisions relating to lighting equipment., including labeling and minimum standards for incandescent and fluorescent lamps. The implementation of these provisions required the development or specification of appropriate test procedures, and a rigorous set of definitions for covered products and exemptions.

\section{Approach}

During FY1997, BFRL will review, evaluate, and validate industry test procedures for fluorescent lamp ballasts, including electronic ballasts, and will conduct laboratory measurements to convert industry test procedures to DOE test procedures. BFRL will provide technical support to DOE in obtaining resolution to outstanding technical issues, such as the inherent wattage characteristics of fluorescent lamps and the definition of vibration service incandescent reflector lamps, as well as assessing the coverage status of new lighting products. BFRL will monitor the Illuminating Engineering Society and the American National Standards Institute test procedure activities, along with the luminaire labeling program, the National Voluntary Laboratory Accreditation Program's accreditation program and voluntary ballast programs. BFRL also will review the HID lamp technical report being prepared by the Lawrence Berkeley National Laboratory.

\section{Recent Results}

Provided DOE with letter reports on fluorscent lamps. 
Revised 'Test Procedures for Ranges and Ovens

\section{Principal Investigator}

Steven J. Nabinger

Building Environment Division

301-975-6416

\section{Sponsor}

Department of Energy

Office of Energy Efficiency and Renewable

Energy

Office of Codes and Standards

\section{Objective}

To provide equitable testing and rating procedures for determining energy performance of ranges and ovens.

\section{Problem}

The Energy Policy and Conservation Act ( $\mathrm{Pl}$ 94-163) (EPCA), as amended, requires the Department of Energy (DOE) to prescribe test and rating procedures and minimum performance standards for various residential appliances. In addition, the 1987

amendnents to EPCA requires analysis of any test procedure amendments to determine their effect on minimum efficiency standards. DOE has, since 1975, relied on BFRL to assist in the development of the test and rating procedures.

\section{Approach}

During FY1997, BFRL will continue to review and revise the draft Final Rule on test procedures for kitchen appliances until it is published. BFRL will complete reports summarizing the data and results obtained from the oven, cooktop and microwave oven tests performed during FY1996.

\section{Recent Results}

Provided the DOE with letter reports on testing and data analysis for ovens, cooktops, and microwaves.

\section{Revised Test Procedures for Water Heaters}

\author{
Principal Investigator \\ Stanley Liu \\ Building Environment Division \\ 301-975-5880
}

\section{Sponsor}

Department of Energy

Office of Energy Efficiency and Renewable

Energy

Office of Codes and Standards

\section{Objective}

To provide equitable testing and rating procedures for determining energy

performance of residential water heaters.

\section{Problem}

The Energy Policy and Conservation Act (PL-94-163) (EPCA), as amended, requires the Department of Energy (DOE) to prescribe test and rating procedures and minimum performance standards for various residential appliances. The 1987 amendments to EPCA requires analysis of any test procedure amendments to determine their effect on minimum standards. DOE has, since 1975, relied on the BFRL to assist in the development of the test and rating procedures.

\section{Approach}

During FY1997, BFRL will provide technical support to DOE in revising proposed revisions into a final rule. BFRL will evaluate test data submitted by GAMA and EPRI on the effects of draw rate, draw schedule and total daily draw on heaters with a storage volume of less than $0.076 \mathrm{~m}^{3}$ ( 20 gallons) and on heat pump water heaters. BFRL, will participate in DOE workshop on unresolved issues in the test procedure. BFRL will review published hot water consumption data for reference in a future revision of the test procedure.

\section{Recent Results}

Provided letter reports to DOE on water heaters. 


\section{Revised Test Procedures for Pool Heaters}

Principal Investigator

Stanley Liu

Building Environment Division

301-975-5880

\section{Sponsor}

Department of Energy

Office of Energy Efficiency and Renewable

Energy

Office of Codes and Standards

\section{Objective}

To provide testing and rating procedures for determining energy performance of pool

heaters.

\section{Problem}

In FY1993, DOE modified the test procedure for pool and spa heaters to include a calculation of energy factor and published the procedure in the Federal Register as a

Proposed Rulemaking on August 23, 1993. In 1996 the proposed energy factor was revised in the draft final rule to delete the energy cost ratio of electrical to fossil fuel energy from the formulation and renamed it as the pool heater heating seasonal efficiency. NIST will continue to assist DOE in finalizing the test procedure so it can be published as a Final Rule.

The current DOE test procedure for pool heaters covers only gas- and oil-fired pool heaters. The test procedure references ANSI Standard Z21.56 for gas-fired pool heaters and specifies certain modifications for the procedure to be applicable to oil-fired pool heaters. It does not cover electric resistance type heaters or the heat pump pool heaters which are recently introduced on the market. A revision to the existing test procedure is needed to include the installation, measurements, test methods and calculation procedures for both the electric resistance type and the heat pump pool heaters.

\section{Approach}

During FY1997, BFRL will continue to assist
DOE in the evaluation of public comments received after the publication in the Federal Register of proposed revision to the existing DOE pool heater test procedure.

\section{Recent Results}

Final rule on the revised DOE test procedure for pool heaters was published in the Federal Register on May 12, 1997. 
Revised Test Procedures for Clothes Washers

Principal Investigator

James Kao

Building Environment Division

301-975-5871

\section{Sponsor}

Department of Energy

Office of Energy Efficiency and Renewable

Energy

Office of Codes and Standards

\section{Objective}

To provide equitable testing and rating procedures for determining energy performance of clothes washers.

\section{Problem}

The Energy Policy and Conservation Act (PL 94-163) (EPCA), as amended, requires the Department of Energy (DOE) to prescribe test and rating procedures and minimum performance standards for various residential appliances. The 1987 amendments to EPCA requires analysis of any test procedure amendments to determine their effect on minimum efficiency standards. BFRL, since 1975, has assisted DOE in the development of the test and rating procedures.

\section{Approach}

During FY1997, BFRL will assist DOE analyze and revise interim clothes washer test procedure Appendixes J and future clothes washer test procedure Jl for the final rule making. Since microprocessor applications in clothes washers are expected to advance rapidly, new consumer washing options provided by clothes washer manufacturers may exceed the coverage of the new test procedure. When waiver petitions from clothes washer manufacturers are requested, BFRL will perform testing at DOE's request.

\section{Recent Results}

Test procedure Appendices J and Jl were completed; publication of these Appendices is expected in late FY1997.

\section{Revised Test Procedures for Clothes Dryers}

\author{
Principal Investigator \\ James Kao \\ Building Environment Division \\ 301-975-5871
}

\section{Sponsor}

Department of Energy

Office of Energy Efficiency and Renewable

Energy

Office of Codes and Standards

\section{Objective}

To provide equitable testing and rating procedures for determining energy performance of clothes dryers

\section{Problem}

The Energy Policy and Conservation Act (PL 94-163) (EPCA), as amended, requires the Department of Energy (DOE) to prescribe test and rating procedures and minimum performance standards for various residential appliances. In addition, the 1987 amendments to EPCA requires analysis of any test procedure amendments to determine their effect on minimum efficiency standards. BFRL has, since 1975, assisted DOE in the development of the test and rating procedures.

\section{Approach}

During FY1997, BFRL will complete testing a conventional clothes dryer and a condenser dryer. The purpose of these tests is to acquire base energy consumption data of different types of clothes dryers which will assist BFRL and DOE in future possible revision of test procedures and in responding to possible manufacturers' request for waivers. The tests also provide data on the effect of energy consumption caused by room humidity variations.

\section{Recent Results}

Provided DOE with letter report on the analysis of test results. 


\section{Revised Test Procedures for Dishwashers}

\author{
Principal Investigator \\ Natascha Castro \\ Building Environment Division \\ $301-975-6420$
}

\section{Sponsor \\ Department of Energy \\ Office of Energy Efficiency and Renewable \\ Energy \\ Office of Codes and Standards}

\section{Objective}

To conduct tests on residential dishwashers to gather data pertaining to efficiency in performance and energy consumption using the International Electrotechnical Commission (IEC) Standard 436. To collect and evaluate this information for use in future revisions of the current dishwasher test procedure to possibly include performance based testing.

\section{Problem}

The current DOE test procedure was developed over ten years ago and does not have provisions for testing dishwashers with adaptive controls. Therefore dishwashers equipped with these and other recent innovations cannot be accurately tested. The main features that contribute to improved energy performance are better thermal insulation, improved motor efficiency, better water distribution, improved food filtering, and improved fill controls (using float controls instead of timer controls). Other items which have energy reducing potential are improved water heating in water-heating dishwashers and innovative control schemes. In light of energy consumption reductions in dishwashers over the past decade, review of the current test procedure is in order.

\section{Approach}

During FY1997, BFRL will run performance based tests on two dishwashers, an adaptive control model and a conventional model. These tests shall be conducted using soiled test loads as specified in the IEC Standard
Publication 436. The principal investigator will evaluate the benefits of this test to the current DOE test procedure. In addition, the principal investigator will evaluate a list of proposed changes to the DOE test procedure for dishwashers, prepared by the Association of Home Appliance Manufacturers. Some testing will be performed in support of this evaluation. Work will focus on gathering information pertinent to future revisions of the dishwasher test procedure. The long-term objective of this research will be the development of new significant performance based test and rating procedures for dishwashers and to further encourage manufacturers to use control features and designs that reduce energy consumption.

\section{Recent Results}

Provided DOE with letter reports on test procedures for dishwashers. 


\section{BUILDING ENVIRONMENT DIVISION}

THERMAL MACHINERY 



\section{Calorimetric and Visual Study of Heat Transfer Enhancements with Alternative Refrigerants}

\author{
Principal Investigator \\ Mark Kedzierski \\ Building Environment Division \\ 301-975-5282
}

\section{Sponsor}

National Institute of Standards and

Technology and

Department of Energy

Building of Equipment Division

Office of Building Technologies

\section{Objective}

To determine the thickness and concentration, of the lubricants and additives at a pool boiling surface, the influence of beneficial boiling additives on condensation performance, and in-tube condensation of R22 replacements in a micro-fin tube.

\section{Problem}

Any increase in the efficiency of a heat exchanger or reduction in the uncertainty in a heat transfer correlation could be used to lower manufacturing or operating costs of refrigeration and air-conditioning equipment. The practice of over designing a heat exchanger to ensure it meets the required duty could be curtailed if more accurate heat transfer correlations were available. There is over 50 years of experience in the design of evaporators and condensers for R22 equipment. By contrast, designers have comparatively little experience in the design of heat exchangers for equipment that operate with the ozone-safe replacements for R22. Accurate condensation heat transfer correlations for R22 replacements can help industry to minimize the over sizing of condensers. Most all refrigeration and air-conditioning equipment operate with refrigerant-lubricant mixtures. The lack of a clear understanding of the effect of lubricant concentration of the heat transfer performance of refrigerants contributes to the over sizing of heat exchangers. Correlations for the prediction of refrigerant/lubricant mixture boiling can be used to more closely size heat exchangers. Further reductions in the size of heat exchangers are possible with the use of liquid additives that enhance boiling heat transfer. Although liquid additives and lubricants interact in similar ways with refrigerants the phenomenon is not understood well enough for a comprehensive correlation to be developed. In general, an improved understanding of the phase change phenomena of alterative refrigerants can contribute to the reduction in manufacturing and operating costs.

\section{Approach}

During FY1997, BFRL evaluate two candidate methods for investigating the characteristics of the lubricant layer at the boiling surface. The candidate methods are ellipsometry and fluorescence spectra measurement. Ellipsometry can be used to determine optical constants, layer thickness, and many physical quantities that effect the optical constants; ellipsometry has not been applied to boiling. The technique requires a stable surface. The boiling tests will be conducted until the lubricant-rich layer has accumulated at the surface. At this point the boiling will be quenched and the ellipsometry measurements taken immediately.

Corrections for the diffusion of lubricant from the surface to the bulk liquid can be made to the measurements. The concentration of the lubricant at the boiling surface can be measured by examining the fluorescence spectrum from the surface.

BFRL's new condensing rig will be used to determine if the boiling additive degrades the condensation performance. An in-tube condensation investigation will measure the local condensation heat transfer coefficient of R22 replacements. The refrigerant will be tested under twelve different operating conditions, which are pertinent to heat pump and air-conditioning applications. The heat-transfer coefficient will be reported as average and local values over specified quality ranges. This study will be a companion study for BFRL's 1996 study that investigated the local flow boiling measurements of R22 
replacements (R32/134a, R32/125, and $\mathrm{R} 32 / 125 / 134 \mathrm{a}$ ) in a micro-fin tube. A designer of new heat pumps will be able to size both the evaporator and the condenser with the results of both studies.

\section{Recent Results}

Kaul, M. P., Kedzierski, M. A., and Didion, D. A., Horizontal Flow Boiling of Alternative Refrigerants within a Fluid Heated Micro-Fin Tube, Bergles Symposium, Georgia Institute of Technology in Atlanta, 1996.

Kedzierski, M. A., Enhancement of R123 Pool Boiling by the Addition of N-Hexane, NISTIR 5780, National Institute of Standards and Technology, 1996.

Kedzierski, M. A., Calorimetric and Visual Measurements of R123 Pool Boiling on Four Enhanced Surfaces, NISTIR 5732, National Institute of Standards and Technology, 1995.

Kedzierski, M. A., Effect of Inclination on the Performance of a Compact Brazed Plate Condenser and Evaporator, NISTIR 5767, National Institute of Standards and Technology, 1995.
Thermodynamic Performance of Natural Fluids as Alternative Refrigerants

\section{Principal Investigators}

Peter Rothfleisch

Building Environment Division

301-975-5868

D. A. Didion

Building Environment Division 301-975-5881

P.A. Domanski

Building Environment Division 301-975-5877

\section{Sponsor}

National Institute of Standards and Technology and

Department of Energy

Building Equipment Division

Office of Building Technologies

\section{Objective}

To evaluate the thermodynamic and heat transfer performance of natural fluids as a working medium for refrigeration systems.

\section{Problem}

With the ozone crisis ruling out the use of chlorine in the manufacturing of refrigerants, the industry is rapidly moving toward the use of hydro fluorocarbon compounds. This conversion has been and continues to be the most dramatic change this industry has ever faced. Virtually all industry resources are focused on meeting the United Nations and U.S. Environmental Protection Agency schedules. However, on the horizon looms the global warming crisis, and the carbon-fluorine bond of the alternative refrigerants causes them to have a high Global Warming Potential (GWP). It is the opinion of many that the ultimate solution is in using of "natural" fluids as refrigerants. The term "natural fluids" describes carbon dioxide, hydrocarbons, ammonia, air and water, which either naturally exists in the atmosphere or would have insignificant 
impact on the earth's climate if released to the atmosphere from a refrigeration system. In the past, these fluids were used as refrigerants, but, except for ammonia in industrial applications, have been disregarded for safety (including flammability) and economic reasons.

\section{Approach}

During FY1997, BFRL will perform three tasks:

1. Perform system testing of flammable refrigerants The evaluation of an alternative refrigerant, is extensive. It requires system performance analysis via computer modeling, laboratory system (breadboard)

measurements and heat transfer, particularly evaporative and condensing flows, coefficient determination. The properties of natural fluids are radically different from halogens and significant hardware changes are required, as well as fundamental changes to the thermodynamic cycle and processes.

BFRL will evaluate the concept of a water-to-water heat pump. The refrigerant is confined in the outdoor section, and the inhabited structure is heated or cooled by a secondary refrigerant. In the early analysis stage, this concept was evaluated using a modified version of CYCLE-11. In FY1996, we performed tests in a general-purpose heat pump apparatus and constructed a new apparatus for system testing with flammable refrigerants. BFRL will perform tests at operating conditions typical for cooling and heating conditions of a ground-source heat pump. The fluids tested will include: R-22 (as a reference), propane, and propane/butane mixture. In addition, R-32/152a mixture will be evaluated because it has a low GWP and high Coefficient of Performance. The use of a secondary refrigerant will inflict a performance penalty due to the increased temperature lifts. Based on the first round of tests and simulations, modifications to the rig will be performed and an additional test program will be formulated for the modified test apparatus.

2. Carbon dioxide will be evaluated for use in different refrigeration systems. Based on this evaluation, a decision will be made for performing future experimental evaluations (design, construction of the experimental rig, and milestones).

3. This work addresses upgrading an air-to-air heat pump model (HPSIM) so it could cover refrigerant mixtures comprising up to five components, including those tested under Task 1. In FY1996, the evaporator model and condenser model were developed. During FY1997, the heat pump model will be completed and made available to the industry.

\section{Recent Results}

D.K. Choi, P.A. Domanski, and D.A. Didion, "Evaluation of Flammable Refrigerants for Use in a Water-to-Water Residential Heat Pump," International Institute of Refrigeration, Int. Conference on Applications for Natural Refrigerants, Aarhus, Denmark, September 3-9, 1996.

Domanski, P., Didion, D., Mulroy, W., Parise, J., "A Simulation Model and Study of Hydrocarbon Refrigerants for Residential Heat Pump Systems," International Institute of Refrigeration, Int. Conference on New Applications of Natural Working Fluids in Refrigeration and Air Conditioning, Hannover, Germany, May 10-13, 1994. 


\section{Development of MicroElectro Mechanical Systems (MEMS) Sensors for Refrigeration Machinery}

\author{
Principal Investigator \\ David A. Didion \\ Building Environment Division \\ 301-975-5881
}

\section{Sponsor \\ National Institute of Standards and Technology}

\section{Objective}

To determine the contribution that the MEMS technology can make to control and maintenance of U.S. refrigeration machinery.

\section{Problem}

MicroElectro Mechanical Systems (MEMS) are an outgrowth of the "computer chip" industry and have been under development as a separate entity since the mid 1970's. Although they are of similar size and manufacture they are significantly different from electronic chips in that they incorporate miniature mechanical devices such as diaphragms, cantilevers, gears, etc. This industry has matured sufficiently that MEMS accelerometers act as "triggers" for most automotive air bags. MEMS is showing up in a wide variety of products of all levels of expense and sophistication (e.g., gauges for checking air pressure in tires, etc.). However, to date no such devices are used in the heat pumping/air conditioning machines.

Heat pump developments of today have included a continual path towards an electronic central processor for operation and control. This digitizing system approach has been producing a product that has increased potential for increased efficiency, reliability, and comfort. These are essential factors indeed, for competing with foreign competitors. However, the preoccupation with system changes required by the new environmental-safe refrigerants has caused the MEMS field to be virtually ignored.

\section{Approach}

During FY1997, BFRL will perform two tasks:

1. Design, fabricate, and install MEMS pressure and temperature sensors and related circuitry.

2. Design and construct a test stand at BFRL for a manufacturer donated compressor. It will also involve a selected compressor manufacturer for consultation on the sensor design for installation purposes since it is intended that said manufacturer will do the installation in their model shop. MEMS sensor and transducer devices will be developed by BFRL to measure compressor gas pressure and temperature in the cylinder during operation.

The pressure sensor will be a micro-machined silicon diagram with polysilicon resistive strain gauges.

The temperature measurement device will be a micro machined silicon bridge or cantilever with polysilicon resistive temperature sensors.

\section{Recent Results}

New project. 


\section{Impact of Air-Side Maldistribution on the Performance of Finned-Tube Evaporator}

Principal Investigator

Piotr Domanski

Building Environment Division

30I-975-5877

\section{Sponsor}

Air-Conditioning \& Refrigeration Technology Institute, Inc. (ARTI)

\section{Objective}

To quantify the performance degradation due to maldistributed air for the evaporator working with R-22 and alternative zeotropic mixture R-407C.

\section{Problem}

The zeotrope R-407C (R-32/125/134a $(23 / 25 / 53))$ was identified as a leading alternative to R-22 for residential application. Although many aspects of R-407C performance were explained in recent years, it is still unknown what effect an air-side and refrigerant-side maldistribution will have on a coil capacity if this zeotropic mixture is employed.

It is reasonable to expect the performance degradation of a coil working with a zeotropic mixture to be different from that found for a single-component refrigerant. The difference in degradation may be related to the temperature glide exhibited by a zeotropic mixture during a phase change. Also, the refrigerant-side maldistribution may cause a different evaporator capacity penalty for a zeotropic mixture than for R-22 because a nonuniform distribution of a zeotrope will affect temperature of each tube.

\section{Approach}

During FY1997, BFRL will use the upgraded version of its evaporator model, EVAP5 to study the impact of air-side and refrigerant-side maldistribution for an evaporator charged with R-407C. Two three-depth-row coils will be studied, one with a cross-counter flow configuration and one with a cross-counter cross-parallel flow configuration.

\section{Recent Results}

New project. 
Procedure for Determining the Energy Efficiency Ratio of DOE 35 ${ }^{\circ} \mathrm{C}$ Rating Point for Mixed Unitary Air Conditioners

\section{Principal Investigator}

Piotr Domanski

Building Environment Division

301-975-5877

\section{Sponsor}

Department of Energy

Building Equipment Division

Office of Building Technologies

\section{Objective}

To develop a calculation procedure that would allow determination of Energy Efficiency Ratio at the $35^{\circ} \mathrm{C}\left(95^{\circ} \mathrm{F}\right)$ rating point $[\operatorname{EER}(95)]$ for a mixed system without laboratory testing.

\section{Problem}

The currently required performance descriptors, capacity at the $35^{\circ} \mathrm{C}\left(95^{\circ} \mathrm{F}\right)$ rating point $[\mathrm{Q}(95)]$ and Seasonal Energy Efficiency Ration [SEER], are not adequate for a meaningful rebate program aiming at reducing peak demand for electricity. For a single-speed system, the SEER value is based on the system's Energy Efficiency Ratio at $27.8^{\circ} \mathrm{C}$ rating point, $\operatorname{EER}(82)$, and on the cyclic degradation coefficient. With SEER having a limited relevance to the system efficiency at a higher temperature, the EER at $35^{\circ} \mathrm{C}\left(95^{\circ} \mathrm{F}\right)$ rating point would be a more adequate criterion for a utility rebate program. For a matched system, EER(95) is known to the manufacturer since the system's capacity and power input are measured during a DOE-required Test $\mathrm{A}$; however, for mixed systems EER(95) is unknown, and a proper methodology for determining it has to be developed.

\section{Approach}

During FY1997, BFRL will verify the developed EER algorithm using laboratory test data obtained from the Air-Conditioning and Refrigeration Institute. This verification will include 22 mixed and matched systems.

\section{Recent Results}

New project. 
FIRE SAFETY ENGINEERING DIVISION

\section{FIRE MODELING AND APPLICATIONS}





\section{Fire Performance Design of High-Performance Materials Used in Construction}

\author{
Principal Investigator \\ Leonard Y. Cooper \\ Fire Safety Engineering Division \\ 301-975-6880
}

\section{Sponsor \\ National Institute of Standards and Technology}

\section{Objective}

To develop a special-purpose version of CFAST, BFRL's Consolidated Fire and Smoke Transport Model, which focuses on structural analysis applications involving traditional and High Performance construction materials.

\section{Problem}

The standard method of insuring integrity in fires of building components is based on the response of building materials to a standard-test-method fire exposure. High performance steel, concrete, organic matrix composites, and combinations of these, are being considered for use in many types of modern construction. Such materials have strength vs temperature and failure characteristics that can differ substantially from those of traditional construction materials. In additions these materials can be used in ways not considered in the development of codes which dictate their use and thus acceptability. Fires involving modern furnishings and work environments may produce exposure conditions that differ substantially from those simulated by standard tests. Further, in making the transition to performance codes for buildings it is crucial that an evaluation tool be developed that supports the performance methodology, and can do this evaluation in realistic scenarios. Finally, in determining the integrity of a particular candidate assembly in the design process itself, it will be increasingly important for industry to use modern methods of engineering analysis to assure the cost-effective fire resistance of buildings.

\section{Approach}

During FY1997, BFRL will evaluate the performance of buildings and other structures in a fire environment. Three types of phenomena need to be simulated: 1) the fire environment and its development; 2) the thermal response of structural elements exposed to the fire environment, including loading and nonloading barriers; and 3) the structural response. The fire model CFAST, developed by BFRL to simulate the first of these phenomena, is well recognized as the leading such model in the world. CFAST calculates heat transfer through walls, ceilings, and floors with a l-dimension analysis that assumes constant properties, not effected by the fire. To use CFAST in the evaluation of the thermal and structural response of practical barrier designs it is important to improve the analysis of barrier thermal response by allowing for

2-dimensionality, where necessary, and for material properties which change in response to the fire. We will establish a catalog that includes a brief list of commonly used barrier designs and develop and incorporate into CFAST barrier heat transfer analyses associated with these designs. The analyses will use measured material properties and will be validated experimentally. An advanced version of the CFAST model will include a thermal response analysis for general barrier design geometries and other structural elements, and for comparison of designs implemented in traditional and High Performance materials. A major feature of further advancements will be a capability for simulations of enclosure-fire scenarios, where fire growth is predicted from a heretofore unavailable accounting of: a) radiation exchanges between relatively detailed fueland wall- surface temperature distributions (i.e., using an analysis that includes multiple, uniform-temperature fuel/wall/ceiling/floor surface elements); b) general combinations of natural- and forced-ventilation configurations; and c) fuel or ventilation-controlled burning. This capability will allow the model to provide heretofore unavailable estimates of time- and 
space-dependent heat flux distributions along enclosure-fire-exposed structural elements. Parallel to the CFAST effort will be an effort to develop a means of coupling the advanced fire model to general structural response models. All these advancements will enhance general acceptance of CFAST in the international structural design community.

BFRL will explore the use of existing and advanced versions of the SAFIR computer code as a reliable model and research tool for simulating the response of structures to fire exposures. The calculation-based methods to be developed will contribute to the Integrated Knowledge System for HP Construction Materials and Systems (HPCMS) and will be distributed electronically to industry and academia through the HPCMS

world-wide-web server and other means.

\section{Recent Results}

Cooper, L. Y., The Thermal Response of Gypsum-Panel/Steel-Stud Wall Systems Exposed to Fire Environments - A Simulation for Use in Zone-Type Fire Models, NISTIR 6027, National Institute of Standards and Technology, May 1997.

Cooper, L. Y., and Reneke, P. A., A Prototype Model for Simulating Barrier Performance in Real Fires: CFAST, GYPST - For Evaluating the Response of Gypsum Panel/Steel-Stud Wall Systems, NISTIR in review.

Cooper, L. Y., A Basis for Using Fire Modeling with 1-D Thermal Analysis of Barriers/Partitions to Stimulate 2-D and 3-D Barrier/Partition Structural Performance in Real Fires, NISTIR in review.

\section{Implementation of Fire on the Web CD ROM}

Principal Investigator

Paul Reneke

Fire Safety Engineering Division

301-975-6696

\section{Sponsor}

National Institute of Standards and

Technology

\section{Objective}

To develop a platform independent method of distributing fire test data on a CD ROM.

\section{Problem}

A unified method of accessing data is crucial to both experimental and modeling efforts in the development of the science of fire. Fire on the Web CD ROM is a platform independent way of distributing such data making use of the technology developed for supporting the World Wide Web. By storing available fire test values in a common format, this data is readily available for fire protection professionals, experimentalist, building code officials, and others concerned with the design and construction of "safe" structures.

\section{Approach}

During FY1997, BFRL will provide a CD ROM of test data in FDMS export format along with a set of Hypertext Markup Language(HTML) files that can be used with a Web browser to search the data. The FDMS export format provides an open file design to accommodate future test apparatus formats. Fire on the Web CD ROM provides access to a set of reviewed test values generated from a variety of sources within the fire community.

\section{Recent Results}

FASTData CD published for distribution by NIST's Office Standard Reference Data, June 1997. 


\section{Zone Fire Modeling}

\section{Principal Investigator}

Walter W. Jones

Fire Safety Engineering Division

301-975-6887

\section{Sponsor}

National Institute of Standards and

Technology

\section{Objective}

To develop and verify computational methods for predicting fire growth and spread for use by manufacturers, architects, FPE's, code officials, and practitioners who evaluate fire safety performance, code equivalency, and code change proposal issues.

\section{Problem}

Traditional approaches to building design, product evaluation, and alternatives to prescriptive codes and standards address fire safety in a piecemeal fashion - for example, evaluating heat release without considering product use, toxicity, or ignition propensity. Quantitative evaluation of the effects of an unwanted fire have the potential of providing significant cost savings and reducing the time it takes to obtain approval for a building design and to receive an occupancy permit. In addition, measures can be evaluated as an interacting system, including the impact of both structure and contents. Alternative protection strategies can be studied to give the benefit-cost relation for each. Providing these alternatives promotes the design flexibility which reduces redundancies and cost without sacrificing safety.

\section{Approach}

During FY1997, BFRL will extend application of zone modeling technology by working with designers and fire protection consultants to determine the primary needs for fire safety design of large buildings. Working with these industries BFRL will help to implement zone modeling. To enhance the widespread use of these zone modeling tools, BFRL experts intend to promulgate a well defined interface for this application, encompassing a core model and user interface. The components will be provided with complete documentation, including a demonstration of predictions in a large building. A model will be developed taking advantage as much as possible on previous experience and existing software to address the primary user needs while maintaining computing times useful for creative design tasks.

\section{Recent Results}

Peacock, R. D., Reneke, P. A., Jones, W. W., Bukowski, R. W., Forney, G. P., A User's Guide to FAST: Engineering Tools for Estimating Fire Growth and Smoke Transport, NIST TN 921, September 1997. 


\section{Enhanced Fire Safety Evaluation System}

Principal Investigator

Richard W. Bukowski

Fire Safety Engineering Division

301-95-6853

\section{Sponsor}

General Services Administration

Public Buildings Service

Office of Real Property Management and Safety

\section{Objective}

To advance the technical basis of the Fire Safety Evaluation System (FSES) and facilitate its evolution to a risk management tool.

\section{Problem}

Current fire safety practice within GSA is rooted in the Life Safety Code prescriptions and using the FSES for equivalency determinations. The goal of GSA Headquarters is to move this to a risk management basis. Lacking is technical guidance and review of fire safety practice and software development of fire safety evaluation management tool.

\section{Approach}

During FY1997, BFRL will embed FSE calculations into the FSES in place of judgmental assignment of scores for system parameters.

\section{Recent Results}

Delivered to GSA a windows version of the Fire Safety Evaluation System, September 1997.

\section{Manufactured Housing Fire Safety}

Principal Investigator

Richard W. Bukowski

Fire Safety Engineering Division

301-975-6853

\section{Sponsors}

Department of Housing and Urban

Development and

Federal Emergency Management Agency United States Fire Administration

\section{Objective}

To develop selected fire safety strategies that address losses in existing and new manufactured housing.

\section{Problem}

In January of 1995, HUD and USFA entered into an agreement to consider possible improvements in fire safety for manufactured homes. Such improvements should be cost effective in that they should not unnecessarily increase the cost of manufactured housing which serves an important role as affordable housing. Improvements which can be applied to the existing stock of manufactured homes are preferred as these will have a larger impact than those limited to new units.

\section{Approach}

During FY1997, BFRL will perform five tasks:

1. Review of smoke detector requirements. Current requirements for number and location of detectors to develop recommendations for changes to be made (especially for double-wide units) to the HUD Standard will be reviewed. Type (ion/photo), number, location, power sources (ac/dc and long-life battery), and audibility shall be studied with analytical techniques currently available utilizing floor plans and typical construction information supplied by industry. Criteria for allowing ceiling mounting where insulation exceeds a specific R-value shall be developed. New technologies such as "hush" features and multi-mode, 
multi-criteria detectors shall be evaluated for application to the manufactured housing market. Specific recommendations with respect to selection of detectors for installation in proximity to cooking areas to minimize nuisance alarms shall be included. Demonstration testing of new technologies identified in this task shall be performed.

2. Universal adaptor for smoke detector replacement. Working with NEMA, a suggested voluntary industry standard for a universal mounting plate/adaptor and electrical connections which would facilitate homeowner replacement of ac powered smoke alarms on a 10-year schedule will be developed.

3. Fire Safety Educational Materials. Brochures on fire safety in manufactured housing along the lines of USFA's Protecting Your Family From Fire will be developed. These materials should be simpler in format and style and cover prevention and care of fire safety features found in manufactured housing. It shall also point out the benefits of post-Standard housing. Individual brochures on smoke alarms, sprinklers, fire safe furnishings, escape planning (including use of escape windows), and electrical safety shall be produced. The residential sprinkler brochure shall include details of the latest sprinkler technologies such as low flow heads, half inch pipe, and combined domestic/sprinkler piping systems in consultation with USFA staff and representatives of the NFPA Sprinkler committee.

4. More Fire Safe Furnishings. A meeting between the Manufactured Housing Institute and the furniture (UFAC), bedding industry (Sleep Products Association), and the textile industry (Man Made Fibers Assn.) will be scheduled to explore the possibilities of providing more fire safe furnishings in new units. The current procedures are voluntary and have been shown to be effective. Thus, no regulatory action would be necessary. Industry data shows the cost impacts to be minimal, so such a program should be attractive to the manufactured housing industry.

\section{Technology Demonstration}

Demonstration of the technologies (detector and sprinkler) studied in this project will be conducted. The use of public/private cooperation to perform this demonstration will be explored. Recently BFRL has performed demonstration tests of residential sprinklers for USFA. The use of the facilities installed and instrumented for those tests will be explored. Cooperative demonstrations with the Manufactured Housing industry through their trade association (MHI) or major manufacturers (e.g., Fleetwood) will be explored.

\section{Recent Results}

Smoke Alarm in Manufactured Housing, to be published a NIST internal Report in review. 


\section{Experimental Application of Fire Hazard Analysis for U.S. Passenger Train Systems}

\section{Principal Investigator}

Richard D. Peacock

Fire Safety Engineering Division

301-975-6664

\section{Sponsor}

Department of Transportation

Federal Railroad Administration

Volpe Transportation Systems Center

\section{Objective}

To demonstrate the practicality and effectiveness of new generation test methods and hazard analysis techniques when applied to passenger rail transportation vehicle fire safety.

\section{Problem}

Considerable advances in fire safety engineering have been made in the decade since the original development of the current U.S. guidelines for passenger train material selection. Some requirements for system design, materials controls, detection, suppression, and emergency egress are included in the variety of requirements with each applying to distinct subsets of rail transportation. New test methods and hazard analysis techniques are leading a revolution in the analysis of a material's overall contribution to fire hazard in a particular application. These advances should be incorporated in future designs of passenger trains.

\section{Approach}

During FY1997, BFRL will perform full-scale tests and computer modeling to perform a fire hazard analysis of a passenger rail vehicle constructed of currently used materials and construction techniques. Assemblies of passenger vehicle components will be tested in full-scale to obtain inputs for modeling efforts. Currently available computer-based methods for fire hazard analysis will be employed to study specific fire scenarios, including an interior fire, exterior fire, and an interior fire on a vehicle located in a tunnel.

\section{Recent Results}

Braun, E., and Peacock, R. D., Fire Safety of

Passenger Trains, Material Evaluation in the Cone Calorimeter, NIST TN 1406, National Institute of Standards and Technology, July 1997. 


\section{Performance Fire Codes}

Principal Investigator

Walter W. Jones

Fire Safety Engineering Division

301-975-6887

\section{Sponsor}

National Institute of Standards and

Technology

\section{Objective}

To provide leadership in the International Council for Building Research, Studies and Documentation (CIB) and the International Building Code (IBC) that results in promoting changes to performance-based codes and standards.

\section{Problem}

The model code and national standards organizations in the United States are now moving to make the change to a performance-base. The implications for these changes are enormous and must be done in a spirit of cooperation. Two important problems with which BFRL is particularly suited to assist are developing the statement of the actual goals and objectives, and developing the engineering tools to assess building design to ascertain compliance with these goals.

\section{Approach}

During FY1997, BFRL will develop with the private codes and standards organizations new documents as part of the IBC consolidation process. At the same time $B F R L$ is leading the CIB effort in verification and uncertainty of engineering methods which will be needed to implement these new concepts. This effort will continue at least until the first U.S. performance code is published by the IBC in 1999 .

\section{Recent Results}

Bukowski, R. W., Fire Safety Engineering in the Pursuit of Performance-based Codes: Collected Paper, NISTIR 5878, National Institute of Standards and Technology, August 1996.

\section{Study of Heat and Smoke Movement and Their Influence on Detector Response in Enclosed Spaces}

\author{
Principal Investigator \\ John H. Klote \\ Fire Safety Engineering Division \\ 301-975-6890
}

\section{Sponsor}

National Fire Protection Research Foundation

General Services Administration

Public Buildings Service

Office of Real Property and Management

Federal Emergency Management Agency United States Fire Administration

\section{Objective}

To examine the effect of complex ceiling geometry and obstructions on the distribution of heat and smoke in order to optimize requirements for automatic fire detector location found in NFPA 72E and for automatic sprinklers as covered by NFPA 13, $13 \mathrm{D}$, and 13R.

\section{Problem}

Recommendations for the placement of automatic fire detectors found in the NFPA Standard on Detection Devices (72E) are based on engineering judgement or on limited experimental data. In the implementation of these data, tables and curves were developed from calculations with a zone model which are also only applicable for flat, unobstructed ceilings. Since $72 \mathrm{E}$ includes recommendations for placement of fire detectors in spaces with sloping or peaked ceilings, or with open beams and joists, some validation of these recommendations is necessary. Further, detector siting problems associated with stratification and high air movement from HVAC systems are mentioned in the standards, but only limited installation guidance is provided which are based only on judgement. 


\section{Approach}

During FYI997, BFRL will examine the space around HVAC return ducts where airactivation cold occur.

\section{Recent Results}

Klote, J. H., Forney, G. P., Davis, W. D., Bukowski, R. W., Field Modeling: Simulating the Effects of HVAC Induced Air Flow from Slot Diffuses on Detector Response, Year 4 Technical Report, NISTIR 5908, National Institute of Standards and Technology, October 1996.

\section{BACnet Support}

Principal Investigator

Richard W. Bukowski

Fire Safety Engineering Division

301-975-6863

Sponsor

National Institute of Standards and

Technology

\section{Objective}

Develop a strategy for the implementation of BACnet (Building Automation and Control Networks) by the fire alarm industry.

\section{Problem}

While BACnet is well accepted in the building controls industry, it should expand into other building systems, such as fire detection and other such systems.

\section{Approach}

During FY1997, BFRL will facilitate adoption of BACnet. This includes promotion of BACnet as a communications protocol for the fire alarm industry. Presentations were made at the Standing Task Group on New Technologies of the National Fire Alarm Correlating Committee, identifying changes needed for the 1999 edition of the NFAC to allow use of BACnet.

Recent Results

New project. 


\section{Fire Research Information Services} (FRIS)

Principal Investigator

Nora H. Jason

Fire Safety Engineering Division

301-975-6862

\section{Sponsor}

National Institute of Standards and

Technology

\section{Objective}

To serve BFRL staff and the broad BFRL user community while serving as a model for information resource management for the next century.

\section{Problem}

To collect, organize in a logical manner, and disseminate international fire literature and experimental data to the BFRL staff and the user community to capture the knowledge of the past so that it may be identified and incorporated into today's technical work thereby avoiding duplication of research.

\section{Approach}

During FY1997, BFRL will provide access to documents, data, and software electronically through the FIREDOC database and the FRIS HomePage and develop a plan to input BFRL building staff documents into FIREDOC from 1970 to the present.

\section{Recent Results}

Martin, Phyllis, M., Jason, Nora H., Editors, BFRL Publications 1995, NIST SP900,

National Institute of Standards and Technology, May 1996.

\section{Fire Forum}

\section{Principal Investigator}

Richard W. Bukowski

Fire Safety Engineering Division

301-975-6853

\section{Sponsor}

National Institute of Standards and Technology

\section{Objective}

To perform the duties of Secretary to the FORUM for International Cooperation on Fire Research

\section{Problem}

The FORUM is an international body of the Heads of fire research organizations around the world, chaired by BFRL. The FORUM represents 14 countries; they require the technical support of a person to compile minutes and ensure that assignments are followed-up between meetings.

\section{Approach}

During FY1997, BFRL, serving as the secretary will produce a meeting report for internal distribution and an annual report for general distribution. The secretary is also responsible for the dissemination of information on the FORUM and its activities to appropriate organizations and to the public through the INTERNET and printed media. The secretary also assures that assignments made at the annual meeting are completed on schedule. The secretary will also provide BFRL input to FORUM special projects on hazard evaluation of enclosure linings and international fire incident data organization.

\section{Recent Results}

Published FORUM related information for the committee members. 
RECENT GRANTS - FIRE

MODELING AND

APPLICATIONS

\section{Review and Evaluation of Thermal Sensors for Use in Testing Firefighter Protective Clothing}

\author{
Principal Investigators \\ Dr. Roger L. Barker \\ Dr. Hechmi Hamouda \\ Center for Research on Textile Protection \& \\ Comfort \\ College of Textiles \\ North Carolina State University \\ Raleigh, NC 27695-830I
}

\section{Sponsor}

National Institute of Standards and Technology

\section{Objective}

To comparatively evaluate thermal sensors used to measure heat transferred through firefighter protective clothing materials.

\section{Problem}

Thermal sensor technologies are available that can be used to measure heat transferred through firefighter protective clothing materials. Instrument readings can be translated to predict skin burn injury.

The purpose of the proposed research is to review the state of the art of these thermal sensor technologies and associated burn translation methods. This research will identify and comparatively evaluate thermal sensors and provide a detailed quantification of performance. It will ultimately result in the selection and development of a thermal analysis system that will provide the optimum utility for instrument evaluation of the thermal protective performance of firefighter protective clothing, in laboratory and in field exposures to fire hazards.

\section{Approach}

A review of available literature pertinent to thermal sensors, as well as methods and criteria used to translate thermal readings into skin burn damage has been conducted. Special emphasis has been given to investigations and studies dealing with measurement of thermal protective clothing systems performance both in laboratory and field tests.

The primary focus of the initial sensor development phase of this project has been on the adaptation and validation of a calorimeter type system developed at NCSU mainly for use in thermal manikins. The NCSU sensor can potentially overcome many of the drawbacks associated with other thermal sensory devices, including heat loss during exposure. It does not rely on reverse heat transfer calculations to estimate incident heat flux. This avoids errors associated with thermocouple location, and the mathematics of the heat transfer calculation. Direct heat flux measurement, using the NCSU calorimeter sensor, should circumvent these errors and provide a more accurate direct reading.

The response of the NCSU calorimeter and other thermal sensors, is being evaluated to establish an initial basis for performance comparisons. Various burn translation models, and associated mathematics are being compared, including translations based on Stoll and Henrique criteria. Laboratory experiments are being performed to determine the effect of the thermal; exposure duration and intensity on the sensor response, and resulting burn predictions.

Based on results obtained in the evaluation phase of this project, a sensor and translation criteria predicting skin burn damage, will be specified. Design modification of the sensor and the translation criteria will also be addressed and detailed when they may be required for field testing.

The final phase of this project will involve detailed quantification of the selected sensor, or sensors, performance. This phase will involve extensive evaluation by NCSU as well as multi-lab evaluation, which will include 
work with NIST and potentially other selected labs.

\section{Recent Results}

Several thermal sensor technologies and associated burn translation methods have been reviewed. This information has been summarized in a comprehensive literature review of sensor technologies for evaluating the thermal protective performance of firefighter protective clothing. Five different state-of-the-art thermal sensors have been identified and laboratory experiments are now underway to comparatively evaluate their performance. The performance range of each candidate sensor is being quantified based on exposures to a laboratory heat source. Laboratory experiments are providing the basis for developing performance criteria for each sensor, and for comparative evaluation based on heat flux tolerance, response time and thermal sensitivity. Thermal leakage, in prolonged heat exposures, is also being assessed for each of the five types of sensors. Integration of burn translation models and sensor performance capabilities is currently being evaluated. A thermal analysis system is being developed that will facilitate and optimize the ultimate integration of sensor instrumentation with burn prediction algorithms.

\section{Enhanced PC-Based Building Fire Assessment System}

\author{
Principal Investigator \\ Edward K. Budnick, P.E. \\ Hughes Associates, Inc. \\ 410-737-8677

\section{Sponsors \\ National Institute of Standards and Technology \\ U.S. General Services Administrative \\ Office of Real Property Management.} \\ Public Building Services
}

\section{Objective}

To develop a PC-based version of the current Fire Safety Evaluation System for office occupancies and integrate selected quantitative methods that will enable engineers to perform detailed fire hazard, risk equivalency, and cost optimization analyses for existing or planned buildings.

\section{Problem}

The need to accurately measure fire risk impact and estimate costs of different fire safety strategies on levels of fire safety in individual buildings is essential to achievement of an overall building risk management philosophy. Limitations in current prescriptive requirements represent significant inhibitions to needed design flexibility and general usefulness. There is a growing need among building owners, local code authorities, and design engineers about the availability of quantitative methods to evaluate building fire safety within a broad, risk-based context which permits examination of "equivalent" alternatives.

\section{Approach}

This effort is being conducted in three phases. Phase I was completed in FY1995 and involves development of a PC-based version of the NFPA-FSES for business occupancies. This program was developed using the Microsoft Visual $\mathrm{C} / \mathrm{C}++$ Windows ${ }^{\circledR}$ development platform and is fully compatible with the normal Windows ${ }^{\circledast} 3.1$ 
environment. It contains explanatory text to assist the user in selecting the correct parameter conditions and uses visual prompts to guide the user through the FSES method.

Phase II will be completed in FY1997 and is directed at enhancing the FSES methodology (EFAS) to allow quantitative assessment of in situ configurations and comparison of design options. The primary emphasis of this phase will be to enable the program user to develop realistic fire heat release rate curves for a space or building under consideration. Several methods are available for this, including basic fuel load-ventilation correlations, fire growth curves, and existing computer models such as ASET or CFAST. Computer models such as CFAST are readily embedded within the $\mathrm{C} / \mathrm{C}++$ source code and may be accessed directly from the EFAS program shell.

Once a user has successfully developed a fire scenario for the space, several algorithms become available to assist in evaluating the appropriate response to the FSES parameters, compare spaces to identify worst case/critical locations within a structure, or estimate the overall risk benefit of various fire safety improvements. Many of the algorithms under consideration for this task are contained within the FPETOOL package and include egress calculations, sprinkler response, flashover estimates, and smoke movement.

Secondary goals in Phase II include assigning quantitative meaning to the relative risk scores obtained in the FSES methodology, enabling the user to make modifications within a parameter, keep track of the added benefit relative to other modifications, and convert the program to a Windows ${ }^{\circledR}$ 95/NT environment while maintaining backwards compatibility with Windows ${ }^{\circledR} 3.1$ environments.

Phase III will attempt to integrate the results and methods developed in the initial phases into a computerized risk management program.

\section{Recent Results}

Hughes Associates, Incorporated, Fire Safety Evaluation System (FSES) for Business Occupancies Software (Version 1.0 for Windows ${ }^{\circledR}$ ) Users Manual, NIST-GCR-96-692, National Institute of Standards and Technology, March 1996. 


\section{Evaluation of Alternative Methods for Fire Rating Structural Elements}

\author{
Principal Investigator \\ Robert J. Dexter, Ph.D. \\ Center for Advanced Technology for Large \\ Structural Systems \\ Lehigh University \\ 610-758-6108
}

\section{Sponsor}

National Institute of Standards and Technology

\section{Objective}

To evaluate current computational methods for assessing the integrity of structures exposed to fire and to develop practical tools for analysis in support of economical fire-safe construction.

\section{Problem}

The current U.S. Standard is ASTM E1 19, but this document has several disadvantages. The primary disadvantage is that the temperature-time history of a real fire in a building is much less severe than the temperature-time history prescribed in ASTM E1 19. However, there are also at least three reasons why the performance of a column in a building would be expected to vary significantly from the fire rating by ASTM El 19, even if the column were subjected to the ASTM El 19 temperaturetime history.

First, ASTM E 19 allows for two rating options for building columns, furnace testing with simultaneous column load, and, furnace testing without simultaneous load. With the no-load option, the criterion for failure is the attainment of a critical temperature on the surface of the column. The United States does not have furnace test facilities capable of carrying out a furnace test of a column under load. Consequently, all ASTM E1 19 column ratings determined in the United States follow the no-load option. However, test data from other countries show that the time to failure of a column may vary as much as
30 percent from the time to attain the critical temperature.

Second, for a variety of reasons, structural elements in buildings are not usually loaded to anywhere near their maximum allowable limits. However, despite the expected level to which individual elements are actually loaded, present building codes would typically require like structural elements to have the same ASTM El 19 rating.

Finally, the structural responses of the individual structural elements are dependent on their end constraints, which: 1) are strongly coupled to the response of the overall structure; and, 2) can have a major impact on element load-bearing capability.

Clearly, computational thermal and structural analyses can provide a means of addressing and resolving these issues. Computational methods may eventually provide an alternative to the ASTM El 19 method for fire rating structural elements.

\section{Approach}

The approach is to evaluate computational methods for advancing accepted U.S. methods of evaluating the fire performance of structures. This 2-year level of effort will review the range of possible approaches, from simple calculations to sophisticated numerical simulation, and gain competence with and apply at least one computer program. As for numerical simulations, ATLSS acquired and installed the specialized computer program SAFIR, developed by J-M. Franssen of the University of Liege, for simulating the thermal and structural response of fire-exposed structures.

Initial applications of SAFIR involved simulating the response of columns subjected to ASTM El 19 furnace fire tests. This study included simulations of furnace tests of axially loaded concrete-filled steel tubes and steel I-sections with and without insulation. The level of natural variability of the results of tests on like specimens was established. The computed results agree with the experimental results with an accuracy about 
the same as this natural variability. This initial SAFIR effort established the feasibility of using a computational approach to determine ASTM E1 19 ratings as a possible alternative to full furnace testing. Further work is required with this promising approach in order to: 1) instill confidence in the U.S. building-code-making and -using community that a calculation-based ASTM E119-type method of determining fire resistance is a reliable alternative to the recognized ASTM E1 19 furnace test method; and, 2) develop a plan to develop this alternative to the point that it is recognized and adopted.

In the second year, ATLSS will: 1) assist Dr. Franssen in the further development of SAFIR to become more user friendly and versatile; 2) perform further analysis on concrete filled tubes; 3 ) explore the potential advantages of fire-resistant steel; 4) simulate response of prestressed concrete structures under load, and 5) evaluate the effects of various fire scenarios on continuous structures.

At the conclusion of the two year program, the scope of the work necessary to complete the development of an advanced, calculation-based, fire-resistance rating system will be clearly defined. This work will include 1) the expanded use of thermal and structural analysis simulations to include evaluation of the fire performance of structural elements to fire environments other than the ASTM E119 standard fire, i.e., to real fire environments; and, 2) evaluation of the fire performance of entire structures, e.g., steel-framed buildings with composite floor slabs, first when exposed to the standard fire environment, and then to real fire environments.

\section{Recent Results}

Gilvery, K. G., and Dexter, R. D., Evaluation of Alternative Methods for Fire Rating Structural Elements, NIST-GCR-97-718, prepared by Lehigh University for National Institute of Standards and Technology, May 1997.

\section{Assessment of the} Technological Requirements for the Realization of PerformanceBased Fire Safety Design in the United States - Phase I: Fundamental Requirements

\author{
Principal Investigator \\ Brian J. Meacham, P.E. \\ Technical Director \\ Society of Fire Protection Engineers \\ Sponsor \\ National Institute of Standards and \\ Technology \\ General Services Administration \\ Public Buildings Service \\ Office of Real Property Management
}

\section{Objective}

To assess the availability and applicability of fire safety engineering tools and design methodologies for use within a performancebased approach to building and fire safety design.

\section{Problem}

Performance-based fire safety design methods are being used or developed in many parts of the world. The based of several of these methods are the many fire engineering tools and methods developed in the United States. Unfortunately, these tools and methodologies are not being widely applied within the United States. There are many reasons for this, including the lack of performance-based fire and building codes in general use, and, where there are such codes or regulations, the lack of documentation on the availability and application of credible fire safety engineering tools and methodologies for fire safety design.

\section{Approach}

The first task will be to determine what is meant by "a performance-based approach" to fire safety design as it relates to the fire protection community in the United States. This will include identification of acceptable terminology and definitions and an outline of 
an approach (thought process) that can serve as a framework for applying quantitative fire protection analysis and design tools in the United States.

The next step would be to identify and inventory the efforts related to performancebased fire safety design approaches worldwide and evaluate their applicability to the United States. Although summaries of many of the existing methods have been published recently, they have not included significant evaluations of their applicability in the United States.

The inventory and evaluation process will examine work underway in the countries of Australia, Canada, New Zealand, Sweden, the United Kingdom, the United States and any others identified during the identification stage. It will also include projects being undertaken by international organizations such as the Conseil International du Batiment (CIB) and the International Organization on Standardization (ISO).

\section{Recent Results}

Meacham, B.J., "Assessment of the Technological Requirements for the Realization of Performance-Based Fire Safety Design in the United States, Phase I: Fundamental Requirements," Society of Fire Protection Engineers, January 1997.

Meacham, B.J., The Evolution of Performance-Based Codes \& Fire Safety Design Methods," Society of Fire Protection Engineers, August 1996.

\section{Interactive Virtual Environments for Fire Simulation}

Principal Investigator

Carlo H. Sequin, Ph.D.

Computer Science Division, EECS

Department

University of California, Berkeley

Berkeley, California 94709

\section{Sponsor}

National Institute of Standards \& Technology

\section{Objective}

To combine Berkeley virtual reality architectural walkthrough technology with NIST CFAST fire simulation technology, providing simulation and scientific visualization of the CFAST model within a real-time, interactive virtual environment.

\section{Problem}

Virtual reality techniques developed at Berkeley over the last 5 years provide intuitive, real-time visualization and interaction with conditions and structures in heavily occluded architectural environments. NIST's CFAST fire simulation software provides fast, accurate computation of conditions within buildings in fire situations, but lacks the ability to interactively construct simulation scenarios or to directly visualize results in $3 \mathrm{D}$. A marriage of these technologies will bring interactive 3D visualization to fire simulation. This will provide immediate benefits in translating real-life scenarios into computer models, as well as converting the results of those computer models into easily understood visualizations of simulation conditions. In the longer term, this combination of technologies has great potential in firefighter training and performance-based standards for building design.

\section{Approach}

In the first two years of this project, our emphasis was on bringing CFAST and WALKTHRU together so that CFAST could run a simulation while basic elements such as 
fire size and interface height were visualized in the WALKTHRU environment. Although the two systems operate on conceptually similar models of the world (i.e. a "cell-and-portal" structure), the specifics of the implementations are sufficiently different that our efforts for the first few years will involve running the two programs on parallel, but separate world models. WALKTHRU provides the front end for interaction with and visualization of the virtual world, and CFAST provides the engine by which environmental conditions in the virtual world are updated. We currently have a working, integrated system in which CFAST and WALKTHRU work side-by-side in this fashion, on a pair of models which are input separately; one CFAST model containing the fire scenario, one WALKTHRU model containing the detailed world geometry, and a "registration map" which allows the two programs to relate their models of the world. We have developed a system in which these registration maps can be created automatically when the database is initially generated from AutoCAD floorplans.

A major portion of the work involves the creation of building models appropriate for fire simulation. The world geometry required by CFAST is a strict subset of the viewing geometry required by WALKTHRU, so it is possible to automate or assist the user in creating CFAST geometry from a WALKTHRU model. 3D building model generation is a difficult and insufficiently studied task; a large part of our research contribution will be to develop techniques by which usable 3D models of interesting environments can be generated either by hand, interactively, and/or by automated processing of CAD floorplan information. This work will allow rapid and accurate creation of the environmental geometry which is needed for any simulation or visualization to take place. The Building Model Generator (BMG), which automatically generates a WALKTHRU model and its corresponding registration map from an AutoCAD floorplan, is a first step toward this goal. BMG corrects common modeling errors and generates a complete 3D model with little or no human intervention, reducing the time required to model a building by two to three orders of magnitude.

Our work thus far has resulted in the ability to take a normal CFAST fire scenario and visualize the fire size, plume, and interface heights within the environment in real time. The viewer can visualize the fire with realistically texture-mapped flames, smoke, and plumes. During 1997/98, we will develop techniques for visualizing the other spatial quantities that result from the simulation in the 3D environment, such as heat levels and gas concentrations. All these quantities should be displayed in a visually plausible manner in the 3D WALKTHRU environment, rather than as separate 2D density plots or graphs.

We will concentrate our efforts on enhancing the interface required to allow users to generate and modify fire simulation scenarios interactively from within the virtual environment and then observe the results of the simulation in a visually informative manner and as close to real-time as possible. The user will be able to set a fire by entering a room within the WALKTHRU program and selecting a wastebasket or chair to begin burning, rather than juggling numbers and codes in a text file. We will also try to make the environment interactively modifiable; for example, we would like the user to be able to open doors and windows and see the effect on the course of the fire scenario in progress in real time. However, this will require enhancements to the CFAST fire simulator that are beyond our own control.

Once these techniques are fully developed and integrated, non-specialist users will be able to quickly and easily create a complete, highly accurate geometric model of an architectural environment from computer-readable floorplans. From within the model, they will be able to interactively set up simulations and watch the results unfold spatially and intuitively in real time. They will also be able to change some building parameters, such as the density of sprinkler heads, and study the effectiveness 
of such measures.

\section{Recent Results}

Bukowski, R. W. and Sequin, C. H., "Interactive Simulation of Fire in Virtual Building Environments," SIGGRAPH, 1997.

\section{An Analysis of Performance Requirements for an International Building Code}

Principal Investigator

Charles W. Van Rickley

Van Rickley and Associates

Sponsor

National Institute of Standards and Technology

\section{Objective}

To support and enhance the Building and Fire Codes in the United States by examining the currently adopted codes in relation to their ability to be merged into one code and being converted from a Prescriptive to a Performance-Based format.

\section{Problem}

The United States is moving rapidly in the direction of a single national model building code. Three different model codes presently exist and are available for use. One or the other of these codes is adopted by nearly every community in the United States. Not infrequently, more than one code is adopted within a single state, or among neighboring communities. This causes confusion among building owners and the building community and frequently causes unnecessary costs.

A second movement is to change from a Prescriptive to a Performance-Based Code. Prescriptive Codes seldom identify their underlying purpose, goals or objectives. The lack of goals or measurable objectives frequently prohibit the acceptance of new technology as an equivalent to prescribed protection. This creates serious hardships when attempting to utilize new or innovative building design or construction methods.

\section{Approach}

The first year focuses on supporting the development of a single International Building Code and the transition form a Prescriptive to a Performance-Based Code format by: 
a) Assembling a research and study group of key code officials, representatives of code and standard development groups and related technical organizations.

b) Reviewing the regulations applied to various building occupancy or use groups, to identify and define the basic goals and objectives.

c) Seeking consensus of the goals and objectives, once defined, by key code officials, code and standard development groups and related technical organizations.

d) Attempting to develop the accepted goals and objectives into statements in a format acceptable for submittal as proposals for model code adoption.

e) Maintaining a positive relationship with all the existing model code and standard publishers throughout the course of the project by continuous communication and interaction in each of their code and standard development processes.

\section{Recent Results}

The Performance Advisory Group was formed with approximately 75 participants representing Code Officials, Design Professionals and Building Industry Representatives.

A workshop was conducted, with an attendance of 65 persons, to enlighten Building Officials, Design Professionals and Building Industry Representatives on the concept of a Performance-Based system.

The Performance Advisory Group Leader is a participant and an Ex-Officio member of the International Building Code, Performance Code Committee, providing group input into the Performance Code development process.

\section{Related Grants}

Meacham, B., and Lucht, D., "Assessment of the Technological Requirements for the Realization of Performance-Based Fire Safety Design in the United States," Society of Fire Protection Engineers, 1996.

\section{Evaluation of the HDR Fire Test Data and Accompanying Computational Activities with Conclusions from the Aspects of Present Code Capabilities}

\author{
Principal Investigator \\ Lothar Wolf, Ph.D. \\ Nuclear Engineering Program \\ Department of Materials and Nuclear \\ Engineering \\ University of Maryland at College Park
}

\section{Sponsor}

National Institute of Standards and Technology

\section{Objective}

To provide fundamental information about the design and performance of fire experiments in the HDR containment building in Karlsruhe, Germany. To assess the performance of the NIST fire code CFAST in modeling the fire experiments and provide insights towards the goal of improving computational capabilities.

\section{Problem}

The U.S. fire community lacks large scale experimental data from large, complex, multiple level, industrial structures. This creates a difficulty in evaluating the performance of fire codes in modeling fires in complex structures. Providing information about the experiments in the HDR facility will improve the code evaluation capability of U.S. fire researchers.

\section{Approach}

The experiments performed in the HDR facility included propane gas, wood crib, oil pool, and cable fires. Tests were performed in specially constructed rooms with the facility and with the exception of the cable fires were allowed to involve the entire $60 \mathrm{~m}$ height and $10000 \mathrm{~m}^{3}$ volume of the HDR containment building. A total of four test locations located at different elevations with the building were used. 
The emphasis on this first year of the project is to provide documentation on a series of 11 propane fires performed at the HDR facility and to perform computations of selected tests with CFAST. These fires are relatively low in power as compared to other tests performed, maximum power of 1.2 MW, but they have well known boundary conditions which is an important consideration when using experimental data to validate a computer code.

The documentation will provide a description of the facility's compartments and their interconnections, the experimental timeliness, instrumentation mappings, types of sensors used, a summary of integral and local tests results, and a discussion on key fire safety parameters for code evaluation that are obtainable from the data. CFAST computations will assess the overall performance of CFAST as well as provide an assessment of the affect of modeling decision.

Future work will provide documentation on the remaining tests groups performed in the HDR, perform further comparisons of CFAST to experimental data, and provide an evaluation of applying nuclear industry safety codes to modeling fires in complex structures.

\section{Recent Results}

Floyd, J., Wolf, L., and Krawiec, J., "Evaluation of the HDR Fire Test Data and Accompanying Computational Activities with Conclusions from Present Code Capabilities, Vol. 2: CFAST Validation for T51 Gas Fire Test Series," NIST Contract 60NANB6D0127, Nuclear Engineering Program, Dept. of Materials and Nuclear Engineering, University of Maryland, College Park, MD, October 1997.

Floyd, J., Wolf, L., and Krawiec, J., "Evaluation of the HDR Fire Test Data and Accompanying Computational Activities with Computational Activities with Conclusions from Present Code Capabilities, Vol. I, Test Description for T5 1 Gas Fire Test Series," NIST Contract 60NANB6D0127, Nuclear Engineering Program, Dept. of Materials and Nuclear Engineering, University of Maryland,
College Park, MD, September 1997.

Wolf, L., and Floyd, J., "Large Scale Fire Experiments in the HDR Containment," 1997 ASME National Heat Transfer Conference, Baltimore, MD, pp. 69-79, August 10-12, 1997.

Floyd, J., and Wolf, L., "Comparison of Measured Data from the HDR-T5 I Gas Fire Tests to Predictions Made by CFAST," 1997 ASME National Heat Transfer Conference, Baltimore, MD, pp. 80-86, August 10-12, 1997.

Floyd, J., and Wolf, L., "Comparisons of Measured Data from the HDR-T51 Gas Fire Tests to Predictions Made by CFAST," 2nd International Conference of Fire Research and Engineering (ICFRE-2), Gaithersburg, MD, August 10-13, 1997.

Floyd, J., and Wolf, L., "Modeling of the HDR-T5 I Gas Fire Tests Using CFAST vol.3," 5th International Conference on Nuclear Engineering (ICONE-5), Nice, France, May 26-30, 1997. 



\section{FIRE SAFETY ENGINEERING}

DIVISION

LARGE FIRE RESEARCH 



\section{In-situ Burning of Oil Spills}

\author{
Principal Investigator \\ William D. Walton \\ Fire Safety Engineering Division \\ 301-975-6872
}

\section{Sponsor \\ Department of Interior \\ Minerals Management Service, \\ Department of Transportation \\ U.S. Coast Guard, and}

State of Alaska

\section{Objective}

To determine conditions where in-situ burning can be used effectively as a response method to accidental spills of crude oil on land and on water.

\section{Problem}

In support of other agency objectives to carry out burning as a response method to oil spills, predictions are needed to assess the impact of the smoke plume produced by burning on downwind locations. BFRL's Large Eddy Simulation (LES) model continues to gain acceptance for use in planning in-situ burns although there has been limited verification. There is a need for predictions that take into account the effect of local terrain features such as mountains. Further, the spill response planning community has shown a strong interest in using the LES model as a planning tools.

One of the most significant remaining obstacles to the acceptance of burning as a spill response technique is the lack of a standard method for evaluating a fire resistant oil spill containment boom. To develop a test method, knowledge of the thermal exposure conditions and physical stresses that the boom is expected to be exposed to, must be determined.

\section{Approach}

During FY1997, BFRL developed two versions of the ALOFT model. The first,
ALOFT-FT, is for flat terrain, and the second, ALOFT-CT, accommodates complex terrain such as mountains. An implementation of ALOFT-FT with a graphical user interface for personal computers, ALOFT-FT-PC has been developed. The program is presently undergoing Beta testing and the user guide is being developed. While the Beta version accommodates a single fire, multiple fires will be added later in the year. ALOFT-CT is being developed for workstations and a GUI interface for personal computers is planned next year. ALOFT verification measurements are planned on burns of opportunity.

In order to characterize the thermal exposure conditions on fire resistant boom, a series of experiments have been conducted to measure the exposure to boom from a characteristic spill fire. The results of these experiments have been analyzed. The results of a series of propane fueled burn experiments have been published and a plan for the future development of a boom test method has been developed. Experiments with the boom test method are planned for FY1998.

\section{Recent Results}

McGrattan, K. B., "Smoke Plume Trajectory from In-Situ Burning of Crude Oil: Complex Terrain Modeling," Proceedings, Twentieth Arctic and Marine Oilspill Program Technical Seminar, Vancouver, B.C., June 1997.

Walton, W. D., Twilley, W. H., and Mullin, J. V., "An Evaluation of Propane as a Fuel for Testing Fire-Resistant Oil Spill Containment Booms," Proceedings, Twentieth Arctic and Marine Oilspill Program Technical Seminar, Vancouver, B. C., June 1997.

McGrattan, K. B., Baum, H. R., Walton, W. D., and Trelles, J. J., Smoke Plume Trajectory from In-Situ Burning of Crude Oil in Alaska: Field Experiment and Modeling of Complex Terrain, NISTIR 5958, National Institute of Standards and Technology, January 1997. 


\section{Demonstration of Water Based Fire Fighting Agents}

\author{
Principal Investigator \\ Daniel Madrzykowski \\ Fire Safety Engineering Division \\ 301-975-6677
}

\section{Sponsor}

Federal Emergency Management Agency

U.S. Fire Administration

\section{Objective}

To develop methods for demonstrating biodegradable, environmentally safe, nontoxic fire suppression liquids which are effective on Class A, B and many D fires.

\section{Problem}

Water based fire fighting agents have been used for many years to enhance the fire fighting capabilities of ordinary water. The most widely used of the water based agents are the foams for use on Class B fires. Agents designed primarily for Class A fires have been used most extensively in conjunction with wildland fires. More recently these agents have been promoted for use on a wider range of Class A and in some cases Class B and D fires. These agents are frequently advertised as more effective than plain water while being environmentally safe. In some cases they are also claimed to reduce the quantity and toxicity of smoke.

There are a number of commercially available water based fire suppression agents designed primarily for Class A fires. Generically these agents can be classified as surfactants which reduce the surface tension of water, potentially modifying the fire fighting capabilities. There are standards for assessing these agents, however most of the criteria do not address the fire fighting (protection/suppression) capabilities of the agent. This is particularly true for Class $\mathrm{A}$ and Class $D$ fires. An evaluation protocol is needed to measure the fire fighting capability of an agent and to relate its performance to plain water or another agent in a given situation. This would enable the fire protection community to select the most cost effective fire suppression agent(s) to fit their specific needs, thus optimizing utilization of their resources.

The use of water based firefighting agents raises the question of potential health and environmental effects. First is the exposure of fire fighters to the agent itself and the products of combustion produced when using the agent. Second is the impact as agent run-off enters the environment. These issues have generally been addressed with standard toxicity and environmental impact tests, although a complete series of these tests has not been performed even for the most commonly used agents

\section{Approach}

During FY1997, BFRL will perform four tasks:

1. Conduct a workshop with users, manufacturers and researchers of biodegradable, environmentally safe, nontoxic fire suppression liquids.

2. Collect information on agents which are considered by their manufacturer to be biodegradable, environmentally safe, nontoxic fire suppression liquids which are effective on Class A, B and many D class.

3. Develop methods as required and assess the biodegradability, environmental safety, toxicity and physical properties of a limited number of water based fire fighting agents.

4. Develop methods as required and demonstrate the fire fighting effectiveness of a limited number of water based fire fighting agents for Class A, B and D fires.

\section{Recent Results}

Johnson, C. W., and George, C. W., Wildland Fire Foam Characterization, USDA Forest

Service Intermountain Fire Science

Laboratory, Missoula, MT, May 1997.

Class B Fire Tests of Biodegradable, Environmentally Friendly, Non Toxic Foam Fire 
Fighting Agents, Report No.

6180/0240A.1:JTL, Naval Research

Laboratory, Washington, DC, April 1996.

Report of Magnesium Chip Fire Tests Utilizing

Biodegradable, Environmentally Safe, Nontoxic,

Liquid Fire Suppression Agents, Project \#

95NK22435/NC 3067, Underwriters

Laboratories, Northbrook, IL, October 1995.

\section{Quantitative Evaluation of Fire Safety Features}

Principle Investigators

David Evans

Fire Safety Engineering Division

301-975-6863

Kevin McGrattan

Fire Safety Engineering Division

301-975-2712

Howard Baum

Fire Safety Engineering Division

301-975-6668

Anthony Hamins

Fire Safety Engineering Division

301-975-6598

Sponsor

National Institute of Standards and

Technology

\section{Objective}

To develop and verify methods to predict the performance of fire safety technologies.

\section{Problem}

There is a need to meet the requirement of future performance based designs by using reliable means to evaluate alternative active and passive fire safety features for buildings.

\section{Approach}

During FY1997, BFRL will develop and verify means to predict the performance of existing practices and lay the technical foundations to evaluate the performance of future technologies. The emerging computational technology of large eddy simulations and its application to the problem of determining the interaction of industrial sprinklers with draft curtains and heat and smoke vents have been selected as an initial demonstration of advanced fire safety analysis. Computations with the large eddy simulation (LES) model of a standard rack storage commodity fire will be used to design large scale tests involving sprinklers, draft curtain, and vents. Under support from 
the National Fire Protection Research Foundation (NFPRF) these large scale tests will be performed in a non-BFRL facility to verify the modeling and develop a data base of full scale fire data.

In order to develop an accurate predictive method auxiliary studies of (1) the burning rate of the standard commodity both with and without water application, and (2) measurement of industrial sprinkler spray characteristics will be performed. Results from this work are likely to result in better performing and cost effective fire protection system designs for warehouse and manufacturing facilities. Laboratory space will be developed in BFRL's fire facility to conduct verification tests of LES model fire flow predictions in geometrically complex spaces. This facility will also serve as a site for fire flow visualization experiments and a platform for intermediate scale evaluation of fire measurement methods. Future assessments of industry needs will indicate priorities for investigations of other fire protection features which may include mist suppression systems, smoke control, smoke detectors, heat detectors, fire resistance of partitions and emerging fire safety technologies developed by BFRL and others.

\section{Recent Results}

Mell, W., Baum, H. R., and McGrattan, K. B., "Simulation of Fires with Radiative Heat Transfer," Proceedings, ICFRE2, Gaithersburg, MD, August 1997.

Baum, H. R., McGrattan, K. B., and Rehm, R. G., Large Eddy Simulations of Smoke Movement in Three Dimensions, NISTIR 6030, National Institute of Standards and Technology, June 1997.

McGrattan, K. B., and Stroup, D. W., "Sprinkler, Vent, and Draft Curtain Interaction: Experiment and Computer Simulation," Proceedings, ICFRE 1, Gaithersburg, MD, August 1997.

\section{Office Building Fire Research Program}

\author{
Principal Investigator \\ Daniel Madrzykowski \\ Fire Safety Engineering Division \\ 301-975-6677
}

\section{Sponsor}

General Services Administration

Public Buildings Service

Office of Property Management and Safety

\section{Objective}

To quantify the impact of large fires on buildings and their occupants, and investigate the use of current technology and resources for mitigating the hazards.

\section{Problem}

Systems furniture or "work stations" have been identified as a source of large heat release rate fires in office buildings. Because of the wide spread use of systems furniture, the potential fire hazard in an open plan office environment needs to be quantified. The means of egress in a long corridor adjoining the fire compartment needs to be determined. If the fire cannot be suppressed in the room of origin, information about the impact that sprinklers have on the smoke flow in the corridor is needed. While the impact of sprinklers has been demonstrated in BFRL experiments, it has not been included in the corridor flow model due to insufficient databases.

\section{Approach}

During FY1997, BFRL will conduct large scale experiments on the effects of obstructed ceiling flows on sprinkler activation will be conducted. Experimental results will be compared with the current capabilities of FPEtool.

\section{Recent Results}

Madrzykowski, D., "Office Work Station Heat Release Study: Full Scale vs. Bench Scale," Proceedings, INTERFLAM '96, Cambridge England, March 1996. 


\section{Modification of Fire Protection Requirements for NRC}

\section{Principal Investigator}

David W. Stroup

Fire Safety Engineering Division

301-975-6564

\section{Sponsor}

U.S. Nuclear Regulatory Commission

Office of Nuclear Regulatory Research

\section{Objective}

To support the Nuclear Regulatory Commission (NRC) in developing a new "rule" that will permit utilities to use performance-based methods to design fire protection provisions for nuclear power plants.

\section{Problem}

Current regulation is based on Appendix $\mathrm{R}$ of 10 CFR 50 which is prescriptive.

\section{Approach \\ During FY1997, BFRL will provide technical assistance to the NRC in the preparation of documents supporting the implementation of performance-based fire safety regulations for nuclear power plants.}

\section{Recent Results}

Provided letter reports to the sponsor.

\section{Firefighter Thermal Environments and Protective Clothing and Equipment Performance}

\author{
Principal Investigator \\ James R. Lawson \\ Fire Safety Engineering Division \\ 301-975-6676
}

\section{Sponsor \\ National Institute of Standards and \\ Technology and}

\section{Federal Emergency Management Agency \\ U.S. Fire Administration}

\section{Objective}

To develop measurement equipment and techniques for the evaluation of thermal environments experienced by firefighters while conducting fire suppression and rescue tasks and the performance of the firefighters protective clothing, while conducting fire suppression and rescue tasks.

\section{Problem}

Firefighters' protective clothing and equipment has seen significant performance improvements over the last few decades; however, thousands of firefighters continue to be burned each year. In addition, firefighters are suffering from heat stress which has an impact on their job performance and health. The apparatus presently used to measure the performance of firefighter clothing can only subject the clothing to fire exposures created in the laboratory.

\section{Approach}

During FY1997, BFRL will obtain input from the fire service and protective clothing equipment manufacturers to identify special needs of firefighters and industry. A standard methodology is being developed to make appropriate measurements and to calculate the thermal properties and performance of firefighters' protective clothing when exposed to a range of thermal and moisture environments. Computer models are being developed to predict the heat flow through 
protective clothing and to predict the stored energy in the clothing. A portable wireless instrumentation package is being developed to measure fire fighting environments.

\section{Recent Results}

Lawson, J. R., and Jason, N. H., Editors, Firefighter Thermal Exposure Workshop: Protective Clothing, Tactics, and Fire Service PPE Training Procedures, NIST SP 911, National Institute of Standards and Technology, February 1997.

Lawson, J. R., Fire Fighter's Protective Clothing and Thermal Environments of Structural Fire Fighting, NISTIR 5804, National Institute of Standards and Technology, August 1996.

\section{Participation in Non-Project Committees and Standards}

\section{Principal Investigator}

David Evans

Fire Safety Engineering Division

301-975-6863

\section{Sponsor}

National Institute of Standards and

Technology

\section{Objective}

To provide support for technical committee and standards group meetings not otherwise part of the fire program technical project effort.

\section{Problem}

There is a need to maintain a continuing relationship with organizations and technical efforts in fire community.

\section{Approach}

During FY1997, BFRL will provide resources for leadership in technical efforts that are not always aligned with specific technical projects underway, but nevertheless are important to the over success of the fire program mission. This project provides partial support for staff to participate in activities that are not otherwise covered as part of the technical program activities. The choices for support are expected to differ somewhat from year-to-year as the priorities and funding opportunities change.

\section{Recent Results}

No publications published to date. 
Large Fire Research Facility

\author{
Principal Investigator \\ Nelson Bryner \\ Fire Safety Engineering Division \\ 301-975-6868
}

\section{Sponsor \\ National Institute of Standards and Technology}

\section{Objective}

To perform large scale fire experiments in a safe and efficient manner. Provide large fire measurement capabilities to meet the needs of industry and government customers.

\section{Problem}

Use of BFRL's large fire research facility must be scheduled for timely performance of experimental programs. Modernization of equipment and facilities is required to address issues of environmental and work place safety.

\section{Approach}

During FY1997, BFRL will continue to provide daily management of the Large Fire Research Facility, including the scheduling of tests and their timely execution, along with the gradual modernization of equipment and facilities. Short term improvements will be developed and executed during the year. Plans for a new emissions control systems to assure full compliance with environmental requirements at BFRL are being developed.

\section{Recent Results}

Two new heat release rate calorimeters were designed and constructed. The smaller calorimeter is designed for $50 \mathrm{KW}$ capacity and the new furniture scale calorimeter has a capacity of $1 \mathrm{MW}$.
RECENT GRANTS - LARGE FIRE RESEARCH

\section{Characterization of Sprinkler Sprays and Their Interaction with Fire Induced Flows}

\author{
Principal Investigator \\ Arvind Atreya, Ph.D. \\ Department of Mechanical Engineering \\ and Applied Mechanics \\ University of Michigan
}

\section{Sponsor \\ National Institute of Standards and Technology}

\section{Objectives}

To develop an appropriately scaled (laboratory-scale) sprinkler to simulate warehouse-scale sprinkler-fire interactions, provide high resolution, large-scale planar data for validation of field models of sprinkler fire suppression, (a) Drop size distribution produced by the scaled pendent sprinkler head under various water flow rate conditions, (b) Droplet velocities in the presence and in the absence of a fire, (c) Sprinkler and fire induced gas velocities, and (d) Actual delivered water density to the burning surface.

\section{Problem}

An optimum sprinkler system, for a given application, is one that provides the maximum fraction of water delivered by the sprinkler (or sprinklers in a large warehouse) to the burning surfaces and suppresses the fire in the shortest time after its initiation. The design of such a sprinkler system depends on the geometrical relationship between the sprinkler(s) and the fire source, the heat release rate of the fire and the sprinkler spray characteristics. To save the expense and complexity of full-scale experiments currently needed for just evaluating sprinkler systems for different fire configurations (never mind optimization), computer models are needed. This project provides both data for experimental 
validation of computer models and results of scaled experiments.

\section{Approach}

Well-instrumented, laboratory-scale (2 m x 2 $\mathrm{m} \times 2 \mathrm{~m}$ ) experiments are being performed using a scaled pendent sprinkler head.

High-resolution, large-scale PIV measurement capability has been developed for making measurements. The following four sets of experiments are being conducted:

1. Experiments for characterizing the sprinkler sprays without the fire plume.

2. Experiments for characterizing the fire induced flows.

3. Experiments for studying the interaction of the sprinkler sprays with the fire plume.

4. Experiments with asymmetrically placed fire plumes with respect to the sprinkler spray.

These experiments will provide the following data for validation of theoretical models of sprinkler fire suppression:

a) Droplet size distribution produced by a scaled pendent sprinkler head under various water flow rate conditions. This data will be provided at all locations of the spray envelope both in the presence and in the absence of a fire.

b) Droplet velocities at all locations of the spray envelope both in the presence and in the absence of a fire.

c) Sprinkler and fire induced gas velocities in the sprinkled volume.

d) Actual delivered water density to the burning surface and in the vicinity of the fire location.

e) Overall exhaust heat release rate to quantify the fire suppression effectiveness.

Dimensionless correlations of droplet and induced gas flow parameters are also being developed to enable application of the experimental results to warehouse-scale fires.

\section{Recent Results}

W. Rho, D. A. Everest and A. Atreya,

Droplet Distribution, Scaling and

Measurements in a Reduced-Scale Sprinkler, 2nd International Conference on Fire Research and Engineering, 1997. 


\section{Fire Protection in Large Industrial Fires}

\section{Principal Investigator}

Marino di Marzo

Mechanical Engineering Department

University of Maryland

301-405-5257

\section{Sponsor}

National Institute of Standards and Technology

\section{Objective}

To investigate fire safety engineering concerns associated with properties characterization and performance evaluation of fire protection foams; ignition and burning of heavy oil emulsion on water; critical literature review, experiments and modeling of two-dimensional fire sources; and integration of CFAST with existing models for the analysis of complex wall assemblies.

\section{Problem}

Fire Protection Foams - The most common active methods to mitigate and contain large industrial and petrochemical fires encompass water sprays and water films. An integrated approach to identify cost-effective, environmentally safe agents and their application strategies are sought. In particular, the performance of water based foams, used in recent wild-fire in suburban settings to protect residential structures, is investigated.

Oil Spill - The environmental impact of oil spills at sea is mitigated by igniting and burning the spill. Ignition and flame spread characteristics of different crude oils in their natural state, weathered and emulsified is characterized. A standard test based on a modified HIFT apparatus is used to estimate the combustion self sustained capability. This project is directed by J. Torero (FPED-UMCP).

Two-Dimensional Fire Sources - The synthetic representation all the available data on point sources as well as on line sources at different burner aspect ratio is pursued. The objective is to derive a universal formulation of temperature and flame height for finite line fires. This project is directed by J. Quintiere (FPED-UMCP).

Thermal and Structural Response of Complex Wall Assemblies - The development of a more realistic model for existing compartment fire models is pursued by validating a simple one-dimensional heat transfer algorithm which can be readily implemented in CFAST with the results of the SAFIR (i.e., a three-dimensional finite element code). This project is directed by J. Milke (FPED-UMCP).

\section{Approach}

Fire Protection Foams - The performance of fire protection foams exposed to fire has been characterized in the previous grant period. Radiant heat absorption in the foam layer was found to be the dominant parameter in the foam destruction process. The density of the foam layer is also a strong function of fire exposure transient and the radiation extinguishment coefficient is dependent on the foam density. A quasi-steady stated model is formulated on these basis to predict the temperature profile within the foam layer. The results indicates that the radiation deposition term and the evaporation term are one order of magnitude larger than the thermal diffusivity and convective terms. Further, the foam density profile causes the radiant absorption to be maximum $2 \mathrm{~cm}$ to 4 $\mathrm{cm}$ in the depth of the foam layer.

Careful evaluation of the radiation extinction coefficient is conducted with a newly developed testing routine for various foam expansion ratios (i.e., the volume of the foam over the volume of the original liquid solution). A testing apparatus is also developed for the measurement of the thermal diffusivity as well as for the determination of the thermal expansion characteristics of a given foam. Enhancement of the foam fire resistance is obtained via the introduction of highly reflective pigments at the foam layer exposed surface. Application of small amounts of pigments (i.e., $1 \%-2 \%$ 
by weight) are shown to produce fire resistance enhancements of the order of 100 $\%$. Optimal foam expansion ratios and pigments loading are evaluated within a broad testing program.

Oil Spills - An experimental technique has been developed to systematically study the ignition and flame spread characteristics of liquid fuels spilled on a water bed. The hardware used for the Lateral Ignition and Flame Spread (LIFT) standard test method (ASTM-1321) has been modified to allow the used of liquid fuels deposited on water. Flammability diagrams are obtained for different fuel characteristics typical of oil spills and for different of oil spill thickness. These flammability diagrams provide a number of essential parameters such as critical heat flux for ignition, ignition delay time and flame spread velocity as a function of the external heat flux. A series of "fire properties" corresponding to each fuel can also be deduced from the flammability diagrams and can be used to quantify the tendency of the fuel to ignite and to sustain flame spread.

\section{Recent Results}

Tafreshi, A., di Marzo, M., Stubbs, L., and Floyd, R., "Characterization and Evaluation of Fire Protection Foams," 2nd International Conference of Fire Research and Engineering, NIST, August 10-15, 1997.

Tafreshi, A., di Marzo, M., Stubbs, L., and Floyd, R., "Performance Enhancement Techniques for Fire Protection Foams by Utilizing Reflective Pigments," 2nd International Conference of Fire Research and Engineering, NIST, August 10-15, 1997.

Wu, N., Baker, M., Kolb, J., and Torero, J.L., 1997, "Ignition and Flame Spread Characteristics of Liquid Fuels on a Water Bed," 2nd International Conference of Fire Research and Engineering, NIST, August 10-15, 1997.

Boyd, C., and di Marzo, M., "Fire Protection Foam in a Radiative Environment," Proceedings of the 31 st National Heat Transfer
Conference, HTD-Vol. 328, Vol. 6, pp. 123-129, 1996.

Boyd, C., and di Marzo, M., "Numerical Model and Experimental Results of Fire Protection Foam Exposed to Heat Radiation," Annual Conference on Fire Research, NIST, Gaithersburg, MD, October 28-31, 1996

Dillon, S.E., and Milke, J., "The Thermal and Structural Response of Light Steel Frame Wall Assemblies Exposed to Fire Using the SAFIR Finite Element Model," 2nd International Conference of Fire Research and Engineering, NIST, August 10-15, 1996.

Gopalnarayanan, S., Floyd, R.,Wang, S., Stubbs, L., and di Marzo, M., "Issues and Techniques Associated with the Measurements of Properties of Fire Protection Foams," Annual Conference on Fire Research, NIST, Gaithersburg, MD, October 28-31, 1996. 


\section{A Study of Two Phase High Liquid Loading Jet Fires}

\author{
Principal Investigator \\ Jay P. Gore \\ Purdue University \\ 7654941452
}

\section{Sponsor \\ National Institute of Standards and Technology}

\section{Objective}

The objective of this project is to study: visible flame lengths, radiation and pollutant emission properties of high liquid loading jet fires, and their gas fired analogs.

\section{Problem}

Two phase jet fires result from effective atomization of a liquid fuel by small quantities of trapped gases. The oil well fires in Kuwait are the most prominent example. The visible flame lengths of such fires increase with increasing heat release rates even in the momentum dominated regime. This increase is contrary to existing knowledge.

\section{Approach}

An effervescent atomizer burner simulates the physical processes that occur in accidental fires involving high liquid loading two phase jets. We built a small burner for operation in the $10 \mathrm{~kW}$ to $60 \mathrm{~kW}$ firing rate range and a large burner for operation in the $30 \mathrm{~kW}$ to $200 \mathrm{~kW}$ firing rate range. We have measured: radiative heat loss fractions, visible flame lengths, chemical flame lengths, and pollutant emission indices for several spray fires stabilized on these burners.

Toluene, haptene, methanol and crude oil were the liquid fuels. The atomizing gas was methane. A hydrogen pilot flame stabilized the spray fires. Non-premixed acetylene jet fires stabilized without a pilot flame on long tubular burners with different diameters were studied as the gas fired analogs of the spray fires.

The visible flame lengths for both the spray fires and the acetylene fires continuously increased with firing rate. The chemical flame heights on the other hand became constant beyond a firing rate which marks the transition between buoyant and forced regimes. Pollutant emission indices for soot, $\mathrm{CO}$ and $\mathrm{NO}_{\mathrm{x}}$ varied significantly with the amount of atomizing methane.

We measured spectral radiation intensities leaving diametric paths at various heights above the burner exit for the acetylene jet fires and the toluene/ $\mathrm{CH}_{4} / \mathrm{H}_{2}$ spray fires. The data showed that the visible intensity increases with wavelength between $450 \mathrm{~nm}$ and $750 \mathrm{~nm}$ at all heights. The visible intensity decreased by 3 orders of magnitude over the length of the flame. We integrated the visible spectral intensity weighted by the standard response curve for a human eye and plotted the resulting visible total intensity as a function of distance from the injector exit. A repeatable lowest total intensity value of $0.2 \mathrm{~W} / \mathrm{m}^{2}$-sr was defined as the cut-off determining the visible flame height. These data agree well with the video-tape based visible flame heights removing the uncertainty concerning the sensitivity of the video tape and transfer efficiency of the various intermediate components.

We estimated entrainment rates based on integration of our particle imaging velocimetry based data around the fires for selected acetylene jet flames and the spray fires. We compared the visible and chemical flame length data for the acetylene flames and the spray flames with the correlations of Becker and Liang, Delichatsios, and Blake and $\mathrm{McD}$ onalds. The data for the luminous flames suggest that the trends of the correlations are appropriate for the visible flame heights. The chemical flame heights become constant at lower momentum rates compared to those estimated by the correlations. The entrainment rates for the acetylene flames agreed well with the Ricou and Spalding correlation. However, those for the spray flames were significantly lower than the estimates based on the correlations. 


\section{Recent Results}

Lawler A., "An Experimental Study of Flame

Length and Pollutant Emission for

Effervescent Atomizer Spray Flames," M. S.

Thesis, Purdue University, 1996.

\section{Measurements of Heat Release Rates and Vorticity Distributions in Pool Fires for the Calculation of Fire Induced Flow Field}

\author{
Principal Investigator \\ Jay P. Gore \\ Purdue University \\ 765-494-1452

\section{Sponsor \\ National Institute of Standards and Technology}

\section{Objective}

The objective of this project is to obtain major species and velocity distributions in gas fires with firing rates selected to simulate pool fires. The measurements are required to have sufficient resolution to yield gradients that allow us to evaluate the heat release rates and vorticity distributions.

\section{Problem}

Mass flow rate of air entrained by a pool fire determines fire size, radiative feedback, and hazardous chemical emission indices. The correlations for entrainment rate currently available in the literature and used in various fire codes show a very large variation. A numerical recipe pioneered at NIST involves a solution of two elliptic partial differential equations for the velocity potential and the stream function. The source terms in these equations involve distributions of heat release rates and vorticity within the fire. The present work will provide measurements of the source terms and allow a direct evaluation of the predictions of the fire induced flow field.

\section{Approach}

Our previous work involved measurements of velocity vectors in the vicinity of $7.1 \mathrm{~cm}, 15$ $\mathrm{cm}$, and $30 \mathrm{~cm}$ pool fires burning toluene, heptane and methanol. An imaging technique called particle imaging velocimetry (PIV) was used for obtaining these data. The results were correlated with the fire Froude number as the nondimensional parameter. 
With the use of this parameter, the normalized entrainment rate data for six fires involving the three fuels and the $15 \mathrm{~cm}$ and $30 \mathrm{~cm}$ pools collapsed within 15 percent when plotted as a function of normalized distance from the fuel surface. The data for the $7.1 \mathrm{~cm}$ fires with the three fuels collapsed to a separate curve showing the effects of a size parameter.

Comparisons of the measurements and predictions of a fire induced flow code developed by Dr. Baum at NIST showed qualitative agreement. However, the distributions of vorticity and heat release rates had to be adjusted using flame radius as an adjustable parameter.

Motivated by this, measurements of heat release rates and vorticity distributions in pool fires have been initiated. To make the measurements feasible, surrogate natural gas fueled fires that allow gas species sampling in all parts and also allow seeding for velocity measurements are being used. However, the fuel flow rates for these surrogate fires are selected to yield identical fire Froude numbers for the gaseous and the liquid fires. Results show that this fire Froude number scaling is crucial.

Early attempts at using measurements from the literature for evaluating the heat release rates and vorticity distributions showed that the species data do not have adequate resolution for this purpose. The velocity data in the literature do not extend far enough beyond the flame sheet to yield a complete distribution.

Measurements of species concentrations in $7.1 \mathrm{~cm}$ and $15 \mathrm{~cm}$ fires show that laminar flamelet state relationships can be used for mean properties. The data show that majority of the heat release occurs in an annular region within 1 diameter distance from the fuel surface. In contrast, the visible flame extends to approximately five diameters. The expansion velocities calculated using the measured heat release rates show that the extent of the fire induced flow field is narrower than that predicted using existing correlations.

\section{Recent Results}

Zhou X. C., Gore J. P. and Baum H. R., "Measurements and Predictions of Air Entrainment Rates of Pool Fires," Twenty Sixth (International) Symposium on Combustion, Naples, Italy, 1997.

Zhou X. C. and Gore J. P., "Estimates of Heat Release Rates and Velocity Potential in Pool Fires Using Measurements of Major Species Concentrations," Central States Section Meeting, Point Clear, AL, 1997. 


\section{Large Fire Analysis}

Principal Investigator

Professor Patrick J. Pagni

Mechanical Engineering Department

University of California, Berkeley

\section{Sponsor}

National Institute of Standards and Technology

\section{Objective}

To develop of a Modular Urban/Wildland Intermix Fire Growth Model.

\section{Problem}

The following elements are currently envisioned of comprising our modular fire growth model:

1. The initial fire strength.

2. The plume above the initial fire.

3. The combined flow field induced by multiple fire sources.

4. The initial distribution of brands.

5. The brand combustion, heat, and mass transfer.

6. The brand dynamics.

7. Interaction with the ambient atmosphere.

8. Interaction with the terrain.

9. Spread mechanisms other than spotting.

10. Fuel characterization and ignition.

11. The strength and duration of a structure threatening fire.

12. Ignition and growth on the structure.

13. Window glass breakage.

14. Structure protection.

\section{Approach}

During this grant period we have completed the fire-induced flow field generated from multiple fire sources and identified its role in lofting brands, which are recognized as the critical mechanism of conflagration fire spread. We presented results at: the NIST/SFPE Meeting in Orlando in September 1995, the 13th UJNR Panel Meeting in Gaithersburg in March 1996, and the 5th International Symposium on Fire Safety Science in Melbourne, Australia in March, 1997. During this grant period, our program produced two Safety Science Doctorates: Prof. Dembsey went to WPI and Dr. Trelles went to NIST. Our study currently focuses on four problems: 1) quantification of the lofting of brands of all conceivable shapes, compositions, and conditions; 2) the time-varying characteristics of those brands as they combust while being transported; 3 ) the dynamics of the brand-wind-plume interaction that determines the brand deposition distribution and the pattern of the downwind ignition sites; and 4) validation of a ground fuels flame spread model. The rich forest fire literature is being fully utilized; we rely on previous work by Tarifa and Albini. Our experience with the 1991 Oakland Hills Fire, the 1993 Los Angles fires, and the 1995 Kobe post-earthquake fires provide specific case studies for the application of these models. Because of the analog between structural rubble piles and forest wood/brush piles as brand sources, this model may also be capable of assessing possible post-earthquake conflagrations. Our experience working with the Baum-McCaffrey mass fire model provides the starting point for the brand lofting study. Spherical, cylindrical, and disk-shaped brands in combusting and non-combusting, maximum drag and tumbling modes are being analyzed theoretically and experimentally. The large scale eddy simulation plume model ALOFT will be used to help identify the downwind brand deposition contours. During a Spring 1997 sabbatical, I will come to the BFRL to work with Dr. Baum.

\section{Recent Results}

J. Waycheese, P. Pagni, D. Liepmann, "Brand Lofting above Large Scale Fires," ICFRE 2, Gaithersburg, MD, August 1997.

J. Trelles and P.J. Pagni, "Fire-Induced Winds in the 20 October 1991 Oakland Hills Fire," Fifth International Symposium on Fire Safety Science, Australia, March 1997.

N.A. Dembsey, P.J. Pagni, and R.B. Williamson, "Compartment Fire Experiments: Comparison to Models," Fire Safety Journal, 25:3, pp. 187-227, 1996. 
P.J. Pagni, "Zukoski's Intellectual Progeny in Fluid Mechanics of Fires," 13th Meeting of the UJNR Panel on Fire Research and Safety,

Gaithersburg, MD, March, 1996.

J. Woycheese, "Brand Lofting in Large Scale Fires," Masters Thesis, Mechanical Engineering Department, University of California at Berkeley, December 1996.

J. Trelles, "Mass Fire Modeling of the 20 October 1991 Oakdand Hills Fire," Doctoral Dissertation, Mechanical Engineering Department, University of California at Berkeley, December 1995.

N.A. Dembsey, P.J. Pagni, and R.B.

Williamson, "Compartment Fire Near-Field Entrainment Measurements," Fire Safety Journal, 24:4, pp. 383-419, 1995. 



\section{FIRE SCIENCE DIVISION}

\section{FIRE SENSING AND EXTINGUISHMENT}





\section{Advanced Fire Detection}

\section{Principal Investigator}

Emil Braun

Fire Science Division

30I-975-6665

\section{Sponsor}

National Institute of Standards and

Technology

\section{Objective}

To complete development of a Fire Emulator Detector Evaluator (FE/DE) and to evaluate by the response characteristics of multi-sensor point detectors using key fire parameters that simulate standard fires.

\section{Problem}

Current test protocols and certification processes have been developed to accommodate specific detection sensor technologies. Test methods exist to evaluate specific classes of sensors, i.e., ionization, optical, temperature, etc. In the past, the fire or smoke sources used in these test methods were optimized for a unique fire or smoke property to quantify detector response. To improve detection sensitivity and reduce false alarm rates, industry has developed new sensors. Some designs are based on the measurement of different aspects of the fire source than those traditionally evaluated by current test methods. Other designs are based on specific combinations of sensors that can help in distinguishing a real fire source from a false reading. Existing test methods may not be able to evaluate and quantify the performance of new sensing methods or multi-detector systems.

\section{Approach}

During FY1997, BFRL will have completed the first generation Fire Emulator/Detector Evaluator (FE/DE) to the point that new generation spot-type fire detector designs may be evaluated. CEN 54 is a European test method that defines a room fire test and several fire sources for the evaluation of specific fire detectors. Using CEN 54 ceiling data at the detection site as representing a standard set of fires, strategies will be developed for controlling velocity, temperature, $\mathrm{CO}$, and smoke concentrations as a function of time to simulate these fire sources. A new smoke generator will be designed to replicate key physical attributes of particulates produced in these standard fires. In collaboration with the detector industry and other researchers, appropriate detector designs will be selected to assess the performance of the FE/DE.

\section{Recent Results}

Grosshandler, W., and Cleary, T., Test Fire

Signatures and the

Fire-Emulator/Detector-Evaluator, UJNR, Proceedings of the Panel on Fire Research and Safety, NISTIR 6030, National Institute of Standards and Technology, June 1997.

Grosshandler, W., Progress Report on Fire Detection Research in the U.S. UJNR Proceedings of the Panel on Fire Research and Safety, National Institute of Standards and Technology, March 1997.

Grosshandler, W., "Towards the Development of a Universal Fire Emulator/Detector Evaluator," Fire Safety Journal, 1996.

Cleary, T., Grosshandler, W., Nyden, M., and Rinkinen, W., "Signatures of Smoldering Fires for Multi-element Detector Evaluation," INTERFLAM, March 1996. 


\section{Next Generation Fire Suppression Program}

Principal Investigator

Richard G. Gann

Fire Science Division

$301-975-6866$

\section{Sponsor}

Department of Defense

Office of the Secretary of Defense

\section{Objective}

To develop and demonstrate, by environmentally acceptable and user-safe processes, techniques, and fluids that meet the operational requirements currently satisfied by halon 1301 systems in aircraft, ships, land combat vehicles, and critical mission support facilities.

\section{Problem}

Halon 1301 (CF3Br), the principal clean fire suppressant used for total flooding applications within the Department of Defense, is not longer in production due to its harmful effect on stratospheric ozone. The DoD has extensively tested the current alternative chemicals and found that their weight and volume penalties would make retrofitting existing systems extremely expensive and difficult. For the near term, a bank of out-of-service halon 1301 is satisfying DoD needs, but this bank is of uncertain size and longevity. The Office of the Secretary of Defense has initiated the Next Generation Fire Suppression Technology Program (NGP) to provide solutions for current systems. NIST has been asked to provide the technical management of the NGP.

\section{Approach}

During FY1997, BFRL will following a request from the Director of Defense Research and Engineering, to develop and demonstrate processes, techniques, and fluids that meet the operational requirements currently satisfied by halon 1301 . The plan consists of 24 research elements organized into six thrusts: Risk Assessment and
Selection Criteria, Fire Suppression Principles, Technology Testing Methodologies, New Suppression Concepts, Emerging Technology Advancement, and Suppression Optimization. The program will be managed by a Technical Program Manager assisted by a Technical Coordinating Committee of experts and will be overseen by a steering committee of DoD officials.

\section{Recent Results}

New project. 


\section{Dispersed Liquid Agent Fire Suppression Screen}

Principal Investigator

Jiann C. Yang

Fire Science Division

301-975-6662

\section{Sponsor}

Department of Defense

Strategic Environmental Research and Development Program

\section{Objective}

To develop a bench-scale suppression screen suitable for comparing the performance of dispersed fluids in extinguishing a laboratory-scale flame.

\section{Problem}

Halon 1301 (CF3Br) has properties that make it particularly effective as a fire extinguishing agent. In addition to the chemical activity attributable to the bromine atom, halon 1301 is a gas at room temperature and pressure. It is stored as a liquid under high pressure making it superheated at atmospheric conditions. When discharged, halon 1301 flashes to a gas and quickly disperses throughout the volume being protected. Replacements are sought which perform equally well in applications critical to the Department of Defense.

\section{Approach}

During FY1997, BFRL will select fluids to span a variety of anticipated operating conditions. These include pure water; water plus an additive (dissolved gas or salt); a low viscosity nonaqueous, zero ODP fluorocarbon (e.g., C6F14); and a high viscosity, higher boiling point compound (unspecified). They will be suspended in air streams at modest velocities and transported to a propane diffusion flame. In order to characterize and calibrate the performance of the burner, gaseous agents will also be used. This will allow comparisons of the performances of gaseous agents with those of aerosols. The burner will be based upon the design of Tsuji, in which a gaseous fuel (propane) is brought into a porous cylinder located cross-flow within an air stream. Flame extinction limits can be observed with little ambiguity and high reproducibility. Two different methods of generating aerosols are envisioned. For larger, close-to-mono-dispersed aerosols (25 $\mathrm{mm}$ to $250 \mathrm{~mm}$ ), a multiple orifice piezoelectric droplet generator will be built. The literature will be scanned to identify candidate techniques for generating droplets in the $0.25 \mathrm{~mm}$ to $25 \mathrm{~mm}$ range. Aerosols generated in these manners can be introduced directly into the burner air stream. However, no existing technique may be suitable for some fluids such as slurries, emulsions, or chemically generated aerosols. A separate aerosol chamber will be needed in which high concentrations of agent can be produced using whatever technique is envisioned in practice. The aerosol will be transported from the generating chamber to the burner where it can be metered into the air stream. Extinction experiments will be conducted with and without obstacles in the air stream just ahead of the flame.

\section{Recent Results}

New project. 


\section{Fire Suppression Chemistry}

Principal Investigator

Gregory T. Linteris

Fire Science Division

301-975-2283

\section{Sponsor}

National Institute of Standards and

Technology

\section{Objective}

To provide by a fundamental understanding of the detailed chemical steps by which the most efficient chemical flame inhibitors act to extinguish flames, for use by the fire protection community to facilitate the development of the next generation of suppression agents and technologies.

\section{Problem}

Fire suppressants and their application methods should be effective, fast-acting, economical, have low toxicity, permit a habitable environment during suppression, and cause no collateral damage to the protected space. Existing suppressants, however, are nonideal for various reasons. There exists a continuing need for better suppressants and suppression methods, but limited scientific understanding of how existing chemical inhibitors act to extinguish flames hinders development of new agents. Some chemical inhibitors have been found to be up to 100 times more effective than $\mathrm{CF}^{3} \mathrm{Br}$ in inhibiting premixed hydrocarbon-air flames. Nonetheless, their mechanism of inhibition is not clearly understood.

\section{Approach}

During FY1997, BFRL will study the behavior of chemical inhibitor $\mathrm{Fe}(\mathrm{CO})^{5}$, in detail to develop a detailed understanding of it's effectiveness that can help in the search for new agents.

\section{Recent Results}

Linteris, G.T. and Reinelt, D. "Inhibition of Flames by Condensed-Phase Agents," in Interflam'96, Seventh International Fire Science and Engineering Conference, March
26 - 28, 1996, Cambridge, England, Interscience, London, 1996, p. 477-486.

Reinelt, D., and Linteris, G.T., "Experimental Study of the Flame Inhibition Effect of Iron Pentacarbonyl," Halon Options Technical Working Conference, Albuquerque, NM, May 7-9, 1996.

Linteris, G.T., Burgess, D.R., Babushok, V., Zachariah, V., Westmoreland, P., and Tsang, W., "Inhibition of Premixed Methane-Air Flames by Fluoroethanes and

Fluoropropanes," Combustion and Flame, June 1996.

Reinelt, D., and Linteris, G.T. "Experimental Study of the Inhibition of Premixed and Diffusion Flames by Iron Pentacarbonyl," Twenty-Sixth Symposium (International) on Combustion, The Combustion Institute, Pittsburgh, Aug. 1996.

Fallon, G.S., Chelliah, H.K., and Linteris, G.T., "Chemical Effects of $\mathrm{CF}^{3} \mathrm{H}$ in Extinguishing Counterflow $\mathrm{CO} /$ Air/ $/ \mathrm{H} 2$ Diffusion Flames," Twenty-Sixth Symposium (International) on Combustion, The Combustion Institute, Pittsburgh, Aug. 1996.

Reinelt, D., Babushok, V., and Linteris, G.T., "Numerical Study of the Inhibition of Premixed and Diffusion Flames by Iron Pentacarbonyl," Eastern States Section Meeting/The Combustion Institute, S. Carolina, Dec., 1996.

Babushok, V., Tsang, W., Linteris, G.T., and Reinelt, D., "Chemical Limits to Flame Inhibition," Eastern States Section Meeting/The Combustion Institute, S. Carolina, Dec., 1996.

Linteris, G.T. and Gmurczyk, G. "Inhibition of Premixed Methane-Air Flames by Iron Pentacarbonyl," 15th International Colloquium on the Dynamics of Explosions and Reactive Systems, July 30 - Aug. 4, 1995, Boulder, CO, p. 298-30I. 


\section{Suppression of Engine Nacelle Fires}

Principal Investigators

Anthony Hamins

301-975-6598

John Yang

Fire Science Division

301-975-6622

\section{Sponsor}

Department of Air Force

Aircraft Survivability \& Safety Branch

Wright Patterson Air Force Base

\section{Objective}

To provide, guidance in measurement techniques, test plan development, data analysis, and interpretation of full scale experiments investigating the effectiveness of available and emerging agents/technologies in full-scale fire testing in an engine nacelle.

\section{Problem}

The Air Force soon will begin testing a solid propellant gas generator (SPGG) in a full scale mock-up of a F-22 nacelle at the Wright Patterson Engine Nacelle Test Facility. For comparison, gaseous agent such as HFC-125 will also be tested. Expertise is needed to provide guidance in the development of a test plan, determination of measurement parameters, measurement techniques, data analysis, and interpretation of the full scale experiments. The mixing/suppression model developed at NIST serves as a basis for design and interpretation of the full scale nacelle experiments.

\section{Approach}

During FY1997, BFRL will review the preliminary nacelle design and test plan developed by Wright Patterson personnel and other contractors. Quantification of fundamental variables is required to assess the suppression effectiveness of replacement agents and techniques. These variables include the rate and duration of agent injection, the air/agent temperature, and the air/agent flow. BFRL will identify instrumentation which will allow quantification of key experimental parameters. The veracity of the acquired data and acquisition methodology will be verified by BFRL staff during site visits. An analysis will be performed of the data in terms of a model which considers the effect of air flow, air temperature, agent type ( $\mathrm{CF}^{3} \mathrm{I}, \mathrm{HFC}-125$, or inert species from SPGG), the rate and duration of agent application, and the local flow field geometry (e.g., effect of an obstacle in the flow field).

\section{Recent Results}

No publications produced to date. 


\section{Chemical Inhibitor Effects on Diffusion Flames in Microgravity}

Principal Investigator

Gregory T. Linteris

Fire Science Division

301-975-2283

\section{Sponsor}

National Aeronautics and Space

Administration

Lewis Research Center

Space Systems Branch

\section{Objective}

To develop an understanding of the differences in flame inhibition effects of halogenated compounds between unit gravity and microgravity.

\section{Problem}

Since halogenated compounds will remain the fire suppressant of choice in many space missions, there is a need for experimental evidence on the effectiveness of these compounds for diffusion flames under zero buoyancy conditions.

\section{Approach}

During FY1997, BFRL will perform experiments with an expert at the Massachusetts Institute of Technology on normal and microgravity studies of laminar jet and co-flow diffusion flames inhibited by halogenated suppressant in the air or fuel stream. In microgravity, visual and temperature diagnostics will be used to detect flame shape, dynamics, and stability limits. Normal gravity experiments will use additional chromatographic and spectroscopic diagnostics in addition to visual and temperature experiments. Analytical and computational work will be performed using existing general 2-D codes with chemical kinetic models for comparison with the observed results.

Determine the effects of flame inhibitors on the physical characteristics (height, shape, color, and luminosity) and stability limits (ignition, extinction, lift-off and blow-off) of gaseous diffusion flames in the presence of halogenated fire suppressants in microgravity; and to develop quantitative analytical models for the observed behavior, including chemical kinetic effects, in order to understand the mechanisms of inhibition of halogenated compounds in gaseous diffusion flames in microgravity.

\section{Recent Results}

VanDerWege, B.A., Bush, M.T., Hochgreb, S., and Linteris, G.T., "Inhibition of CH4 Laminar Flame Speeds by CF3H and C2F6 in a Combustion Bomb," Combustion Science and Technology, July 1995.

VanDerWege, B.A., Bush, M.T., Hochgreb, S., and Linteris, G.T., "Effect of CF3H and $\mathrm{CF} 3 \mathrm{Br}$ on Laminar Diffusion Flames in Normal and Microgravity," Eastern States Section Meeting/The Combustion Institute, Worcester, MA, October 1995. 
Payload Specialist on STS-83

Principal Investigator

Gregory T. Linteris

Fire Science Division

301-975-2283

\section{Sponsor \\ National Aeronautics and Space Administration}

\section{Objective}

To perform duties as a payload specialist on space shuttle missions to launch on April 2, 1997 and July 4, 1997. Experiments included those in combustion, material science, protein crystal growth, plant biology, and fluid mechanics.

\section{Problem}

The high temperatures associated with fires and combustion processes often lead to complex fluid motion that is strongly influenced by the gravitational field. Because the spread of a fire can be either accelerated or retarded as the force of gravity is changed, the level of safety associated with the design of a spacecraft is uncertain. In addition, buoyancy driven flows render even the simplest flame almost impossible to model from first principles.

\section{Approach}

The Microgravity Sciences Laboratory (MSL) was developed by NASA to perform experiments on physical phenomena that are significantly affected by the earth's gravity. Greg Linteris underwent a rigorous training period to qualify as an astronaut on Columbia, during which time he worked closely with the principal investigators of the micro-gravity combustion experiments. He conducted numerous combustion and fluid mechanics experiments, as well as experiments with biological and crystalline materials as a Payload Specialist on two different launches of the Orbiter.

\section{Recent Results}

Duties successfully performed as required.

\section{Low Environmental Impact Fire Suppression}

\author{
Principal Investigator \\ William Grosshandler \\ Fire Science Division \\ 301-975-2310
}

\section{Sponsor}

National Institute of Standards and Technology

\section{Objective}

To facilitate the adoption of promising low environmental impact fire suppression technologies by developing for fire simulators improved phenomenological models for agent transport; and establishing for users, manufacturers, and regulators scientifically defensible test methods for evaluating the fire suppression performance of proposed alternatives.

\section{Problem}

Currently fielded technologies for suppressing fires can adversely effect the local or global environment. Proposed halon alternatives containing chlorine or iodine have a non-zero ozone depletion potential; fluorine containing alternatives may have very long atmospheric lifetimes. Other approaches to fire protection such as inert gas, powder or aqueous systems are not without occupant risk or have features that make them less desirable from an operational standpoint. Development of new technologies is hampered by a lack of understanding of the physical processes controlling dispersion and by the absence of metrics for establishing agent/system effectiveness.

\section{Approach}

During FY1997, BFRL will perform two tasks. First, an assessment of the state of understanding of droplet and spray dynamics will be conducted prior to developing a research plan targeted at generating phenomenological sub-models for meaningful CFD and zone-type predictions of physical suppression processes (up to the point of significant flame/suppressant interactions). 
Second, new test methods will be developed to evaluate the performance of solid propellant gas generators (SPGGs) in suppressing baffle-stabilized pool fires and to quantify the impact of an energy source within the targeted volume on the amount of a gaseous suppressant to control a class- $C$ fire.

\section{Recent Results}

Yang, J., and Grosshandler, W., Solid Propellant Gas Generators: Proceedings of the 1995 Workshop, NISTIR 5766, National Institute of Standards and Technology, November 1995.

Grosshandler, W., "In Search of Alternative Fire Suppressants," Symposium on Thermal Sciences and Engineering in Honor of Chancellor Chang-Lin Tien, Berkeley, pp. 275-282, November 1995.

Yang, J., and Grosshandler, W., "Solid Propellant Gas Generators: An Overview and Their Application to Fire Suppression," International Conference on Fire Research and Engineering, P. Lund, editor, Society of Fire Protection Engineering, pp. 88-90, 1995.

\section{Analysis of High Bay Hangar Facilities for Detector Sensitivity and Placement}

\author{
Principal Investigator \\ William Grosshandler \\ Fire Science Division \\ 301-975-2310
}

\section{Sponsor \\ Department of Navy \\ U.S. Naval Facilities Engineering Command}

\section{Objective}

To provide a comprehensive report of full scale tests including experimental data on flame detection, smoke detection, and smoke movement in high bay aircraft hangars using aviation fuels conducted during FY1995.

\section{Problem}

Fire protection criteria for aircraft hangars employ "best engineering judgement" using NFPA codes and standards which are based upon maximum ceiling heights of $9.1 \mathrm{~m}$. For years, DoD and the private sector have extrapolated data from research conducted in buildings with conventional ceiling heights. although there are no actual data to support this practice for fire detection and suppression systems located over $9.1 \mathrm{~m}$ or more above the fuel level. The effects of stratification, wind, and the movement of smoke and heat in high bay areas such as aircraft hangars are not presently known.

\section{Approach}

During FY1997, BFRL will perform additional editions of test footage and compilation of graphical tables and charts to include in video production. The final report will present building specifications, instrumentation layouts, detector descriptions, overall results, conclusions, and recommendations. It has yet to be decided if a CD-ROM which includes all additional information and an entire data set for both test series, will be included with the final report. 


\section{Recent Results}

Goff, J. E., Lowe, D. L., Notarianni, K. A., and Davis, W., Analysis of High Bay Hangar

Facilities for Fire Detector Sesitivity and

Placement, NIST TN 1423, National Institute of Standards and Technology, February 1997.

Agoff, J. E., Lowe, D. L., Notarianni, K. A., and Davis, W., Aircraft Hangar Fires and Fire Protection Improvements, NIST video, National Institute of Standards and Technology, March 1997.

\section{Smoke Movement in High Bays}

Principal Investigators

William Davis

Fire Science Division

301-975-6884

Kathy Notarianni

Fire Science Division

301-975-6883

\section{Sponsor}

National Aeronautics and Space

Administration

NASA Headquarters

\section{Objective}

To develop and validate algorithms for predicting and detecting smoke movement in high bay spaces.

\section{Problem}

The NASA inventory of buildings contains a large number of buildings with ceiling heights in excess of $9 \mathrm{~m}$. At these heights, design tools such as fire models have not been validated and only a few fire experiments have been conducted. With the completion of the Navy's high bay hanger facilities experiments in $15 \mathrm{~m}$ and $22 \mathrm{~m}$ high hangars, a unique set of data exists which allows the validation of existing fire models and provides the opportunity for developing new detection algorithms which are appropriate for use at these building heights.

During the past year, the experimental data has been analyzed for both the $15 \mathrm{~m}$ and 22 $\mathrm{m}$ high hangars. Using the $15 \mathrm{~m}$ data, the results of a number of fire models have been compared with the data in order to validate these models and to identify physical algorithms which may require modification at these heights.

\section{Approach}

During FY1997, BFRL plans to extend the validation effort to the $22 \mathrm{~m}$ high facility. Algorithm development will use the computer model, LAVENT, as a test bed for the development of an improved ceiling jet model 
and a smoke detection algorithm. The algorithms will be generic and will be capable of being transported to other computer models with a minimum of effort.

\section{Recent Results}

Davis, W. D., Notarianni, K. A., and McGrattan, K. B., Comparison of Fire Model

Predictions with Experiments Conducted in a Hangar with a 15 m Ceiling, NISTIR 5927, National Institute of Standards and Technology, December 1996.

\section{Research in Fire Protection Technologies - A Resource Allocation and Impact Study}

\author{
Principal Investigator \\ Kathy Notarianni \\ Fire Science Division \\ 301-975-6883
}

\section{Sponsor \\ National Institute of Standards and Technology}

\section{Objective}

To develop a decision analytical framework to determine where research into various fire protection technologies would have the greatest payoff, as defined by reduction in annual fire deaths and injuries, reductions in dollars of property loss, cost/benefit to society, and impact on industry.

\section{Problem}

BFRL, other groups involved in fire research, and the policy makers funding fire research face decisions about what initiatives to fund and what pay-off can be expected. Although it is almost never intuitive as to how much it is worth investing in a particular technology, and what the pay-offs are, these decisions have become more critical each year as the budget has become tighter and decision makers are faced with harder choices.

\section{Approach}

During FY1997, BFRL will evaluate four groups of fire protection technologies : technologies that reduce the number of ignitions; materials that don't burn or don't burn readily; fire detection technologies; and fire suppression technologies. A decision model incorporating technical and economic feasibility evaluations will be developed to forecast pay-off investments in each of the above areas. Three different time frames will be considered: less than 5 years, 5 to 20 years, and greater than 20 years. As a first approximation, fire loss statistics from the past years will be used to determine which of these technologies shows the greatest potential for each type of pay-off and time 
frame. One area of technology, and ultimately one specific technology in that area, will be selected for a detailed study of its impact potential and cost. Computer fire models will be used to forecast future performance, effectiveness, and reliability. A cost and uncertainty analysis will be included.

\section{Recent Results}

New project.

\section{High Heat Flux Measurement Standards}

Principal Investigator

William Grosshandler

Fire Science Division

301-972-2310

\section{Sponsor}

National Institute of Standards and

Technology

\section{Objective}

To demonstrate the effect of different modes of heat transfer on the absolute reading of heat flux gauges, as a means for industry designers and regulators to identify new reliable heat flux measurement methods which are required to enable the development of more fire safe materials, effectively packaged electronics, and efficient energy systems.

\section{Problem}

Standard methods exist for calibrating thermal radiation detectors at flux levels extending to $10 \mathrm{~kW} / \mathrm{m}^{2}$ using controlled blackbody cavities, and up to $40 \mathrm{~kW} / \mathrm{m}^{2}$ using a monochromatic laser radiation source. However, heat flux transducers are often used under conditions where convection is dominant, where radiation emanates from a source with different spectral character, or where the flux levels exceed $40 \mathrm{~kW} / \mathrm{m}^{2}$.

\section{Approach}

During FY1997, BFRL will complete an experimental facility consisting of a wind tunnel with a heated wall in which a heat flux transducer can be mounted flush. Air at a cooler temperature will flow through the duct in a precisely controlled manner. The gas temperature and velocity will be variable, with heat fluxes at the surface designed to be preset between $0.5 \mathrm{~kW} / \mathrm{m}^{2}$ and $5.0 \mathrm{~kW} / \mathrm{m}^{2}$ within an uncertainty of less than \pm 5 percent. Flow visualization, hot-wire probing, thermocouples, and temperature sensitive liquid crystals will be used to measure the temperature fields in the air and on the 
surface adjacent to the flux gauge. Numerical simulations by co-workers in NIST's Chemical Science and Technology Laboratory and in the Electronics and Electrical Engineering Laboratory of the energy transfer will be used to refine the design and minimize uncertainties. In a second facility, the guarded hot-plate concept will be extrapolated to produce heat fluxes up to 100 $\mathrm{kW} / \mathrm{m}^{2}$. A $1.0 \mathrm{~mm}$ thick layer of helium will separate two flat, polished copper plates maintained at a temperature difference of several hundred degrees. This type of construction should minimize the contribution of radiation and convection to the conductive heat transfer.

\section{Recent Results}

Grosshandler, W., and Blackburn, D., "Development of a Heat Flux Conduction Calibration Apparatus," 1997 International Mechanical Engineering Congress and Exposition, Dallas, TX, November 1997.

Holmberg, D., Steckler, K., Womeldorf, C., and Grosshandler, W., "Facility for Calibrating Heat Flux Sensors in a Convective Environment," 1997 International Mechanical Engineering Congress and Exposition, Dallas, TX, November 1997.

\section{RECENT GRANTS-FIRE SENSING AND EXTINGUISHMENT}

\section{Fire Detection Using Reflected Radiation and Source Temperature Discrimination}

Principal Investigator

Dr. Yudaya Sivathanu

Thermal Sciences and Propulsion Center

School of Mechanical Engineering

Purdue University

West Lafayette, IN 47907

765-494-9364

\section{Sponsor}

National Institute of Standards and

Technology

\section{Objective}

To determine the efficacy of a near-infrared fire detector which detects fire based on a statistical analysis of apparent source temperatures and to simulate the effects of surface reflections on the apparent source temperatures measured by the near-infrared fire detector.

\section{Problem}

Conventional fire detectors, that sense fires based on the local concentrations of smoke or hot gases, have a very slow response time. This time delay is associated with the diffusion of the combustion products from the fire to the detector. Fire detectors that utilize radiation either in the infrared or in the ultraviolet or a combination of both have a much faster response time. However, conventional radiation detectors suffer from a high false alarm rate that limit them to specific applications. There is a commercial need for a general purpose, fast acting fire detector which has a very low false alarm rate.

\section{Approach}

Natural fires can be distinguished by their apparent source temperature and the power spectral density of radiation emitted by them. 
The near infrared fire detector measures the radiation intensities incident on it at $900 \mathrm{~nm}$ and $1000 \mathrm{~nm}$ and uses them to calculate a time series of apparent source temperatures. A statistical analysis of the source temperatures is used to discriminate fires from background radiation. Radiation intensities from the six standard test fires (specified in the CEN guidelines) were studied to obtain a suitable fire detection algorithm. The near infrared fire detector was tested for both false alarm rates and response times with fires started within and outside it's direct view.

Numerical evaluation of the fire detector was also conducted at the same time by using a discrete probability function (DPF) method to trace radiation from a standard test fire to the detector within different enclosures. The walls of the enclosures were assumed to reflect part of the radiation (both specularly and diffusely) with the remainder being absorbed. The effect of the surface reflections on the apparent source temperatures was studied to ascertain that the fire detector could function adequately even if the fire was not within the direct view of the detector.

The major conclusions of the study are:

(1) Utilizing near infrared radiation and source temperature discrimination provides an effective method of detecting open and smoldering fires.

(2) Numerical and experimental evaluation suggest that the near infrared fire detector can detect the presence of fire, even when the fire is not within the direct view of the detector.

\section{Recent Results}

Y. R. Sivathanu and L. K. Tseng, "Fire

Detection Using Time Series Analysis of Source Temperatures," Journal of Fire Safety, 1997.

Y. R. Sivathanu and J. P. Gore, "Effects of Surface Properties on Radiative Heat Transfer in a Cylindrical Tube with Nonparticipating Media," Journal of Heat Transfer, August 1997.
Y. R. Sivathanu and L. K. Tseng, "Characterization of the Radiation Properties of Fires Using Multi-Wavelength Measurements," 1996 Proceedings of the Thirtieth Section Anniversary Technical Meeting of the Central States Section of the Combustion Institute, St. Louis, MS, p. 305, 1996.

Y. R. Sivathanu and J. P. Gore, "Radiative Heat Transfer Inside a Cylindrical Enclosure," 1996, Proceedings of the ASME Heat Transfer Division, Vol. 1, HTD-vol. 332, 1996. 


\section{Water Mist Penetrations Through Complex Openings of Compartments}

\author{
Principal Investigator \\ Prof. S. C. Yao \\ Dept. of Mechanical Engineering \\ Carnegie Mellon University \\ Pittsburgh, PA 15213 \\ Tel. 412-268-2508 \\ email:scyao@cmu.edu
}

\section{Sponsor}

National Institute of Standards and Technology

\section{Objective}

To understand the phenomena, to reveal the mechanisms, and to correlate the results of the mist penetration through openings of compartments during fire extinguishment.

\section{Problem}

During equipment fires, water mist are difficult to penetrate the compartment openings. This complex transport process is strongly influenced by both the structures of the openings which could be screens or slots, etc. and the water mist conditions which are droplet sizes, velocities and number densities etc.

\section{Approach}

The interaction of the water mist and the compartment is modeled through numerical computations. The mist may come at gravity fall or at a prescribed velocity. The impaction efficiency of the mist to the compartment is correlated with a non-dimensional Impaction Parameter. This determines the amount of mist arrives to the compartment boundary. For large droplets, they will impact onto the screen wires or structures directly. Therefore, the area ratio of the wire or structure to the overall opening will determine the amount of interceptions. For small droplets, they can follow with the air flow and come into the compartment easier. Computation is performed to model the escaping efficiency of small droplets with respect to the array of slots to estimate their chance of penetrating into the compartment. For the droplets which are intercepted by the structures, The impaction phenomena are studied experimentally. Single droplets are produced from a monosize droplet generator. The study covers droplets with a range of sizes and velocities impacting to wires of various diameters and at different offset. The results are correlated with the incoming droplet Weber number, the drop to wire size ratio, and the nondimensional offset in a regime map.

\section{Recent Results}

Hung, L.S. and Yao, S.C., "Interactions of Droplets with Cylindrical Objects," Submitted for ILASS-Americas, Ottawa, Ontario, Canada, 18-21 May 1997.

Hung, L.S. and Yao, S.C., "Experimental Investigation of the Water Mist Impacting Phenomenon on Horizontal Wires," Presented at NIST Annual Conference on Fire Research, Gaithersburg, MD, October 28-31, 1996.

Hung, L.S. and Yao, S.C., "Numerical Studies on the Deposition and Transport of Water Mist to a Horizontal Plate," Presented at NIST Annual Conference on Fire Research, Gaithersburg, MD, October 28-31, 1996. 


\section{A Theoretical and Experimental Investigation on Physical, Thermal and Chemical Effects of Condensed Phase Fire Suppressants}

\author{
Principal Investigator \\ Harsha K. Chelliah \\ Department of Mechanical, Aerospace \\ and Nuclear Engineering \\ University of Virginia \\ Charlottesville, VA 22903 \\ (804) 924-6037
}

\section{Objective}

To quantify the physical, thermal and chemical effects of condensed-phase fire suppressants in extinguishing counterflow laminar flames by experimental and computational techniques.

\section{Problem}

The production of chemical fire suppressants containing $\mathrm{Br}$-atoms (e.g. $\mathrm{CF}^{3} \mathrm{Br}$-- halon 1301) has been banned because of its adverse effects on the upper-atmospheric ozone layer. However, on a mass basis, sodium bicarbonate $\left(\mathrm{NaHCO}^{3}\right)$ is known to be more effective than halon 1301, and certainly far more effective than most alternate gas-phase fire suppressants. Recent experiments aimed at quantifying the effectiveness of $\mathrm{NaHCO}^{3}$ particles of varying sizes have shown counter-intuitive trends in suppression effectiveness. In order to understand these results and provide information valuable in the search for alternative fire suppressants, a comprehensive experimental and theoretical approach is adopted in the present work.

\section{Approach}

Nonpremixed flames of hydrocarbon fuels and air, established in a steady, laminar, counterflow field, provide an excellent configuration for theoretical and experimental studies directed at better understanding the fundamental characteristics of fire suppressing agents. In this flow field, the axial velocity gradient, or the flow strain rate, at flame extinction provides a convenient parameter to quantify the suppression effectiveness. Numerical calculations on flame extinction condition in this flow field are being performed using two approaches. In the first approach, quasi-one dimensional calculations along the axis of symmetry are performed using a hybrid Eulerian-Lagrangian description for the gas-particle motion, with detailed chemical kinetic models. The flame extinction results with fine-water droplets have shown interesting nonmonotonic effect on water droplet size in extinguishing the counterflow nonpremixed methane-air flames. In subsequent analysis, the exact thermal, physical and chemical contributions have been quantified. In the second approach, two-dimensional axisymmetric conservation equations, with simplified reaction models, are solved numerically. The aim here is to investigate the effect of water droplet number density on the approximations introduced in deriving the quasi-one dimensional formulation used in the first approach. This effort will be extended to investigate the effect of sodium bicarbonate particles next.

In the supporting experiments, an enclosed, counterflow burner has been designed and built with provision for introducing condensed-phase suppressing agents with the air-stream. Because of the seeding of the air stream with the condensed phase agents, use of screens is not an option to make the flow uniform. Therefore, converging nozzles made out of Pyrex glass are used to obtain uniform flow at the jet exit. An LDV system has been set up to verify the quality of the flow and also the local flow strain rate. Significant effort has been devoted to developing a steady particle feed system, for a wide range of particle sizes. The next goal is to characterize the effectiveness of various sizes of $\mathrm{NaHCO} 3$ particles (sized into groups of 0 $\mathrm{mm}-10 \mathrm{~mm}, 10 \mathrm{~mm}-20 \mathrm{~mm}, 20 \mathrm{~mm}-30 \mathrm{~mm}$, $40 \mathrm{~mm}-60 \mathrm{~mm}$, and $60 \mathrm{~mm}-75 \mathrm{~mm}$ ) in suppressing nonpremixed gaseous flames, based on the local extinction strain rate measurements using the LDV system. In subsequent years, advanced laser diagnostic facilities will be used for point measurements and planar imaging of the temperature and 
species profiles to further validate the numerical model.

\section{Recent Results}

Lentati, A.M. and Chelliah, H.K.,"The

Dynamics of Water Droplets in a

Counterflow Field and its Effect on Flame

Extinction," Eastern States Section Meeting,

The Combustion Institute, Hilton Head, SC,

December 1996. 


\section{FIRE SCIENCE DIVISION}

\section{MATERIALS FIRE RESEARCH}





\section{Fire Safe Materials}

\section{Principal Investigator}

Takashi Kashiwagi

Fire Science Division

301-975-6699

\section{Sponsor}

National Institute of Standards and

Technology

\section{Objective}

To develop theoretical models describing thermal degradation behavior of polymer chains in the presence of flame retardant additives, new approaches to flame retardant materials, and methods to measure material flammabilities and their relationship to fire performance of specific end products for the material.

\section{Problem}

Many inexpensive, large volume commodity polymers have excellent physical properties. However, almost all of them are highly flammable. Therefore, flame retardant additives are commonly used in the end application when good fire performance is required. The development of new environmentally friendly, inexpensive flame retardant additives is expensive and time consuming for U.S. industry. Instead of the traditional trial-and-error approach, a more scientific approach based on various technical tools is needed for the industry to make more fire safe, environmentally friendly end products. The problem is the need for rational development of new materials, as well as appropriate evaluation of the flammability properties of end products with new flame retardants to assure their improved fire performance. This requires appropriate, bench-scale methodology to determine relevant flammability properties of candidate materials and their relationship to fire performance of the specific end products made from these materials.

\section{Approach}

During FY1997, BFRL will further develop a molecular dynamics model describing the thermal degradation of commodity polymers with potential flame retardant additives to determine the effects of the additives on thermal stability of the polymers and the formation of stabilizing crosslinks. These calculated results will be compared with the experimentally measured changes in the polymers with the additives during thermal degradation. After the specific end products are selected, BFRL will conduct full scale experiments with various samples with and without flame retardants to understand their controlling physical processes. A fire growth model will be developed for the specific end products based on the controlling physical processes. The inputs to the model will be measured for the samples tested in full scale experiments. The calculated results are be compared with the full scale data to examine the accuracy of the model and to continue the improvement of the model. The results will establish the relationship between the effectiveness of flame retardancy for the materials measured in bench scale tests and their fire performance in the selected end use. An industrial consortium has been formed and potential end applications will be determined shortly after evaluating the inputs from the consortium members.

\section{Recent Results}

Gilman, J.W., Ritchie, S.J., Kashiwagi, T., and Lomakin, S.M. " Fire Retardant Additives for Polymeric Materials. 1. Char Formation from Silica Gel - Potassium Carbonate" Fire and Materials, $21: 23-32$, 1997. 
Development of

Environmentally-Friendly, New Flame Retardants Consortium

\author{
Principal Investigator \\ Takashi Kashiwagi \\ Fire Science Division \\ 301-975-6699
}

\section{Sponsors}

Consortium Members (AKZO NOBEL, FMC, PQ Corp., Sekisui America)

\section{Objective}

To understand the mechanisms of char formation and heat release rate reduction due to the addition of silica gel in polypropylene, PP.

\section{Problem}

Many inexpensive, large volume commodity polymers have excellent physical properties. However, almost all of them are highly flammable. Therefore, flame retardant additives are commonly used in the end application when good fire performance is required. Some of the most common additives contain halogens, chemicals that have raised some environmental concerns, especially in Europe. U.S. manufacturers are seeking new, environmentally friendly flame retardants in order to manufacture the same products for export as well as domestic sale. Polypropylene is a commodity polymer which is used for fabric in upholstered furniture, carpets, cables, in automobile and so on. One environmentally friendly flame retardant approach is to alter the thermal degradation processes so as to enhance char formation during polymer burning. Char formation reduces the amount of carbon containing, combustible, volatile, degradation products, char also insulates the underlying polymer, due to the char's low thermal conductivity. However, PP does not generate char during its burning. We know that the addition of silica gel in PP generates a significant amount of char and reduces heat release rate. We do not yet understand the mechanisms for the formation of char, in this system. A thorough investigation of these mechanisms is needed to optimize the structure and composition of silica gel to generate more char and enhance the reduction in heat release rate.

\section{Approach}

During FY1997, BFRL will use its Cone Calorimeter to evaluate the effect of particle size, pore size, pore fraction, and silanol content of the silica gel on the flammability properties of PP. The Cone Calorimeter data will assist in determining what parameter of the silica gel controls the flammability of PP. BFRL will use the gasification apparatus (unique to NIST) to measure gasification rate and temperatures in the sample in nitrogen atmosphere to determine the effects of the silica gel structure/composition on the gasification processes of PP. Polymer residues generated from the gasification apparatus or our nitrogen flow reactor at various temperatures will be analyzed by $1 \mathrm{H}, 13 \mathrm{C}$, and 29Si solid state NMR. Changes in the thermal degradation processes of PP with the addition of the silica gel will be measured using FTIR evolved gas analysis. A series of computer experiments will be conducted using BFRL's developed molecular dynamics model in an effort to elucidate the mechanism by which the presence of silica gel alters the thermal degradation chemistries or physical gasification processes of PP.

Combined analysis of the computational results with the experimental data will reveal the char formation mechanism and also will determine the optimal structure/composition of silica gel for the formation of char and reduction in heat release rate in PP.

\section{Recent Results}

New project. 


\section{Flammability of Automotive Materials and Components}

\author{
Principal Investigator \\ Thomas J. Ohlemiller \\ Fire Science Division \\ 301-975-6481
}

\section{Sponsor \\ National Institute of Standards and \\ Technology}

\section{General Motors Corporation}

$\mathrm{R} \& \mathrm{D}$ Center

Automotive Safety Research Department

\section{Objective}

To measure the flammability of materials and assemblies from the engine and passenger compartments of various automobiles and identify means of improvement.

\section{Problem}

This is one task of three undertaken under a CRADA with General Motors Corporation.

There is need to examine the origins, progression and severity of post-crash automobile fires and to assess potential means to alleviate this fire problem.

Required is a quantitative measure of the heat release rate from functional assemblies found in automobiles, especially under the hood. Since thermoplastics are involved in most of these, the expected mode of burning is one of the object interacting with its self-generated pool fire.

\section{Approach}

During FY1997, BFRL will measure the heat release rate from objects yielding a peak HRR of about $50 \mathrm{~kW}$ or less. This includes a provision for a pool fire beneath the object. BFRL will perform experiments using its Cone Calorimeter of the factors affecting an interacting object/pool fire.

\section{Recent Results}

New Project.

\section{Vehicle Fire Initiation and Propagation}

\author{
Principal Investigators \\ Thomas G. Cleary \\ Fire Science Division \\ 301-975-6858 \\ Thomas J. Ohlemiller \\ Fire Science Division \\ 301-975-6481
}

\section{Sponsor \\ General Motors Corporation \\ R\&D Center \\ Automotive Safety Research Division}

\section{Objective}

Develop a better understanding of the dynamics of post-collision fires that threaten the safety of vehicle occupants and develop realistic, repeatable ignition protocols for vehicle fire safety testing.

\section{Problem}

Approximately 1 percent-2 percent of all high-speed vehicle crashes are attended by fire which results in an estimated 300 vehicle occupant deaths per year due to fire in otherwise survivable crashes. It is unknown whether cost-effective solutions (less flammable materials substitution, active suppression, etc.) could be devised to improve the death and injury rate from post-collision fire.

\section{Approach}

During FY1997, BFRL will analyze a series of instrumented high-speed crashes performed by GM for clues suggesting ignition sources, the distribution of flammable fluids and the potential for ignition. Plausible ignition scenarios will be hypothesized: then, repeatable fire initiation protocols will be developed that mimic ignition scenarios in terms of the initial fire insult to the vehicle. The crashed vehicles will be heavily instrumented (video, temperature, heat flux, and gas analysis) and burned given a predetermined initiation protocol to examine the role specific vehicle components play in 
the fire growth and spread into the passenger compartment. From these results, intervention (active or passive) strategies could be proposed and tested, leading to safer vehicles.

\section{Recent Results}

New project.

\section{Evaluation of Potential Fire Intervention Materials and Technologies}

Principal Investigator

Anthony Hamins

Fire Science Division

301-975-6598

\section{Sponsor}

General Motors Corporation

R\&D Center

Automotive Safety Research Department

\section{Objective}

To identify and evaluate fire protection and suppression technologies that could improve fire safety of vehicles.

\section{Problem}

Heat transfer, transport of toxic gases, and flame propagation into the passenger compartment lead to fatalities associated with post-accident vehicle fires.

\section{Approach}

During FY1997, BFRL will evaluate the progression of fires in vehicle tests and determine where active and passive fire protection systems can effectively intervene. Identification of superior materials and appropriate fire protection technologies will be sought from industry. Based on the information gained from the vehicle fire tests, one or more representative fire scenarios will be developed for use in intermediate and full-scale evaluation of selected materials and technologies. Intermediate-scale testing of selected materials and technologies will be conducted using the representative scenarios.

\section{Recent Results}

New project. 
Quantitative Evaluation of Fire Safety Features

Principal Investigator

Anthony Hamins

Fire Science Division

30 I-975-6598

\section{Sponsor}

National Institute of Standards and

Technology

\section{Objective}

To predict the burning rate of a standard rack-storage commodity fire, with and without water sprinkler application.

\section{Problem}

Draft curtains, a fire safety requirement for industrial rack storage of commodities are expensive. Models which provide a reliable means to predict the effectiveness of alternative active and passive fire protection are desirable. Computations using the methodology of large eddy simulations have been developed to model the interaction of sprinklers and draft curtains for rack storage commodity fires. Furthermore, the model has been shown to be capable of predicting the major features in two existing large scale tests. Verification of the micro-scale combustion sub-models are needed to improve computational reliability.

\section{Approach}

During FY1997, BFRL will observe small, intermediate, and if possible, large-scale burn experiments observed to ascertain fire behavior. Relevant literature will be consulted in an effort to develop an improved first generation burning rate model. A series of small and intermediate scale measurements will be conducted to validate the improved burning rate model. Small scale experiments, such as in the cone calorimeter, will investigate the combustion characteristics of wet and dry cardboard. The effect of sample orientation on flame spread will be studied using a large radiant panel. The burning of single and multiple box arrays will be conducted to observe key fire phenomena such as radiative emission, fire growth and spread. The effect of water on these parameters will also be investigated.

\section{Recent Results}

New project. 


\section{Combustion of Silicone}

\author{
Principal Investigator \\ Takashi Kashiwagi \\ Fire Science Division \\ 301-975-6699
}

\section{Sponsor \\ Dow Corning Corporation}

\section{Objective}

To understand the combustion mechanism of siloxane and why the heat release rate (as measured in the Cone Calorimeter) of burning siloxane is nearly independent of external thermal radiant flux.

\section{Problem}

The heat release rate (HRR) of burning materials increases significantly with an increase in external thermal radiant flux applied to the burning surface. This is true for non-charring materials and for charring materials. However, the burning behavior of siloxanes differs markedly from carbon-based materials. Perhaps most significant, the HRR for siloxanes (chain length $>15 \mathrm{Si}-\mathrm{O}$ units) does not increase significantly with an increase in external thermal radiant flux. Whereas carbon based materials may form products of incomplete combustion such as soot and carbonaceous chars, siloxanes form very minimal char but produce substantial amounts of solid amorphous silica $(\mathrm{SiO} 2)$ as a major product of combustion. Previous studies suggest that amorphous silica plays a significant role in mediating the burning behavior of siloxanes.

\section{Approach}

During FY1997, BFRL will perform three tasks:

1. Gasification rates of silicone fluids will be measured in nitrogen as a function of a well-defined simulated silica layer in the fluid to determine the role and mechanism of the silica ash layer in the burning behavior of silicone fluids.

2. Determine the distribution of temperature in silicone flames. A number of techniques will be explored including aspirated thermocouples as well as optical methods as an effective grey body spectral emission approximation.

3. Author technical paper on the gasification rate, global heat of gasification, vapor products and residue analysis for submitted to an appropriate technical journal.

\section{Recent Results}

Buch, R., Hamins, A., Konishi, K., Mattingly, D., and Kashiwagi, T., "Radiative Emission Fraction of Pool Fires Burning Silicone Fluids," Combustion and Flame, 108:1 18-126, 1997.

Austin, P. J., Buch, R. R., and Kashiwagi, T., Gasification of Silicone Fluids Under External Thermal Radiation, NISTIR 6041, National Institute of Standards and Technology, July 1997. 


\section{Production and Certification of Cone Calorimeter SRMs}

\section{Principal Investigator}

Kenneth Steckler

Fire Science Division

301-975-6678

\section{Sponsor}

National Institute of Standards and Technology

\section{Objective}

To produce and certify two standard reference materials for heat, mass, and smoke release rates in the Cone Calorimeter.

\section{Problem}

There are about 140 Cone Calorimeters in the world and their number is increasing annually. This device and attendant test method were developed at in the middle 1980's to measure simultaneously three different flammability properties of a single end-product specimen: heat release rate, mass loss rate (burning rate), and smoke production. The method is used widely by testing companies, materials/chemical companies, and end-products producers to evaluate fire performance of existing materials as well as new, exploratory materials. However, there often is substantial scatter in lab-to-lab results, and there are no standard reference materials to calibrate the entire system in a manner which closely mimics the behavior of a real sample (a methane burner currently is used for heat release rate). Therefore, realistic calibration samples in slab form are critically needed to make certain that the device measures heat release rate, mass loss rate, and smoke production accurately, repeatably, and reproducibly.

\section{Approach}

During FY1997, BFRL plans to certify and produce two standard reference materials; one will be a thermoplastic which forms no char during burning; it will tend to generate a nearly steady, high heat release rate (and burning rate), with high smoke production.
The other standard sample will be a charforming material which tends to generate an unsteady, low heat release rate (and burning rate), typically with two different peak heat release rates during burning, and with low smoke production. Several materials will be assessed, including polystyrene and phenolics, and two will be selected for certification and production as SRM's.

\section{Recent Results}

New project. 


\section{Radiative Ignition and Subsequent Flame Spread in Microgravity}

\author{
Principal Investigator \\ Takashi Kashiwagi \\ Fire Science Division \\ 301-975-6699

\section{Sponsor \\ Technology and \\ National Aeronautics and Space \\ Administration \\ Microgravity Science Project} \\ National Institute of Standards and
}

\section{Objective}

To extend the BFRL theoretical model of ignition and subsequent flame spread over a thermally thin material in microgravity to a thick material and conduct experiments in drop towers for comparison of the predicted results with the experimental observation.

\section{Problem}

Fires in spacecraft pose significant dangers to the crew due to toxic combustion products and over pressurization by heat release. Momentary ignitions due to electrical shorts or overheating might be an acceptable and recoverable hazard, but a transition from the ignition to flame spread is an acceptable risk. The transition mechanism has not been well understood.

\section{Approach}

During FY1997, BFRL will perform a parametric study to examine the effects of many physical and chemical parameters on transition from ignition and flame spread and flame growth will be conducted using the newly developed code based on full Navier-Stokes equations (time-dependent and 2D/3D). BFRL will continue to analyze experimental results obtained in the USMP-3 flight and also in JAMIC II. Experiments in 50 percent oxygen will be conducted in JAMIC using thin PMMA samples and thicker paper samples as JAMIC III.

\section{Recent Results}

McGrattan, K.B., Kashiwagi, T., Baum, H.R., and Olson, S.L., "Effects of Ignition and Wind on the Transition to Flame Spread in a Microgravity Environment," Combustion and Flame, 106:377-391, 1996.

Kashiwagi, T., McGrattan, K.B., Olson, S.L., Fujita, O., Kikuchi, M., and Ito, K., "Effects of Slow Wind on Localized Radiative Ignition and Transition to Flame Spread in Microgravity," Twenty-Sixth Symposium (International) on Combustion, The Combustion Institute, 1345-1352, 1996. 


\section{Combustion of a Polymer (PMMA) Sphere in Microgravity}

\author{
Principal Investigator \\ Jiann C. Yang \\ Fire Science Division \\ 301-975-6662
}

\section{Sponsor}

National Aeronautics and Space

Administration

Lewis Research Center

\section{Objective}

To determine the burning rates of PMMA spheres in a low gravity environment under various ambient oxygen conditions.

\section{Problem}

The need to use polymeric materials that may be flammable cannot be totally eliminated aboard the space shuttle or the future manned permanent space-station. This study is pertinent to the problem associated with the potential fire threat caused by the presence of polymeric materials. The use of spherical geometry has many advantages because a spherical flame, which is one-dimensional, is amenable to simple mathematical analysis and facilitates a detailed examination of the many interesting phenomena associated with the combustion of a solid phase material without involving the complications of flame-spread, which is still an active research area.

\section{Approach}

During FY1997, BFRL will perform fire experiments using polymeric materials in low gravity aboard the NASA Reduced Gravity DC-9 Aircraft. The sphere will be ignited using a pair of heating coils. Experiments using suspended spheres will be conducted, and a mechanism for deploying an unsupported sphere will also be developed. Suspended spheres will be obtained by supporting the spheres at the tip of a thermocouple. Results will be compared with those obtained under normal gravity condition.

\section{Recent Results}

Yang, J.C., Hamins, A., Gorchkov, N., and Glover, M., "Combustion of Polymethymethacrylate Spheres," Work-in-Progress Poster Sessions, Twenty-sixth Symposium (International) on Combustion, Naples, Italy, August 1996.

Yang, J.C., Hamins, A., Gorchkov, N., and Glover, M., "Combustion of

Polymethymethacrylate Spheres at Normal and Reduced Gravity," Annual Conference on Fire Research, October 1996. 
RECENT GRANTS-MATERIALS FIRE RESEARCH

\section{Cross-Linking of Polystyrene by Friedel-Crafts Chemistry to \\ Enhance Resistance to Thermal Degradation}

\author{
Principal Investigators \\ Charles A. Wilkie \\ Michael A. McKinney \\ Department of Chemistry \\ Marquette University \\ P. O. Box 1881 \\ Milwaukee, WI 53201
}

\section{Sponsor \\ National Institute of Standards and \\ Technology}

\section{Objective}

To develop a suitable system for FriedelCrafts chemistry to achieve cross-linking of polystyrene only under conditions which approximate those which may be encountered in a small fire.

\section{Problem}

It is usually assumed that a cross-linked polymer will be more thermally stable than is a thermoplastic material. One may easily cross-link the majority of polymers but they lose all processability upon cross-linking. The goal of this work is to maintain the processability of polymers by incorporating materials which will promote the crosslinking of polymers only under thermal conditions which exceed those which would be used during the processing of the polymer.

\section{Approach}

Any cross-linking scheme must take advantage of the functional groups which are present on the polymer. In the case of polystyrene, the only functional group which is present is the aromatic ring and this means that a reaction must be performed on this ring to achieve cross-linking. One chemical reaction which may occur on aromatic rings is Friedel-Crafts alkylation and acylation reactions. In the typical reaction, one uses aluminum chloride as the catalyst with an alkyl halide as the alkylating agent. This is unsuitable because the catalyst is quite hygroscopic so it will seriously erode the characteristics of the polymer and because hydrogen chloride is evolved as a byproduct of the reaction. An additional problem is that an alkyl halide will alkylate benzene at room temperature when aluminum chloride is used as the catalyst. In order to use this reaction one must identify an inefficient catalyst which will only promote the reaction at elevated temperatures and/or an inefficient alkylating agent. Another requirement is that the alkylating agent be dysfunctional so that cross-linking is possible. The combinations which has proven most efficacious to date uses zeolite catalysts with diols as the alkylating reagents.

\section{Recent Results}

Li, J., and Wilkie, C. A., "Improving the Thermal Stability of Polystyrene by FriedelCrafts Chemistry," Polymer Degrad. Stab., has not yet been published. 


\section{A Fire Growth Simulation Model for Materials}

\author{
Principal Investigator \\ Professor James Quintiere \\ Fire Protection Engineering \\ University of Maryland \\ College Park, MD \\ 301-405-3993
}

\section{Sponsor \\ National Institute of Standards and Technology}

\section{Objective}

The proposed research seeks to develop and assess a simulation model to predict the fire growth on commercial materials used in building construction and finish applications.

\section{Problem}

Many standard regulatory test methods are intended to assess and control the flammability of interior finish and construction materials. While these tests vary, room-corner tests of wall and ceiling materials have emerged as an alternative and more universal measure of material performance. Predictive methods to assess fire growth on such materials in realistic scenarios are limited and lack confidence.

\section{Approach}

In 1992 a simulation model was published which had good success at predicting the performance of materials in the ISO DP 9705 room corner test protocol. Since then 24 materials have been assessed by the model and compared to its actual test performance. Encouraging results were obtained. Subsequent analysis of UBC room-corner test protocol results for textile wall materials demonstrated the model's versatility and its reasonably accurate predictability. The model offers the framework for fire growth prediction within the context of building fire and smoke models such as CFAST.

The model is a systems approach to fire growth. The approach has been to maintain simplicity but completeness. Simplicity is needed in order to easily accommodate material data from standard tests. Property data for the model are derived from tests results of the Cone Calorimeter and the LIFT apparatus. Data over a heat flux range are needed to adequately develop the needed property data to predict ignition, flame spread and burning rate. Other needed model input data include the heat flux and flame height characteristics of the corner ignitor burner. This controls the heat flux during flame spread in the corner. Recent studies of the heat flux characteristics of corner burners can provide more accurate and more general data inputs for the model. Currently the model consists of four differential equations for flame spread and burnout fronts in two directions, an integral equation for room surface temperature, and an algebraic equation for smoke layer temperature. A complete documentation and reassessment of the model is underway.

New data from full-scale corner tests will be examined. These include 12 materials tested in the ISO standard, former work by Kokkala in a much larger test, and NIST data for a composite material in a non-standard corner test.

The goals are to present a clear description of the model so that others might consider its use, to improve the physical basis for the model in view of recent research, and to assess the accuracy of the model against new full-scale data.

\section{Recent Results}

Quintiere, J. G., Haynes, G., and Rhodes, B. T., "Applications of a Model to Predict Flame spread over Interior Finish Materials in a Compartment," Journal of Fire Protection Engineering, Vol. 7, No. 1, 1995.

Quintiere, J. G., Hopkins, M., and Hopkins, D. Jr., "Fire Hazard Prediction for Textile Wall Materials," Department of Fire Protection Engineering, University of Maryland, prepared for the American Textile Manufacturers Institute, January 1995. 


\section{The Development of Novel Low Flammability Siloxane-Based Impact Modifiers for Cyanate Ester Resins}

\author{
Principal Investigator \\ Professor Steven K. Pollack \\ Department of Chemistry \\ Howard University \\ 202-80-6892
}

\section{Sponsor \\ National Institute of Standards and Technology}

\section{Objective}

To develop siloxane polymers terminally functionalized with cyanate ester group capable of being compounded with commercial cyanate ester resins such that they impart higher impact resistance with no increase or with a decrease in flammability.

\section{Problem}

Cyanate ester resins (CERs) have been proposed as a potentially useful matrix material for airframes. CERs have seen their widest use in printed circuit wiring board (PCWB) technologies. Their use in radomes and for application in near earth orbit has also seen a recent increase. However, commercial CERs do not currently have the appropriate fracture toughness for applications such as airframe construction. Standard techniques for improving the performance of brittle polymer matrices would include the addition of a phase separated rubbery materials as impact modifiers. These serve to induce microfracturing in a controlled fashion and the rubbery particles then act as energy dispersing elements in the matrix. Thus a rubber-modified matrix will fail "gracefully" rather than catastrophically. A major concern for the increase in the use of polymeric materials in commercial airline construction is their potential for combustibility. The CERs have flammability comparable to conventional phenolic resins and possess excellent processibility. Added impact modifiers must not lead to increases in flammability or to the release of toxic materials during combustion.

\section{Approach}

We are developing compositions of cyanate functional siloxanes and determine the appropriate formulations to provide optimal mechanical performance with combustion properties as good as or better than pure CERs. To accomplish this, we are synthesizing cyanate terminated siloxane polymer. This involves the synthesis of disiloxanes functionalized with terminal phenol groups. These dimers are then equilibrated with the cyclic trimer or tetramer of dimethylsiloxane and in some formulations with the addition of diphenylsiloxane, the latter intended to improve the solubility of the siloxane in the CER resins. After formation of the phenol terminated oligomers, they are reacted with cyanogen bromide to create the final CER-siloxane. This is then blended with oligophenol derived commercial cyanate ester resins.

\section{Recent Results}

No published report on this work. 


\section{FIRE SCIENCE DIVISION}

\section{ADVANCED FIRE MEASUREMENTS}





\section{Improvement and Development of Fire Diagnostics}

\author{
Principal Investigator \\ William M. Pitts \\ Fire Science Division \\ 301-975-6486
}

\section{Sponsor}

National Institute of Standards and

Technology

\section{Objective}

To quantitatively characterize fire behavior using experimental measurement techniques having reliable estimates of accuracy and precision.

\section{Problem}

As the understanding of fire behavior and modeling has advanced, the need for quantitative characterization of fire properties has increased dramatically. Such measurements are required to improve the understanding of fire physics and chemistry. Also, detailed measurements are needed to validate the zone and field models which are being developed to predict fire behavior. Nearly all measurement techniques currently employed for fire characterization have been in use for several decades and have generally not incorporated the great strides made in instrumentation and data acquisition abilities. Compounding the problem is that all currently used techniques are subject to systematic and random errors which have not been fully characterized.

\section{Approach}

During FY1997, BFRL will assess many currently used methods characterizing fire properties and based on analysis and testing, recommend modifications which will improve both precision and accuracy. A systematic program will investigate potential new fire diagnostics and develop practical systems for implementation.

\section{Recent Results}

New project.

\section{Particle Measurement in Support of the Semiconductor Industry}

\author{
Principal Investigator \\ George W. Mulholland \\ Fire Science Division \\ 301-975-6695
}

\section{Sponsor \\ National Institute of Standards and Technology}

\section{Objective}

To develop a facility for accurately measuring particle size/concentration and for depositing monodisperse particles of specified size, number, and chemistry on calibration artifacts to support the Semiconductor Roadmap goal of qualifying $60 \mathrm{~nm}$ diameter particles.

\section{Problem}

The detection, quantification and characterization of particulate contamination on semiconductor surfaces is essential to advanced semiconductor manufacturing. The present practical limit for particle detection is $100 \mathrm{~nm}$ diameter. The National Technology Roadmap for Semiconductors calls for the ability to detect and quantify particles with a $60 \mathrm{~nm}$ diameter by 2001 . There is currently a need for accurately sized monodisperse particles in the size range from $70 \mathrm{~nm}$ to 200 $\mathrm{nm}$ for developing and calibrating improved scanning surface inspection systems.

\section{Approach}

During FY1997, BFRL will perform electrical mobility measurements by VLSI Standards on a reduced data set. The mean particle size will be determined from the data in collaboration with Statistical Engineering Division and a report prepared enabling the particle suppliers to provide more accurate particle samples. The stability of the aerosol generation system will be improved and then used in assessing the performance of a modified inlet for the electrical mobility analyzer. The improved system will be used in accurate particle size measurement for 80 $\mathrm{nm}$ polystyrene spheres, which is the key 
target particle size for new scanning surface inspection systems. A trajectory model has been developed for the electrical mobility analyzer in collaboration with NIST's Statistical Engineering Division and is being used to assess the effect of particle diffusion on the classifier performance.

\section{Recent Results}

Mulholland, G.W., Bryner, N., Liggett, W., Scheer, B.W., and Goodall, R.K., "Selection of Calibration Particles for Scanning Surface Inspection Systems," Proceed. of SPIE Meeting, August, 1996, Denver.

Mulholland, G.W., and Bryner, N.P., "Application of the Electrostatic Classifier for Particle Metrology Relevant to the Semiconductor Industry," Fine Particle Society Meeting, August 1996, Chicago, IL.

\section{Carbon Monoxide Production and Prediction}

Principal Investigator

William M. Pitts

Fire Science Division

301-975-6486

\section{Sponsor}

National Institute of Standards and

Technology

\section{Objective}

To develop a fundamental understanding of the mechanisms of carbon monoxide formation in flames sufficient to produce a detailed predictive model.

\section{Problem}

$\mathrm{CO}$ generated by fires in enclosures is responsible for roughly two-thirds of fire deaths. The conditions necessary and the mechanisms responsible for the generation of high concentrations of $\mathrm{CO}$ are poorly characterized. As a result, it is currently impossible to predict the generation of $\mathrm{CO}$ by fires. Such a predictive capability is required by Laboratory fire models such as HAZARD.

\section{Approach}

During FY1997, BFRL will continue to perform fundamental and engineering investigations. The engineering studies are designed to develop appropriate correlations for $\mathrm{CO}$ formation for fires in enclosures and provide the necessary knowledge to incorporate the findings into existing BFRL fire models. The fundamental investigations will identify the principal chemical and physical mechanisms responsible for the formation of high $\mathrm{CO}$ concentrations in fires and to theoretically justify the use of the engineering correlations. Ultimately, the findings will be incorporated into a simple physical model for $\mathrm{CO}$ production in enclosure fires.

\section{Recent Results}

Identified four mechanisms which are responsible for the formation of $\mathrm{CO}$ within an enclosure containing a fire. The 
mechanisms were incorporated into an algorithm designed to allow the user to identify which mechanisms are important for a given fire and to provide guidance on estimating the amounts of $\mathrm{CO}$ generated.
Lean Flammability Limit as a Fundamental Refrigerant Property, Phase III

\author{
Principal Investigators \\ William Grosshandler \\ Fire Science Division \\ 301-975-2310 \\ Carole Womeldorf \\ Fire Science Division \\ 301-975-4415
}

\section{Sponsor}

Air-conditioning and Refrigeration

Technology Institute

\section{Objective}

The ultimate goal of this research program is to provide industry (by 1999) with a high precision, repeatable method for measuring flame limits based upon a counter-flow burner design. The specific objectives of Phase III are to determine if I) the absolute value of the lower flammability limit is sensitive to small changes in burner design;

2) the burner can operate and produce flame limits and critical flammability ratios at elevated temperatures, or with marginally flammable refrigerants; and 3) how the burner design might be simplified for use by industry.

\section{Problem}

CFCs have been phased out of production for use as refrigerants because of their destructive effect on stratospheric ozone. Replacing halogen atoms in the molecule with hydrogen atoms can transform a nonflammable CFC into a potentially flammable material. The efficiency and flammability of R-32 and other alternative refrigerants must be carefully balanced in mixtures to provide safe and environmentally friendly refrigerants. ASTM Standard E 68194 identifies test equipment and methods for measuring the flammability limits. For strongly flammable gases it provides a well defined limit of flammability; however, for weakly flammable alternative refrigerants, the test method gives results with a larger 
uncertainty due to its sensitivity to ignition conditions, wall quenching effects, and operator interpretation of the flammable condition. The ambiguity hinders attempts to optimize the efficiency and safety of alternative refrigerant mixtures.

\section{Approach}

During FY1997, BFRL will vary nozzle spacing and geometry to determine the effect on the zero-strain limit and to confirm that the design chosen for the NIST burner is appropriate for the purposes of the refrigeration industry. The opposed flow burner will also be modified to operate at inlet gas temperatures up to $100{ }^{\circ} \mathrm{C}$. Measurements of the lower flammability limit of R-245ca in air at room temperature and $100{ }^{\circ} \mathrm{C}$ will be attempted using the extrapolation-to-zero-strain approach developed in Phase I. If a stable flame can not be obtained, the initial conditions will be varied to enhance the combustion process. A new burner and flow control system will be designed for industrial use and an operating procedure formalized based upon experience with the current NIST burner.

\section{Recent Results}

Womeldorf, C., and Grosshandler, W., "Lean Flammability Limit as a Fundamental Refrigerant Property, Phase II," Interim Technical Report, DOE/CE/23810-68, April 30, 1996.

\section{Laminar Flame Speeds in Refrigerant/Air Mixtures}

Principal Investigators

William Grosshandler

Fire Science Division

301-975-2310

Carole Womeldorf

Fire Science Division

$301-975-4415$

\section{Sponsor}

National Institute of Standards and Technology

\section{Objective}

To support the continued development of an improved experimental procedure for use by industry (in 1999) to refine safety standard measurements of the flammability of refrigerant blends.

\section{Problem}

The standard method for determining flammability limits of refrigerants is somewhat subjective and difficult to analyze. Research at NIST has shown that a counter flow burner avoids the pitfalls for the ASTM devise for methane, but for slow burning HFCs the flame is much thicker. Detailed information on the flame structures and speed is needed in the counter flow burner to properly analyze the results and to guide the development of an alternative test method for the industry.

\section{Approach}

During FY1997, BFRL will take LDA velocity measurements for lightly-strained, stoichiometric R-32/air flames and for mixtures near the flammability limit. Prior to these measurements, an exhaust scrubber system will be designed and installed to trap the HF which is released during the combustion process. The refrigerant delivery system will be modified to accommodate liquids with normal boiling points up to 30 ${ }^{\circ} \mathrm{C}$. Measurements of the lower flammability limit of different compounds will be compared and interpreted in light of flame 
speeds predicted from a chemical kinetics model.

\section{Recent Results}

A counter-flow burner has been designed and built to operate on R-32 and R-32 blends. In related work done for the Air-conditioning and Refrigeration Technology Institute, it has been established that the burner can be used to define the flammability limits of these refrigerants in ambient air mixtures.

\section{A Numerical Model for Combustion of Bubbling Thermoplastic Materials in Microgravity}

\author{
Principal Investigator \\ Kathryn Butler \\ Fire Science Division \\ 301-975-6673
}

\section{Sponsor \\ National Aeronautics and Space Administration}

\section{Objective}

To improve our fundamental understanding of the behavior of burning thermoplastic materials in microgravity. The end product, to be delivered by June 2000 , is a threedimensional model that predicts the temperature field, burning rate, and bubble bursting characteristics for a combusting thermoplastic sphere.

\section{Problem}

Recent microgravity experiments on combustion of thermoplastics, including velcro made of nylon and electrical wire insulation, have pointed out a fire hazard unique to low gravity. Chemical reactions within the bulk of certain burning thermoplastic materials generate internal bubbles, which grow and migrate until they burst at the surface and eject fuel and fuel vapor into the surroundings. Under normal gravity conditions, the primary danger of fire spread by contact with burning thermoplastics is from the dripping of the molten material. In microgravity, however, the forcible ejection of molten fuel droplets and fuel vapor uniquely enhances fire growth by transporting burning material in random directions, threatening the safety of the crew and spacecraft.

\section{Approach}

During FY1997, BFRL will develop a timedependent, three-dimensional numerical model to predict the temperature field, burning rate, and bubble bursting 
characteristics of these materials. The model will include the dynamics of bubble growth and migration, heat transfer through the condensed material, the chemistry of gasification, and coupling to the gas phase. In this model, the thermoplastic material is initialized as a volume of highly viscous material in which a number of bubble nucleation sites (up to 10000) are randomly distributed. A separate model will study details of the bursting process. Gas phase mechanisms will be calculated in sufficient detail to adequately represent the coupling between the flame and the surface of the burning thermoplastic sample.

Model results will be compared with experimental results from the BFRL performed NASA research project "Combustion of a Polymer (PMMA) Sphere in Microgravity," and with ground-based experiments performed using BFRL's cone heater. Values to be compared include temperature as a function of time at the locations of thermocouples embedded in the samples, growth and migration of bubbles with time, and bursting rate, given by the number of bubbles that arrive at the sample surface as a function of time. A parametric study of the model will investigate the effects of variations in material properties and combustion condition on burning rate and combustion behavior.

\section{Recent Results}

A preliminary model including bubble nucleation, bubble growth and migration, and heat transfer has been developed for a rectangular sample. Three-dimensional visualization tools are in place.

\section{Flammability of Structural Composites}

\section{Principal Investigator}

Tom J. Ohlemiller

Fire Science Division

30l-975-6481

\section{Sponsor}

National Institute of Standards and Technology

\section{Objective}

Develop quantitative procedures for assessing the impact of fire on structural composites with the ultimate goal of devising materials guidelines which assure fire safe performance.

\section{Problem}

Composites have great potential for a wide variety of structural uses. However, the organic nature of the binder resin that constitutes roughly half of these materials renders them flammable. Thermal degradation of this resin in a fire also could lead to structural failure. At present, BFRL is focused on the flammability issue, in particular on upward flame spread since it is the fastest, most threatening mode of fire growth. Some of the most likely resins for large volume structural usage, e.g., polyester and vinyl ester, are known from previous work to be susceptible to fire growth by upward flame spread. Intumescent coatings are a promising technology used in the past to suppress fire growth on materials such as wood. Need is similar technology for composite materials.

\section{Approach}

During FY1997, BFRL will examine the problem of fire growth on the surface of composites in a specific configuration, i.e., a vertical, $90^{\circ}$ corner. This is a generic representation of an end use configurations in which two burning surfaces can interact radiatively thereby enhancing the likelihood and rate of fire growth. Fires of varied size and imposed heat flux level are applied at the base of this corner and the subsequent fire growth on the composite wall surfaces is 
measured. These tests are expensive to conduct and inherently limited in the parameter ranges. It is of interest to generalize the results, if possible, by means of a fire growth model. The method of choice is to employ the type of semi-empirical model developed at the University of Maryland and BFRL for fire growth on more conventional materials. Such a model uses inputs measured in bench-scale tests to characterize a particular material. When validated against available fire growth data, the model can be used to predict the behavior of a material in other conditions. This lends much greater credibility and usefulness to the limited full-scale tests likely to be done for a new material.

\section{Recent Results}

One intumescent coating was successfully tested in a full-scale corner fire and was found to limit fire growth.

Ohlemiller, T. J., Cleary, T., and Shields, J. R., "Effect of Ignition Condition on Upward Flame Spread on Composite Material in a Corner Configuration," 4lst SAMPE Meeting, March 1996.

\section{Fire Safe Aircraft Interior Materials}

\author{
Principal Investigators \\ Jeffrey Gilman \\ Fire Science Division \\ 301-975-6573 \\ Marc Nyden \\ Fire Science Division \\ 301-975-6692
}

\section{Sponsor \\ Federal Aviation Administration}

\section{Objective}

To determine the effects of preceramic polymers and clay-nano-composites on the flammability of engineering polymers useful in aircraft interiors and develop theoretical models to describe thermal degradation behavior of a variety of polymers including crosslink formation, products composition, and relative heat release rate from polymer burning.

\section{Problem}

Advancement of materials to be used in the interior of commercial aircraft is urgently needed to gain more egress time for passengers to escape from fire which may occur as a result of crash landings. However, the current capability to predict the flammability of aircraft materials on the basis of their molecular structure is limited. In this laboratory, molecular dynamics modeling has been developed to explore mechanisms of thermal degradation and crosslink formation in vinyl polymers. Development of a new code that extends this model to include gas phase reactions and also to apply to engineering plastics will bring a new tool to aid in the design of new generation fire resistant aircraft materials. Inorganic polymers which convert to a ceramic are new advanced material that may be useful in fire retarding organic polymers. These "preceramic" when heated to high temperature pyrolyze to form a ceramic residue in high yield, this thermally insulates the underlying material. Indeed, this concept 
has been proved promising in initial studies and a provisional patent application has been filed. The clay-nano-composite approach is another important new method which has shown promise for flame retarding polymers. However, we need to determine the mechanism by which these new systems functions and determine if these approaches will work in polymers useful in aircraft interiors.

\section{Approach}

During FY1997, BFRL will extend the range of the applicability of the currently available molecular dynamics model to permit investigation of polymers, such as $\mathrm{PBO}, \mathrm{PT}$, and PEEK, which are of particular interest to the FAA. Further extension of the model will be to develop code to include reaction pathways involving the attack of the polymer and its degradation products by $\mathrm{OH}, \mathrm{H}$ and $O$ radicals generated in the gas phase combustion. Analysis of the energetics of these reactions will provide a means to calculate the relative heat release rate from burning polymers. The effect of preceramic polymers and clay-nano-composites on the flammability properties of organic polymers will be determined. Polysilsesquioxanes, polycarbosilazanes will be evaluated for their compatibility with various organic polymers and the mixtures and blends prepared. Claynano-composites with both delaminated and intercalated structure will be prepared using organic modified montmorillonite calys. The organic polymers examined will include thermosets, engineering polymers, and thermoplastics. The blends will be prepared and the degree of mixing will be evaluated using special solid state $\mathrm{CP} / \mathrm{MAS}{ }^{13} \mathrm{C}-\mathrm{NMR}$ techniques and SEM (to determine the effects of the degree of mixing on flammability properties). Preceramic-blends and nano-composites which show significant improvement in flammability will be studied in detail to determine mechanistic information on how these new materials affect the flammability of a particular organic polymer.

\section{Recent Results}

Gilman, J. W., Brown, J. E., and Oliver, K.
D., "Synthesis of New Cyanate Ester Resins for Polymer Flammability Studies," Proceedings of Society of Plastics Engineer, ANTEC ‘96 Annual Meeting, Indianapolis, IN, May 1996.

Nyden, M. R., Coley, T. R., and Mumby, S., "Applications of Molecular Dynamics to the Study of Thermal Degradation in Aromatic Polymers; 1. Polystyrene," Proceedings of Society of Plastics Engineer, ANTEC '96 Annual Meeting, Indianapolis, IN, May 1996. 
RECENT GRANTS-ADVANCED FIRE MEASUREMENTS

\section{Mixing and Radiation Properties of Buoyant Luminous Flame Environments}

\section{Principal Investigator}

G.M. Faeth

Department of Aerospace Engineering

The University of Michigan

Ann Arbor, MI 48109-2118

313-764-7202

\section{Sponsor}

National Institute of Standards and Technology

\section{Objective}

To measure the radiation and mixing properties of luminous buoyant turbulent flame environments and use these results to improve fire models.

\section{Problem}

Radiation and turbulent mixing of luminous flames affect fire spread, growth and combustion rates and are important elements of fire models. Unfortunately, available information about soot optical properties is limited even though continuum radiation from soot dominates radiation in fires. Similarly, information about the properties of buoyant turbulent flows typical of fire environments is limited which impedes of the development of fire models. Thus, the problems being studied include the optical properties of soot and the mixing properties of buoyant turbulent flows.

\section{Approach}

Past work has shown that soot optical properties approximate Rayleigh-Debye-Gans scattering of lydisperse fractal aggregates of primary soot particles (RDG-PFA theory); thus, current work is addressing soot refractive index properties and how they vary with fuel type and flame condition. RDG-PFA theory has been used for in-situ measurements of the refractive index properties in the visible of soot emitted from gaseous-hydrocarbon fueled buoyant turbulent diffusion flames, finding good agreement with the often-criticized ex-situ measurements of Dalzell and Sarofim. Current work involves extending the in-situ measurements to soot for other hydrocarbon fuel and flame conditions, and given their acceptable evaluation, using ex-situ methods to find soot refractive index properties in the infrared that are needed for practical continuum radiation predictions for flames.

Past studies of buoyant turbulent flows established the properties of self-preserving round buoyant turbulent plumes and used these results to show that existing turbulence models gave effective mean properties predictions even though predictions of turbulence properties were not very effective. This deficiency is a concern because predictions of rapidly-developing flows typical of fire environments require good estimates of turbulence properties. Current work is extending the study to self-preserving plane free plumes; the new measurements show that these flows are observed farther from the source and are narrower than previously thought. Subsequent work will measure additional properties in both free and attached self-preserving plane turbulent plumes and exploit these results to evaluate and develop turbulence models.

\section{Recent Results}

Faeth, G.M., and Koylu, U.O., "Structure and Optical Properties of Flame-Generated Soot," Transport Phenomena in Combustion (S.H. Chan, ed.), Taylor \& Francis, Washington, vol. 1, 19-44, 1996.

Dai, Z., and Faeth, G.M., "Measurements of the Structure of Self-Preserving Round Buoyant Turbulent Plumes," J. Heat Trans., vol. 1 18, 493-495, 1996.

Koylu, U.O., and Faeth, G.M., "Spectral Extinction Coefficients of Soot Aggregates from Turbulent Diffusion Flames," J. Heat Trans., vol. 1 18, 415-421, 1996.

Farias, T.L., Carvalho, M.G., Koylu, U.O., 
and Faeth, G.M., "Light Scattering from Soot Aggregates with Radially Inhomogeneous Primary Particles," Int. J. Heat Tech., vol. 13, 27-47, 1995.

Dai, Z., Structure of Self-Preserving Round Buoyant Turbulent Plumes, Ph.D. Thesis, Dept. Of Aerospace Engineering, the University of Michigan, 1995.

\section{Experimental and Modeling Studies of Soot and Polycyclic Aromatic Hydrocarbon Oxidation in Post-Flame Gases}

\author{
Principal Investigator \\ J. Houston Miller \\ Department of Chemistry \\ The George Washington University \\ Washington DC 20052
}

\section{Objective}

To gain insight into the role of Polycyclic Aromatic Hydrocarbons (PAH) and soot oxidation contribution to the post-flame chemistry that leads to high levels of carbon monoxide (CO) in room fires.

\section{Problem}

Unwanted fires burning under ventilated lead to toxic emissions. These toxic emissions such as $\mathrm{CO}$ and $\mathrm{PAH}$ are found to be correlated to the Global Equivalence Ratio (GER) of the flame or fire. Moreover, the amount of $\mathrm{CO}$, attributable for two-thirds of all deaths in fires, is also found to be a function of the post-flame temperature. The contribution of soot and PAH oxidation to the toxicity of the effluents of fires needs to be investigated in order to accurately predict levels of $\mathrm{CO}$ in these situations.

\section{Approach}

Under ventilated and over ventilated laminar ethylene diffusion flames were burned in an enclosed apparatus. The resultant emissions pass through a quartz tube that is heated to temperatures typical of those found in upper layers of room fires. Both optical absorption and scattering measurements are used to characterize the gas phase and condensed phase components of the flow. Furthermore, extractive sampling coupled with GC/MS provided for another method of condensed phase analysis (PAH). Some of the key results of our measurements have been the concentrations of the products of incomplete combustion all increase with GER. For lean stoichiometries, the oxidation chemistry proceeds at a greater rate with increasing 
tube furnace temperature. For rich stoichiometries, evidence exists that chemical processes (including both paralytic and oxidation chemistry) occur at all tube furnace temperatures. However, these chemistries undergo a marked change in intensity at about $800 \mathrm{~K}$. The magnitude of the soot oxidation in our combustor agreese qualitatively with what may have been expected from high temperature extrapolations. However, the activation energies for our rates are substantially lower.

These results agree with not only fundamental kinetic measurements and calculations but also the observations made in hood and enclosure fire experiments. With these results in hand, further experimental work in FY1997 will concentrate on accurate determination of particle size and velocities within the flow tube using a Phase Doppler Particle Analyzer. A diffusion flame/plug flow reactor model will also be in development. This treatment of the combustor will include both the condensed phase and gas phase compounds in order to gain fundamental kinetic and mechanistic insight of the intermediate temperature oxidation chemistry.

\section{Recent Results}

Skaggs, R.R., Tolocka, M.P., and Miller, J.H., Combust. Sci. and Tech. 1996, I I6-1 17, 399.

Tolocka, M.P., Richardson, P.B., and Miller, J.H., Chem. Phys. Proc. Combust. 1996, 111.

\section{Dynamics, Transport and Chemical Kinetics of Compartment Fire Exhaust Gases}

\author{
Principal Investigators \\ Uri Vandsburger \\ Virginia Tech \\ Blacksburg VA \\ (540) 231-4459 \\ Richard J. Roby \\ Hughes Associates Inc. \\ Baltimore, MD \\ (410) 737-8677
}

\section{Objective}

To determine the conditions leading to the transport of high concentrations of $\mathrm{CO}$ to locations remote from the burning compartment in building fires and to provide quantitative correlations to be used in building fire safety design, to reduce the risks of $\mathrm{CO}$ poisoning in building fires.

\section{Problem}

Over the past decade, the percentage of deaths from smoke inhalation in building fires has risen by I percent every year, and was responsible for 75 percent of the deaths during 1992. Presently used fire safety engineering models do not incorporate the transport and evolution of compartment fire gases.

\section{Approach}

The reduced-scale building fire facility at Virginia Tech was arranged with the compartment ( $1.22 \mathrm{~m}$ by $1.52 \mathrm{~m}$ by $1.22 \mathrm{~m}$ ), which contained a liquid hexane pool fire, placed on the side at the end of the hallway ( $1.67 \mathrm{~m}$ by $1.22 \mathrm{~m}$ by $5.18 \mathrm{~m}$ ) forming an Lshape. The global equivalence ratio of the compartment fires was $3.0 \pm 0.3$ during the post-flashover period.

The degree of oxidation of CO-transported into the hallway is controlled by the amount of oxygen entrained into the compartment fire exhaust plume, and also by the thermal evolution of the plume and ceiling jet in the hallway. The size of the opening connecting 
the compartment and hallway, the height of the soffit at the opening and the hallway upper-layer depth (controlled by the height of the soffit at the end of the hallway) all play a role in the entrainment of ambient (hallway) gases into the plume.

Work during the reporting period addressed two issues:

1. Development of correlations for oxygen entrainment into the compartment fire gases entering a hallway, and for predicting the $\mathrm{CO}$ yield at the hallway exit. 2. Initial stages of a study examining the role/effect of heat transfer in the hallway on the CO levels.

Three situations were examined, which differed in the upper layer thickness and hence in the exhaust gas recirculation time in the hallway. For very long recirculation times the upper layer depth varied between $0.0 \mathrm{~m}$ and $0.20 \mathrm{~m}$, and the CO yield was at a minimum; magnitude controlled by opening size. A long recirculation time, upper layer depth $0.2 \mathrm{~m}-0.6 \mathrm{~m}$, resulted in higher $\mathrm{CO}$ yields. For short recirculation times, upper layer depth $\geq 0.6 \mathrm{~m}$, the $\mathrm{CO}$ yields were equal or higher to the levels inside the compartment $(0.22)$. The yield was independent of opening size, and was highest with external burning. The findings were explained qualitatively, last year, in terms of the reacting flowfield structure inside the hallway (also explaining fire death in the Hillhaven Nursing Home fire.)

To explain the observed $\mathrm{CO}$ yield, the controlling parameter which is the entrainment of oxidizer into the plume of hot gases exiting the compartment into the hallway was quantified. This was done measuring $\mathrm{O}_{2}$ levels in the upper layer. Experiments were run using over ventilated flames inside the compartment. The concentrations of $\mathrm{O}_{2}$ were measured in the compartment exhaust plume and in the ceiling jet in the hallway. The compartment exhaust vent area was varied between 0.04 $\mathrm{m}^{2}$ and $0.12 \mathrm{~m}^{2}$. Ceiling jet entrainment was determined without an inlet soffit. Air entrainment was found to increase with a decrease in exit vent size, and increase in inlet soffit size. The parameters controlling the $\mathrm{CO}$ yield in the hallway were determined to be the compartment vent size, inlet soffit height, depth of upper layer, occurrence of external burning and GER of compartment fire. The first two control the entrainment dynamics, while the third controls the $\mathrm{O}_{2}$ levels in the entrained gases. Correlations were developed for the hallway CO yields as a function of the entrainment function, and a nondimensional heat release rate. These functions incorporate the Froude number, geometrical vent parameters, and a nondimensional upper layer height in the hallway.

Work started on quantifying the effect of heat transfer in the hallway on the evolution of $\mathrm{CO}$ levels. Presently the data is qualitative, indicating the regions of high reaction rates/heat release. Newly purchased miniature heat flux sensors will be utilized in a detailed study beginning March 1997.

\section{Recent Results}

Lattimer, B. Y., Vandsburger, U. and Roby, R. J.,The Transport of High Concentrations of Carbon Monoxide to Locations Remote from the Burning Compartment, Annual Report, 1996, NIST GCR, National Institute of Standards and Technology, 1996. 


\section{BFRL HEADQUARTERS}

\section{OFFICE OF APPLIED ECONOMICS}





\section{Building for Environmental and Economic Sustainability (BEES)}

\author{
Principal Investigator \\ Barbara C. Lippiatt \\ Office of Applied Economics \\ 301-975-6133
}

\section{Sponsor}

National Institute of Standards and

Technology

\section{Objective}

To develop decision-support software for selecting building products that achieve the most appropriate balance between life-cycle environmental and economic performance.

\section{Problem}

Environmental and economic performances are two key factors in building product selection decisions. The environmental performance of building products, however, is not readily assessable and comparable to economic performance. A methodology is needed for assessing and comparing environmental against economic performance. To maximize technology transfer, the methodology should be implemented in publicly-available, user-friendly, decision-support software.

\section{Approach}

During FY1997, BFRL will specify five additional building products for which its contractor will collect and deliver environmental performance data for the BEES system (Building for Environmental and Economic Sustainability). The Building and Fire Research Laboratory will refine its default set of relative weights for synthesizing these data into overall environmental performance scores. The staff also will continue to assess economic performance using the life-cycle costing concept, and collect life-cycle cost data for the five additional building products.

A full-featured Beta Test version of BEES will be developed, incorporating ten building products. Algorithms and code will be added to the Alpha version completed in FY1996 to enable reporting of embodied energy results and parameterization of transportation distances, relative weights for environmental impacts, and the discount rate. A Beta Test will be conducted, including more than 70 individuals and organizations who have expressed interest in reviewing the software. The Beta Test comments will be incorporated, and BEES 1.0 for WERB review will be completed.

In FY1998, with additional funding, BFRL plans to publish, market, expand, and standardize the BEES methodology

\section{Recent Results}

Lippiatt, B.C, "Selecting Environmentally and Economically Balanced Building Materials," Chapter 2, Sustainable Building Technology Manual: Green Building Practices for Design, Construction, and Operations, DoE's Center of Excellence for Sustainable Development (http://www.sustainable.doe.gov/ss/ptipub2.ht $\mathrm{ml})$. 


\section{Purchasing Environmentally Preferable Products}

\author{
Principal Investigator \\ Barbara C. Lippiatt \\ Office of Applied Economics \\ 30 I-975-6133
}

\section{Sponsor}

Environmental Protection Agency

Pollution Prevention Division

\section{Objective}

To develop decision-support software for purchasing products that achieve the most appropriate balance between life-cycle environmental, economic, and technical performance.

\section{Problem}

In October 1993, President Clinton signed Executive Order 12873, "Federal Acquisition, Recycling, and Waste Prevention," which directs Federal agencies to evaluate the environmental attributes of the $\$ 200$ billion in products and services they purchase each year. EO 12873 directs EPA to provide guidance to Federal agencies on incorporating environmental preferability into their purchase decisions. EPA is recommending that the environmental life-cycle analysis (LCA) approach be used to assess environmental performance. While LCA provides a comprehensive examination of a product's environmental effects throughout its lifetime, it is difficult to implement and its environmental performance results are sensitive to a number of key parameters. Furthermore, to be practical, environmental performance must ultimately be balanced against economic and technical performance. To carry out the mandate of EO 12873 while not overwhelming Federal purchasers or exceeding purchasing budgets, a flexible LCA technique that incorporates economic and technical performance needs to be developed and implemented in user-friendly decision-support software for the Federal procurement community.

\section{Approach}

In support of EO I 2873 and the EPA Environmentally Preferable Products (EPP) Program, this 4-year, four-phase project will develop a flexible methodology for selecting products that achieve the most appropriate balance between life-cycle environmental, economic, and technical performance. During FY1997, BFRL will implement this methodology in Windows-based decision-support software tailored to the Federal procurement community. BFRL will develop a demonstration version of the EPP software with performance data for two major product categories. BFRL will develop a methodology for balancing the environmental and economic performance of products using the LCA and LCC approaches. The methodology will involve assessing, synthesizing, and balancing multiple environmental and economic attributes, all of which are measured in different units. These attributes include five global and regional environmental impacts (global warming, acidification, nitrification, natural resource depletion, and solid waste), and product costs over the economic life cycle (first costs and future costs).

In consultation with the EPP Program, BFRL will select two major product categories (such as building products and infrastructure products) representing a significant share of Federal purchases for which to illustrate the technique. This will involve selecting specific product categories (e.g., paint products and parking lot paving products) within each major product category in order to provide the level of detail necessary to identify mutually exclusive product alternatives (e.g., latex vs. acrylic wall finish paint). The staff will contract for LCA inventory data such that a total of five products is included in the two product categories (two alternative products in one category, and three in the other category). BFRL will develop LCA impact assessment and valuation data for the five global and regional environmental impacts, along with LCC data to complete the data set for each product. The LCA impact valuation data will consist of several alternate sets of relative importance weights 
for the five impacts, including weights derived from published sources and user-defined weights.

The methodology and data will be incorporated into a demonstration version of the EPP software. The demonstration version will permit users to select a product category of interest and set key study parameters (e.g., weights for the five environmental impacts, weights for the relative importance of environmental vs. economic performance, the discount rate for converting future costs to their equivalent present value, and transportation distance from a factory of final manufacture to point of end use). The software will conduct LCA and LCC analyses on the alternative products and graphically display overall and detailed LCA and LCC results. Software features will include context-sensitive help, visually intuitive screens, and printed reports.

\section{Recent Results}

New project

\section{Economics of New-Technology Materials}

Principal Investigator

Mark A. Ehlen

Office of Applied Economics

301-975-4522

\section{Sponsor}

National Institute of Standards and

Technology

\section{Objective}

To develop life-cycle economic methods for evaluating the cost effectiveness of substituting new construction materials-such as high-performance concrete and steel, FRP composites, and aluminum-for traditional materials in civil engineering applications.

\section{Problem}

Federal, state, and private agencies that maintain building and bridge infrastructure face decreasing budgets, suggesting that they consider specifying new, higher-performance construction materials that can reduce the cost of constructing and maintaining their facilities. Although these high-performance materials may be technically sound, barriers need to be overcome for these materials to be accepted for general use. Engineers and designers need to be satisfied that the material, when used in a civil structure, will be safe and behave predictably. Once satisfied, project managers and other decision makers then need sophisticated but practical guidelines for evaluating the cost effectiveness of these alternative building materials over their life cycle. Providing a method for evaluating life-cycle cost effectiveness will give decision makers a tool to help them select, both for research and applications on the job, those materials that will deliver their infrastructure at least cost.

\section{Approach}

During FY1997, BFRL will develop an alpha version of the decision support software BridgeLCC to aid state and Federal department of transportation officials choose cost-effective materials when issuing 
specifications for the construction and repair of bridges. BridgeLCC will incorporate the methodology and cost classification scheme of BFRL's 1996 published report 5864 (see below). It will include techniques for taking into consideration uncertainties associated with the life-cycle costs of new construction materials, and will allow state departments of transportation that use the PONTIS bridge management system (BMS) software to calculate the life-cycle costs of their existing bridges. An integral part of the project will be the development of an ASTM standard classification of bridge elements so that life-cycle cost data can be shared amongst designers, estimators, cost engineers, and project managers.

\section{Recent Results}

Ehlen, M.A. and Marshall, H.E., The

Economics of New Technology Materials: A Case

Study of FRP Bridge Decking, NISTIR 5864.

National Institute of Standards and

Technology, 1996.

\section{How to Select Research Projects and Measure Their Impacts}

\author{
Principal Investigator \\ Robert E. Chapman \\ Office of Applied Economics \\ 301-975-2723
}

Sponsor

National Institute of Standards and

Technology

\section{Objective}

To provide economic support to BFRL on how (1) to identify industries affected by BFRL research, estimate economic impacts resulting from BFRL research, and estimate the return on BFRL's research investment dollars, and (2) to select appropriate research projects for funding.

\section{Problem}

The measurement of economic impacts of research is a major objective of NIST.

Managers need to know the impact of their research programs in order to achieve the maximum social benefits from their limited budgets. Improved methods for measuring economic impacts are essential to BFRL to help select the "best" among competing research programs, to evaluate how cost effective are existing research programs, and to defend or terminate programs on the basis of their economic impact. This need for measurement method exists across programs in both BFRL and NIST.

\section{Approach}

During FY1997, BFRL will (1) initiate a new economic impact assessment and (2) develop an approach for use by BFRL senior management in selecting among competing research projects. This work will be performed with BFRL senior management and key technical experts to select a BFRL research project for an economic impact assessment. Next, work will identify and classify the benefits and costs associated with the project (e.g., those sectors of the national economy affected by the research and the likely types of outcomes). Potential sources of 
data to estimate project-related benefits and costs will then be identified along with a strategy for estimating benefits and costs. The principal investigator will initiate date collection and compile it in a form which will facilitate a rigorous analysis of project-related benefits and costs. The impact assessment will be completed in FY1998.

Many research investment alternatives differ in characteristics that decision makers consider important but that are not readily expressed in monetary terms. When nonfinancial characteristics are important, decision makers need a method that accounts for these characteristics when choosing among alternative research investments. The analytical hierarchy process (AHP) is a method that considers nonfinancial characteristics in addition to common economic evaluation measures when evaluating project alternatives. A prototype "management approach" will be developed which may be used for screening and selecting among competing BFRL research projects. The prototype will enable BFRL senior management to ( 1 ) assess fit to the mission, (2) set priorities, and (3) evaluate performance against a specific management goal. OAE will prepare a white paper outlining the approach.

\section{Recent Results}

Chapman, Robert E., and Fuller, Sieglinde K. Benefits and Costs of Research: Two Case Studies in Building Technology, NISTIR 5840, National Institute of Standards and Technology, July 1996.

Chapman, Robert E., and Weber, Stephen F., Benefits and Costs of Research: A Case Study of the Fire Safety Evaluation System, NISTIR 5863, National Institute of Standards and Technology, July 1996.

\section{Baseline Measures for National Construction Goals}

\author{
Principal Investigator \\ Robert E. Chapman \\ Office of Applied Economics \\ 301-975-2723
}

\section{Sponsors}

National Institute of Standards and Technology

\section{Objective}

To provide economic support to the Subcommittee on Construction and Building $(C \& B)$, identify data that can provide baseline measures of current practice with respect to the seven National Construction Goals (NCGs), and to represent BFRL on the Construction Industry Institute (CII) Benchmarking and Metrics Committee (BMC).

\section{Problem}

Both the $C \& B$ activities and the CII BMC activities are aimed at promoting the competitiveness of the construction industry. Support of BFRL's C\&B-related activities is focused on the seven NCGs; they are to be attained by the year 2002. The NCGs are:

(1) 50 percent reduction in delivery time, (2) 50 percent reduction in operation, maintenance, and energy costs, (3) 30 percent increase in productivity and comfort, (4) 50 percent fewer occupant-related illnesses and injuries, (5) 50 percent less waste and pollution, (6) 50 percent more durability and flexibility, and (7) 50 percent reduction in construction workforce illnesses and injuries. Data describing current practices of U.S. firms with respect to the NCGs are needed to establish a baseline against which to measure progress of the construction industry toward achieving these goals. It is essential to have baseline data and associated measures of progress toward improved performance to determine the success of actions taken to improve the competitiveness of the construction industry in U.S. and international markets. Having these measures of progress makes it possible 
to demonstrate the benefits of advanced technologies and practices.

\section{Approach}

During FY1997, BFRL will accumulate data on current industry performance with respect to the NCGs. A significant effort will be made to develop methods for measuring progress. In subsequent years these methods will be applied to the measurement of progress toward each of the seven NCGs. The methods will ultimately be made available on the Internet. User-friendly decision support software will also be developed to access baseline data and to measure progress toward attainment of the NCGs.

A white paper will be prepared describing baseline measures (e.g., approach, goals covered, goals yet to be covered, strategy for data collection, data collected, and analyses performed) and proposed measures of progress. Work on the CII BMC will focus on ensuring that CII's extensive data collection effort continues to have a focus on those NCGs which are of mutual interest to BFRL and CII. OAE will continue to provide guidance in analyzing data received from CII member organizations and will participate actively in the development of new metrics for measuring performance and/or process improvements.

\section{Recent Results}

Chapman, Robert E., and Fuller, Sieglinde K., Baseline Measures of Construction Industry Practices and Measures of Progress for the National Construction Goals: Status and Future Directions, January 1997.

\section{Life-Cycle Costing Methodology}

\author{
Principal Investigator \\ Sieglinde Fuller \\ Office of Applied Economics \\ 301-975-6134
}

Sponsor

Department of Energy

Federal Energy Management Program

\section{Objective}

To provide, on a continuing basis, economic analysis methods, data, software, training, and consulting to the Federal Energy Management Program in support of energy and water conservation projects in federal buildings and facilities.

\section{Problem}

The National Energy Conservation Policy Act directs BFRL to provide expert consulting to DOE related to economic analysis of energy conservation projects in federal buildings. Executive Order 12902 of March 8, 1994, requires that energy usage in federal facilities be reduced by 30 percent by the year 2005 relative to 1985 levels (on a Btu/SF basis), in a cost-effective manner.

\section{Approach}

During FY1997, BFRL will provide on a continuing basis, economic analysis method, data, software, training, and consulting. BFRL is responsible for assisting DOE in the development and modification of FEMP LCC rules, as promulgated in 10 CFR 436 Subpart A. BFRL is amplifying these rules and procedures in NIST Handbook 135, Life-Cycle Costing Manual for the Federal Energy Management Program.

Annually, BFRL computes the discount rate to be used in the analysis of federal energy and water conservation projects, using the procedure specified in 10CFR436. In addition, staff computes tables of discount factors and energy price indices, based on this discount rate and on energy price projections received from DOE/EIA for this purpose. These data are published each October 1 in the Annual Supplement to 
Handbook 135, and included in electronic form with the NIST LCC software.

BFRL has developed five computer programs for economic analysis of energy and water conservation projects: BLCC, Quick Input, DISCOUNT, ERATES, and EMISS. The programs are maintained, updated, and enhanced with new analytical capabilities annually. These programs are distributed by DOE and numerous private-sector software vendors. The programs, as well as the publications can be downloaded from the internet. User manuals are provided with each program. The OAE software has also been incorporated into several other software projects outside NIST, sponsored by DOE.

BFRL has developed a basic LCC workshop which it has conducted five times each year at locations throughout the United States, primarily for federal engineers and energy managers, but attended by representatives from state and local government, utilities, and consultants from the private sector. A condensed version of this basic workshop is taught semi-annually as a teleseminar which is broadcasted to many sites across the United States. In FY1996, staff developed an advanced LCC workshop that is more oriented toward project analysis and the OAE LCC software. Staff has trained 22

instructors, mostly university professors and private consultants, to conduct the basic LCC workshop, and is providing them with required teaching materials. These trainers are now conducting additional workshops throughout the United States, significantly expand the reach of BFRL training activities. Staff have developed three LCC training videos with workbooks to promote the use of economic analysis in project design and maintenance.

BFRL provides consulting to DOE related to methods of economic analysis for federal energy and water conservation projects on a continuous basis. For example, changes to the FEMP LCC rules in 10 CFR 436 are made in consultation with OAE; users of BFRL publications and software frequently call with technical questions related to these materials and to interpretation of 10 CFR 436; and staff have successfully worked with DoD and FEMP to coordinate their LCC applications. Staff participates in the development of standard economic evaluation methods by ASTM's Building Economics Subcommittee, and ensure that the recommended FEMP methods for LCC are consistent with current ASTM standard methods.

\section{Recent Results}

Fuller, Sieglinde K., Energy Price Indices and Discount Factors for LCC Analysis April 1997, Annual Supplement to Handbook 135, NISTIR 85-3273-1 1, National Institute of Standards and Technology, 1997. 


\section{Minimizing Compliance Costs of the Life Safety Code for Correctional Facilities}

\author{
Principal Investigator \\ Stephen F. Weber \\ Office of Applied Economics \\ (301) 975-6137
}

\section{Sponsor \\ National Institute of Standards and Technology}

\section{Objective}

To develop a systematic procedure for finding low cost, safety-equivalent solutions compliant with the Life Safety Code for Detention and Correctional Facilities and to incorporate the procedure into Windows software.

\section{Problem}

The Fire Safety Evaluation System (FSES) for Detention and Correctional Facilities (Chapter 4 of the NFPA 101A Guide to Alternative Approaches to Life Safety) offers the managers and fire safety engineers of such facilities many alternatives equivalent to prescriptive code compliance. This flexibility makes possible major cost savings when achieving compliance with the Life Safety Code. Because so many acceptable solutions are available, however, economical solutions cannot be found by simple trial and error. What is needed is a systematic procedure for finding a practical set of low-cost, safety-equivalent solutions from which the building owner can choose. The NIST Office of Applied Economics has successfully developed a similar procedure and supporting software for Health Care Occupancies. The Public Health Service has applied this software to 86 military hospitals and identified code-compliant solutions with cost savings of over 40 percent (about $\$ 2,200$ per bed) compared with the prescriptive solution.

\section{Approach}

During FY1997, BFRL will develop a comprehensive list and detailed specifications for all construction retrofits that apply to each of the 13 fire safety parameters included in NFPA 101A for Detention and Correctional Facilities. Then cost estimating algorithms and supporting cost data will be developed for all the construction retrofits specified under item 1 . A cost minimization model will be developed with supporting algorithms capable of systematically evaluating the costs of all safety-equivalent alternatives to quickly identify the least-cost alternative for any given building zone. The model will address all exceptions codified in the nine footnotes to Table 4-I of NFPA 101A. Then software will be designed and developed to permit easy user specification of the current safety conditions for each of the 13 fire safety parameters and for the quantities of each construction retrofit to be considered for evaluation by the cost minimization model and algorithms. The software will also let users apply the cost minimization model and supporting algorithms to identify the least-cost alternative for any zone in the correctional facility. Other modules of the software will generate a list of low-cost safety-equivalent solutions for any zone in the correctional facility and another list of simultaneous solutions for all zones in the facility compatible with selected facility-wide design criteria. A User Manual with tutorial will also be developed. The software and manual will be distributed to a large set of Beta testers, revised accordingly, and published.

\section{Recent Results}

New project 
Decision Support Software for Hospitals Financed by HUD-Guaranteed Loans

\section{Principal Investigator}

Stephen F. Weber

Office of Applied Economics

301-975-6137

\section{Sponsors}

Department of Health and Human Services

Health Resources and Services

Administration

\section{Objective}

To develop a comprehensive decision support software system for the hospitals and health care facilities financed by HUD-guaranteed loans.

\section{Problem}

The Division of Facilities and Loans of the Health Resources and Services Administration (HRSA) manages a large portfolio of HUD-guaranteed loans made to hospitals and health care facilities. Existing software is used solely for manual recording and reporting on the current status of outstanding loans and does not support optimization of decisions on operation, maintenance, repair, and expansion expenditures over the life cycle of the facilities. Moreover, the system is not integrated with other critical HUD data about the current condition of the hospital facilities themselves. The source code is unavailable, so that the software cannot be modified or updated. HRSA sponsors need a new system that can access all relevant data to support critical decisions, such as when to survey hospitals for compliance with the Life Safety Code, when an energy conservation audit is advisable, and whether to renew or refinance a loan in light of the facility's operation and maintenance performance.

\section{Approach}

During FY1997, BFRL will develop a fully functional test version of the Loan Manager software with data entry and review modules as well as a standardized quarterly report module. After the test version of the software has been evaluated by HRSA, BFRL will revise it per comments and integrate the report module into it. Staff will deliver the software to HRSA, install it, and import the existing data into the new software.

During the follow on phases, BFRL will conduct a study to determine the appropriateness and feasibility of read-only remote access to the data by HUD Hospital Mortgage Insurance Staff as a substitute for the existing centrally printed quarterly reports. Such access at the local level will make possible more cost-effective decisions about the health care facilities. BFRL will develop the necessary modules to permit customized, user-defined queries of the data and will also develop decision support modules to guide actions on major expenditures for repairs, renovations, and expansions of the health care facilities.

\section{Recent Results}

In July 1997, Loan Manager 1.0 was completed and delivered to the HHS sponsors. The software has been used to generate both quarterly and annual reports on $\$ 10$ billion portfolio of HHS and HUD loads. The reports were distributed to all loan officers throughout the United States. 


\section{Allocating Capital Improvement Budgets Among Historic Buildings}

\author{
Principal Investigator \\ Barbara C. Lippiatt \\ Office of Applied Economics \\ 301-975-6133
}

\section{Sponsor}

General Services Administration

Public Buildings Service

Office of Portfolio Management

\section{Objective}

To develop a comprehensive decision-support software system for allocating capital improvement budgets among historic buildings.

\section{Problem}

Sixty percent of the buildings owned by the Public Buildings Service are classified as historic structures based solely on their age. Some of these buildings are truly historic, while others have little historic significance. In addition, at any given time, some of these buildings require relatively large investments in maintenance, repair, and alteration activities, while others require little. In order to manage them effectively, PBS needs to know their relative historic importance, and weigh historic importance against proposed investment costs in allocating capital improvement budgets. PBS has developed and is currently implementing the Building Preservation Plan (BPP), a system for collecting detailed data on the historic properties of its buildings. PBS has also developed the Building Engineering Report (BER) system for collecting detailed data (including costs) for proposed maintenance, repair, and alteration activities. These two systems offer a rich set of detailed data at the individual building level, yet they are not now integrated. Moreover, there is no consistent, reliable method for analyzing and combining these data to support critical budget allocation decisions by PBS.

\section{Approach}

BFRL recently completed work for PBS that developed and automated in the software HIST 1.0 a method for rating the portfolio of PBS buildings by their historic significance. During FY1997, BFRL will upgrade the software to a visually based, graphical environment, generating new graphical analysis methods for decision support, and ultimately combining the "benefits" of historic preservation (as reflected in the historic ratings) with its costs to support capital improvement budget allocation decisions. The project will be conducted in three phases, each culminating in an enhanced, working version of the HIST software.

1. Convert the HIST system to the Windows environment to permit new graphical analysis capabilities. A HIST 2.0 prototype was completed in FY1996, and in FY 1997 will be made compatible with new BPP data file formats and structures emanating from an ongoing PBS project to upgrade the BPP system to the Windows environment. HIST also is being redesigned to take advantage of the event-driven capabilities of Windows by developing object-oriented code and permitting simultaneous tasking. New features include a pull-down menu structure, redesigned and visually intuitive screens with mouse support, and enhanced and redesigned printed reports. BFRL, in collaboration with PBS, also will complete development of a set of new analytical tools, including reporting average historic ratings by "class," such as by National Register status, age category, building class, and city size. BFRL will specify the structure and content for any new data fields to be added to the BPP data files to implement these new analytical tools.

2. BFRL will automate and integrate in HIST the new analytical tools developed under Phase I. For visual decision support, the new tools will be implemented using a true graphical user interface, displaying "live" graphs that may be customized by the user. Graphical printed reports based on the new analytical tools will also be added to the HIST system. The system will be networked to enable simultaneous use of the BPP and HIST systems both by PBS Headquarters 
and the GSA regions. Phase 3. BFRL will develop and automate in HIST a method for allocating capital improvement budgets among the PBS historic building portfolio by weighing the "benefits" of historic preservation (as reflected in the historic ratings) against its costs. The method will use the data in the BPP and BER systems.

\section{Recent Results}

In February 1997 the beta test version of HIST 2.0 was delivered to PBS. PBS staff are currently using the software to rank historic buildings in the PBS portfolio.

\section{Economic Support to NIST Manufacturing Extension Partnership}

\author{
Principal Investigator \\ Stephen F. Weber \\ Office of Applied Economics \\ 30-975-6137
}

\section{Sponsor \\ National Institute of Standards and Technology}

\section{Objective}

To support the economic and program evaluation missions of NIST's Manufacturing Extension Partnership (MEP) by identifying economic data sources, developing economic data analysis software, developing economic maps, modeling economic impacts, and identifying resources for conducting economic analyses.

\section{Problem}

MEP management needs economic consulting support for planning, reporting, and program evaluation.

\section{Approach}

During FY1997, BFRL will continue to assist NIST's Manufacturing Extension Partnership (MEP) in interpreting the survey questionnaires as new monthly survey data become available. BFRL will use these results to develop statistics that indicate the regional performance of the Manufacturing Extension Centers (MECs) and to determine which types of assistance yield the largest economic impacts. These survey results will be used to conduct, using the REMI macroeconomic modeling system, both national and state-level economic impact studies of MEC activities.

BFRL will implement the application of Data Envelopment Analysis (DEA) to measure and suggest improvements in the relative efficiency of MECs. BFRL will work with MEP headquarters and selected MECs to identify and obtain the best data to serve as 
input, output, and control variables in the DEA analysis. Staff will apply DEA software to the data and then perform a series of post-processing operations to identify the "reference" MEC(s) for each MEC in the data sets. Summary reports will be developed that present the set of optimal weights and measures of efficiency as well as reference points for increased levels of output at current levels of input and current levels of output at reduced levels of input.

MEP will provide with economic data and maps to define the scope, scale, and geographic distribution of manufacturing establishments and MECs. BFRL also will support individual MECs with program-related economic analysis, and with resource identification and liaison with other sources of economic expertise needed to conduct these analyses.

Two reports are planned for publication in the Fall of 1997 will illustrate the use of the REMI model in estimating the economic impacts of productivity improvements in small and medium manufacturing plants caused by the MEP program. The other will apply the DEA approach a large set of MEC performance data.

\section{Recent Results}

Prepared a draft report on REMI analysis (I) summarizing the survey data in terms of economic impacts by substance code, activity type, MEC, and State, (2) outlining the economic model used to prepare data for REMI, and (3) presenting the standard REMI measures of economic impact, such as changes in GDP. Developed economic maps showing small manufacturing industry concentrations and the coverage by county of all MECs in the MEP system.

\section{Economic Support to NIST Advanced Technology Program}

\section{Principal Investigator}

Stephen F. Weber

Office of Applied Economics

301-975-6137

\section{Sponsor \\ National Institute of Standards and Technology}

\section{Objective}

To support the economic and program evaluation missions of ATP by providing reviews of economic impact proposals; providing economic modeling and analysis services; designing and developing economic questionnaires; and implementing questionnaires in software to permit electronic submission by ATP awardees of a variety of periodic reports on economic progress and economic impacts.

\section{Problem}

ATP management is developing and administering questionnaires to track the technological and economic progress of awardees. Economic consulting is needed to help develop and review the questions, and software is needed to implement the questionnaires in electronic form. ATP also needs help in conducting economic impact assessments of its projects, including application of the REMI simulation and forecasting econometric model, and reviewing proposals from economists outside of NIST.

\section{Approach}

During FY1997, BFRL will support ATP by helping to develop economic questions, working with ATP economists to specify data requirements, and designing efficient ATP awardee questionnaires to support economic impact models as well as REMI analyses. Staff also will restructure the existing questions and collected data from the Quarterly and Anniversary Report system into a new format for baseline questions and annual questions . OAE will develop data 
structures, files, and data relations for collecting in the field and storing in a centralized database all questionnaire responses. Data validation features will ensure data integrity and reliability. BFRL will develop software utilities for creating distribution diskettes and for consolidating data from floppy disks into a centralized database. Full support for mouse pointing devices will be included in the restructured version of the software.

Staff will work with ATP economists to develop methods to estimate economic impacts of ATP funded research and to apply econometric forecasting and simulation tools such as REMI to case studies of ATP projects. Staff will provide an economist to serve on a Source Evaluation Board (SEB) for evaluating proposed economic studies.

\section{Recent Results}

In March 1997 completed a new version of the ATP economic questionnaires, which incorporate the new Baseline/Annual/Closeout reporting cycle for awardees.

\section{Economic Support for the NIST Office of Law Enforcement Standards}

\author{
Principal Investigator \\ Stephen F. Weber \\ Office of Applied Economics \\ 301-975-6137
}

\section{Sponsor \\ National Institute of Standards and Technology}

\section{Objective}

To update AutoBid software to support police vehicle acquisition decisions.

\section{Problem}

AutoBid software that supports police vehicle acquisition decisions needs to be updated each year to include the latest model year data on police vehicle performance. The data files contain the performance test results for police patrol vehicles published annually by the Michigan State Police. Data files are explicitly referenced in the source code of the software. This feature requires that the source code be modified each year when the new model year data become available. As a result, the entire program must be recompiled each year.

\section{Approach}

During FY1997, BFRL will assist NIST's Office of Law Enforcement Standards (OLES) prepare the data files compatible with AutoBid for the 1997 model year, as soon as the police patrol vehicle performance data become available. Staff will complete work on modifying the software to automatically recognize any vehicle model year data files in the current directory and provide the user with a menu to select any given year for which the data are present. This will enable OLES to maintain the data files in the future. BFRL will also prepare a system of JAVA - based software and files to permit direct access to vehicle performance data on the World Wide Web. 


\section{Recent Results}

Maintained, over 8 years, the AutoBid software and included the performance data for the most recent model year police patrol vehicles.

\section{Cost-Effective Decisions for Police Patrol Vehicle Disposal}

Principal Investigator

Stephen F. Weber

Office of Applied Economics

301-975-6137

Sponsor

National Institute of Standards and

Technology

\section{Objective}

To develop a systematic procedure and supporting Windows software for cost-effective disposal and replacement of police patrol vehicles.

\section{Problem}

The disposal and replacement of police patrol vehicles have major cost consequences for law enforcement budgets. Most current approaches to vehicle disposal/replacement decisions use average costs to predict future repair costs for an entire class of vehicles (defined by model and year). But this works only if every vehicle's repair history closely follows the average repair history of the class. More sophisticated repair models should be applied to produce significant cost savings compared with the current approaches.

\section{Approach}

A statistical model has been developed at NIST that permits estimation of the number of failures expected to occur in the coming planning period. During the FY1997, BFRL will apply this model to help fleet managers make cost-effective decisions regarding the disposal and replacement of vehicles. A prototype version of software, AutoRank was developed to test the feasibility of the statistical model. The approach consists of applying data on the frequency of repairs for a vehicle class to estimate a generalized model of vehicle repairs based on the Weibull distribution, widely used for reliability analysis. Then, for each vehicle in the fleet, the model will use data on the particular vehicle's pattern of repairs to estimate expected repair costs for that vehicle over the 
coming period. Vehicle repair estimates can be grouped by repair category. The model will then rank all vehicles for disposal based on expected repair costs, operation and maintenance costs, and loss of resale value. The fleet manager would then dispose of those vehicles with the highest predicted costs, resulting in a cost-effective strategy for vehicle disposal and replacement.

BFRL will apply the statistical model to national vehicle repair data from large police fleets to develop reliable estimates of the population parameters for each vehicle class. These derived national estimates are essential for smaller fleets whose sample sizes will not permit reliable parameter estimation. The software will be developed to manage the fleet's repair history data and to apply the national statistics to estimate the costs of keeping each vehicle in the fleet for the coming year. The software will be able to generate at any time a priority ranking of individual vehicles for disposal to minimize fleet maintenance and repair costs.

\section{Recent Results}

Developed and tested statistical model for estimating expected failures on hypothetical data. 



\section{BFRL HEADQUARTERS}





\section{Performance Standards System for Housing}

\author{
Principal Investigator \\ Joel Zingeser \\ Headquarters \\ 301-975-4630
}

\section{Sponsors \\ National Institute of Standards and \\ Technology, and \\ Department of Housing and Urban \\ Development \\ Policy Development and Research}

\section{Objective}

To support the development of a comprehensive national and international performance standards system that guides the procurement, evaluation and acceptance of innovative housing products and systems.

\section{Problem}

The present prescriptive system for regulating housing construction is a primary barrier to innovation and limits competition both nationally and internationally. U.S. housing products, components, systems, and know-how have not been widely accepted in the global economy. The creation of a well conceived and functioning performance based standards system for the procurement and evaluation of housing will more readily allow for and should encourage the use of innovative designs, products and processes leading to improved quality, lower life-cycle costs of housing to consumers and increased competitiveness for U.S. companies. The need for a performance standards system for housing is a priority component of the Residential Sector Strategic Approach aimed at meeting the National Construction Goals. Research is required to develop better criteria and methods for evaluating performance.

\section{Approach}

During FY1997, BFRL will focus on creation of national (ASTM) and international (ISO) performance standard guides for one- and two-family dwellings. The process of developing these standard guides will lead to the identification, scoping, and implementation of a variety of research projects, generally based on industry determined needs and focussed on defining the most appropriate criteria and evaluation measures. BFRL will lead in the development of a coordinated set of individual standard guides for each of the 16 attributes identified as relevant to the specification and evaluation of the performance of housing. These individual standard guides will be based on a matrix of attributes and elements (building subsystems) and will use the RCEC (requirements, criteria, evaluation, and commentary) structure. The matrix and the standard guides will be reviewed for acceptance by ASTM and ISO. The drafts of these standard guides will be prepared by individuals from BFRL, other government agencies, industry volunteers, consultants, and others as appropriate. The draft documents will be reviewed by leading industry participants and used to define specific areas of research necessary to better define the appropriate criteria and evaluation methods. Potential areas of research include wind, fire, seismic, indoor air quality, lighting, energy conservation, sustainable building, waste management, durability and maintainability of materials and products, automation and communications. The levels of performance established must assure that products which meet current standards are not precluded from the market and new and improved products are allowed access to the market. The program will include three levels of partnership -- other government agencies, organizations and individuals that participate in the development and use of standards, and industry supporting the use of the performance approach in national and international markets.

\section{Recent Results}

New project. 


\section{Subcommittee on Construction and Buildings}

\author{
Principal Investigator \\ Andrew Fowell \\ Headquarters \\ 301-975-6865
}

\section{Sponsors}

National Institute of Standards and

Technology

and

10 Federal Agencies

\section{Objective}

To coordinate Federal agency programs to support the enhancement of the competitiveness of U.S. industry, public safety and environmental quality through research and development, in response to the needs of U.S. industry, labor, and academia, for improvement of the life cycle performance of constructed facilities to meet the National Construction Goals by 2003 .

\section{Problem}

The construction industry comprises about 12 percent of the Gross Domestic Product, and yet it lags other business sectors on $R \& D$ investment. This is partly because only a few firms have the capability to conduct significant $R \& D$, and to make competitive bids few construction firms can absorb the risk inherent in the pursuit and development of innovation. Most innovation in the industry is done by manufacturers of products that are used in buildings. For the construction industry to be competitive in a global economy, where Japan and Western Europe are making significant investments, it must overcome the slow pace of introduction of innovative technology. The industry is desegregated, lacks leadership, and faces many barriers to the use of new technology. There has been a lack of coordination between government and industry, and between agencies within the Federal Government involved in construction.

\section{Approach}

During FY1997, BFRL will provide the secretariat for the Subcommittee on Construction and Building of the National Science and Technology Council Committee on Technological Innovation. The Subcommittee coordinates activities within the Federal Government and works with the construction and building industry to stimulate research and adopt both process and product innovations. Sixteen Federal agencies are represented on the Subcommittee which meets monthly. The National Association of Homebuilders (NAHB), The National Institute of Building Sciences (NIBS), the Construction Industry Institute (CII), and the American Public Works Association (APWA) representing the residential, commercial/institutional, and public works sectors of the industry are developing strategic implementation plans to address the National Construction Goals. CERF is under contract to summarize the sector plans. The Building Economics Group of BFRL will continue to search and analyze available data relating to current practices to provide baseline data on the goals. As sufficient funds are acquired we will contract for additional tasks with NCSBCS to develop streamlined model administrative processes and procedures, and enabling legislation for an improved regulatory process. A program similar to CONMAT will be developed for mechanical systems and furnishings industries. We will develop a framework for improving tracking of construction $R \& D$ within the federal government.

\section{Recent Results}

Report on the Construction Industry Collaborations Workshop, NISTIR-GCR-9771 I, National Institute of Standards and Technology, March 1997.

Wright, R. N., Rosenfeld, A. H., and Fowell, A. J., Construction and Building: Federal Research and Development in Support of the U.S. Construction Industry, Subcommittee on Construction and Building, Secretariat, National Institute of Standards and Technology, Gaithersburg, MD 1995.

Fowell, A. J., editor, White Papers Prepared for the White House - Construction Industry 
Workshop on National Construction Goals, NISTIR 5610, National Institute of Standards and Technology, 1994.

\section{Computing and Network Resources}

\author{
Principal Investigator \\ Tze Fai Chu \\ Headquarters \\ 30 I-975-6724
}

\section{Sponsor \\ National Institute of Standards and Technology}

\section{Objective}

To provide improvements, day to day support, and long range planning for the BFRL network, Web site, intranet services, and $\mathrm{PC}$ users.

\section{Problem}

Efficient computing requires a uniform and consistent environment for both scientific and administrative services. PC users need expert day to day support to configure and install new software, and to minimize software problems during use. The World Wide Web is becoming a means for communicating the results of BFRL activities to the user audience. BFRL needs to update and make more user friendly, its presentation on WWW. BFRL also must take full advantage of the network for internal communications.

\section{Approach}

During FY1997, BFRL will configure, purchase, and install new hardware and operating software for local area networks to provide a uniform and reliable system. During the year, BFRL will be upgraded to 100 mps. Software will be added to local area networks to enable BFRL staff to send Facsimile messages directly from their computer. The BFRL home page will be updated to make the BFRL site on WWW user friendly and informative. Technical assistance will be provided to BFRL staff to make reports available on WWW. The BFRL intranet will be developed as a user friendly information resource for the staff. Included on the intranet will be project descriptions, quarterly reports, financial information, news 
from the director, information on upcoming seminars and meetings, lists of publications in process, staff information, etc. Training will be of a high priority to ensure that the project teams are able to provide fast problem solving, reliable advice to staff, and maintain a high quality and user-friendly internet presentation.

\section{Recent Results}

The BFRL network, consisting of 3 subnets, has been upgraded to 100 Mbps capability. The network has been configured to allow access to any of the 3 subnets from any physical location within BFRL. The BFRL Internal Intranet has been enhanced and made available only to those on the BFRL network. A Windows NT server has been purchased and will be used to provide data storage, centralized faxing capabilities and Intranet Web hosting. 

NUT 